\title{
NBSIR 74.496 \\ Standard Measurements of the \\ Resistivity of Silicon by the \\ Four-Probe Method
}

W. Murray Bullis

Electronic Technology Division Institute for Applied Technology

National Bureau of Standards

Washington, D. C. 20234

August 1974

Final

Orginally Prepared for

Electronics Research Center

National Aeronautics and Space Administration

Cambridge, Massachusetts 02139 

NBSIR 74-496

\section{STANDARD MEASUREMENTS OF THE \\ RESISTIVITY OF SILICON BY THE \\ FOUR-PROBE METHOD}

W. Murray Bullis

Electronic Technology Division

Institute for Applied Technology

National Bureau of Standards

Washington, D. C. 20234

August 1974

Final

Originally Prepared for

Electronics Research Center

National Aeronautics and Space Administration

Cambridge, Massachusetts 02139

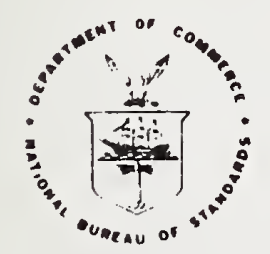

U. S. DEPARTMENT OF COMMERCE, Frederick B. Dent, Secretary 


\section{PREFACE}

This work represents the concluding phase of a long-range program designed to establish the technical basis for a method of measuring the resistivity of silicon slices with an interlaboratory precision such that the relative standard deviation is 1 percent or less. This phase was supported by the Electronics Research Center of the National Aeronautics and Space Administration. Mr. L. M. Pauplis of the Qualifications and Standards Laboratory, Component Standards Branch, Electronics Research Center, was project manager for NASA. Significant contributions to the project were made by J. C. French, F. H. Brewer, L. J. Swartzendruber, and W. M. Bullis (project leader). The participation and cooperation of many industry members of the Resistivity Task Force, Subcommittee VI, ASTM Committee F-l were instrumental in the successful completion of the work, and their contributions of time, materials, and suggestions are gratefully acknowledged. 
This report was originally printed on 29 December 1967 as NBS Report 9666, NASA-CR-86032 and is available from the National Technical Information Service by Accession Number N68-18067. The present printing was prepared to provide the information in a slightly updated form. In this printing, the original resistivity data from which were calculated the temperature coefficients for silicon are added and the interim test method (Revision 1 of ASTM Method of Test F-84-67T) and reference thereto are omitted. The present test method, which has been accepted as a standard by the American Society for Testing and Materials, is designated F-84-73. It may be found in Part 8 of the 1973 edition of the Annual Book of ASTM Standards. Beginning with the 1974 edition (available in November 1974), it may be found in Part 43. With the exception of the changes noted above, the text, tables, and figures in this printing are reproduced from the original masters. 
PREFACE

PREFACE TO SECOND PRINTING iv

LIST OF FIGURES

vi

LIST OF TABLES

vii

ABSTRACT

1. INTRODUCTION AND STATEMENT OF PROBLEM . . . . . . . . . . . . . 3

2. ANALYSIS OF THE ROUND-ROBIN EXPERIMENTS • . . . . . . . . . . . 7

2.1 Introduction . . . . . . . . . . . . . . . . 7

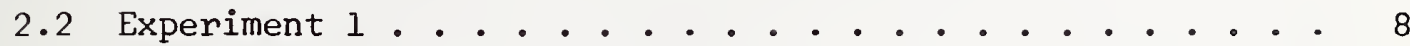

2.2 .1 Results . . . . . . . . . . . . . . 8

2.2.2 Error Analysis . . . . . . . . . . . . 15

2.3 Experiment 2 . . . . . . . . . . . . . . . . . . 21

2.3.1 Results . . . . . . . . . . . . . . 21

2.4 Conclusions . . . . . . . . . . . . . . . 27

2.5 iotes and References . . . . . . . . . . . 28

3. EXPERIMENTAL STUDIES . . . . . . . . . . . . . . . . . 29

3.1 Introduction . . . . . . . . . . . . . . . . . 29

3.2 Thermal Equilibration Time . . . . . . . . . . . 29

3.3 Effect of Non-Uniform Thickness . . . . . . . . . . 30

3.4 Effect of Probe Needle Wander . . . . . . . . . . . . 31

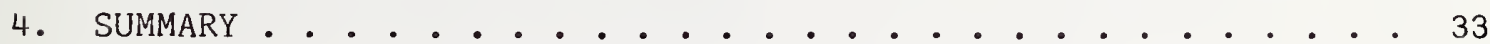

APPENDIX A - Report on a Special Round Robin . . . . . . . . . . 35

APPENDIX B - Special Round Robin Procedure . . . . . . . . . . 45

APPENDIX C - Probe Separation Correction Factors for Thin Slices.................. 53

APPENDIX D - Errors Introduced Through Diameter and Thickness Correction Factors . . . . . . . . . . . . 57

APPENDIX E - Resistivity of Silicon over the Temperature Range 0 to $50^{\circ} \mathrm{C}$ 


\section{LIST OF FIGURES}

FIGURE

1. Probe Methods of Measurement of Resistivity . . . . . . . 4

2. Specimen Resistivity Profiles for the Slices Used in Experiment 1. . . . . . . . . . . . . . . . . . . Il

3. Specimen Resistivity Profiles for the Slices Used in Experiment 2. . . . . . . . . . . . . . . . . 22

4. History of the Interlaboratory Precision of Measurement of Silicon Resistivity in the Range 0.01 to $100 \Omega \cdot \mathrm{cm}$ by the Four-Probe Method. . . . . . . . . . . . . . 32 


\section{LIST OF TABLES}

TABLE

I - Average Resistivity $(\Omega-\mathrm{cm})$ at $23^{\circ} \mathrm{C}$ (as Reported) . . . . 9

II - Average Resistivity $(\Omega-\mathrm{cm})$ at $23^{\circ} \mathrm{C}$ (Recomputed). . . . . . 9

III - Sample Standard Deviation in Per Cent (Recomputed) . . . 9

IV - Per Cent Difference of One Reading from Overall Average Resistivity. . . . . . . . . . . . . . . . 12

V - Per Cent Difference of Median of Three Readings from Overall Average Resistivity. . . . . . . . . . . 14

VI - Probe Separation Measuremert in Millimeters. . . . . . . 14

VII - Average Resistance (Recomputed). . . . . . . . . . . 16

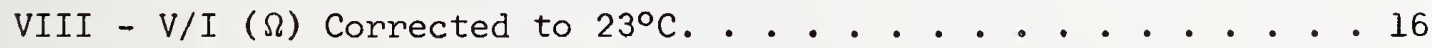

IX - Specimen Diameter Measurement (Centimeters). . . . . . . 20

X - Specimen Thickness Measurement (Centimeters) . . . . . . 20

XI - Average Resistivity $(\Omega-\mathrm{cm})$ at $23^{\circ} \mathrm{C}$ (as Reported) . . . . 23

XII - Average Resistivity $(\Omega-\mathrm{cm})$ at $23^{\circ} \mathrm{C}$ (Recomputed). . . . . 23

XIII - Sample Standard Deviation in Per Cent (Recomputed) . . . . 23

XIV - Per Cent Difference of One Reading from Overall Average Resistivity. . . . . . . . . . . . . . . 24

XV - Per Cent Difference of Median of Three Readings from Overall Average Resistivity. . . . . . . . . . . 24

XVI - Probe Separation Measurement in Millimeters. . . . . . . 24

XVII - Average Resistance (Recomputed). . . . . . . . . . . 25

XVIII - V/I $(\Omega)$ Corrected to $23^{\circ} \mathrm{C}$. . . . . . . . . . . . 25

XIX - Specimen Diameter Measurement (Centimeters). • • . • . 26

XX - Specimen Thickness Measurement (Centimeters) . . . . . . 26

XXI - Angle Lapped Wafer: Thickness and Resistivity . . . . . . 30 
STANDARD MEASUREMENTS OF THE RFSISTIVITY

OF SILICON BY THE FOUR-PROBE METHOD

by

W. Murray Bullis

ABSTRACT

An improved standard procedure for measurement of circular silicon slices with four in-line point probes has been developed in cooperation with the Resistivity Task Force of ASTM Committee F-l. Detailed analysis of a series of round-robin experiments showed that the procedure can attain a precision of \pm 2 per cent (three standard deviations) for interlaboratory comparisons of slices with room temperature resistivity between 0.005 and $120 \mathrm{ohm}-\mathrm{cm}$. Resistivity non-uniformity in the test slices was shown to be a significant factor in limiting the precision which could be achieved. The importance of including correction factors for temperature, finite thickness, finite diameter, and unequal probe separations was demonstrated. The results of the round-robin experiments also emphasized that the precision quoted can only be achieved if the measurements are carefully and correctly made on a well maintained, accurately calibrated test system which meets the requirements imposed by the test method. Determination of the precision to be expected from the method in non-referee applications such as routine production and quality control will require additional study of such factors as surface conditions, probe force, current levels, etc. Nevertheless, use of the various procedures of the method, in particular the sections on probe and measuring circuit evaluations and on thermal sinking of the wafer, would be expected to yield significantly improved precision in such applications. Use of these procedures on a regular and widespread basis should be encouraged. 


\section{INTRODUCTION AND STATEMENT OF PROBLEM}

The resistivity of a semiconducting material is controlled principally by the density of free carriers which exists in the material. In commercially useful semiconductors, such as silicon and germanium, the number of free carriers is tailored and controlied for particular applications by the addition of specific small quantities of impurity dopants. The electrical characteristics of semiconductor devices depend in a critical way on the free carrier density in the various regions of the device structure. Because of this basic importance of resistivity, and of the relative simplicity with which a resistance measurement may be made by means of the four-probe method on a surface, this parameter is the one most widely used in design and production control of semiconductor devices.

For similar reasons, resistivity is the parameter which is most widely used in specifying semiconducting materials from which devices are to be fabricated. Although the standard four-probe method is quite simple in principle, the precision and reproducibility which were obtainedin actual practice have been inadequate for some time. A substantial expense to the indusiry, and ultimately to the users of devices, arises from disagreements between vendors and users. In addition disagreements among different test sets within the same organization are frequently found when comparisons are made. Need for improved precision in measuring resistivity of silicon for high quality, high reliability devices led the industry, through the Committee F-I on Materials. for Electron Devices and Microelectronics of the American Society for Testing and Materials, to request the Electron Devices Section of the National Bureau of Standards to assist in the development of new standards with the aim of achieving a precision of 1 per cent or better (one standard deviation). The necessity for determining variations in resistivity along a slice radius which developed in connection with power devices and integrated circuits further emphasized the need for this precision.

When the project began, it was thought that sufficiently precise measurements could only be made by using the two-probe method. In this method, current of uniform density is passed through a rectangular bar with metallic contacts completely covering the ends of the bar and the potential drop is measured between two pointed or wedge shaped probes applied to the side of the bar a known distance apart as shown in Fig. 1. Careful comparisons of this method were made with the fourprobe method. In this latter method, the current is passed through the outer two of four pointed probes in a linear array placed on a flat semiconductor surface and the potential drop is measured between the inner pair as shown in Fig. 1. Detailed investigations of the effects of variations in specimen surface preparation, probe force, probe diameter, and probe material were carried out. The importance of allowing for the variation of resistivity with temperature was demonstrated 
FOUR-PROBE METHOD

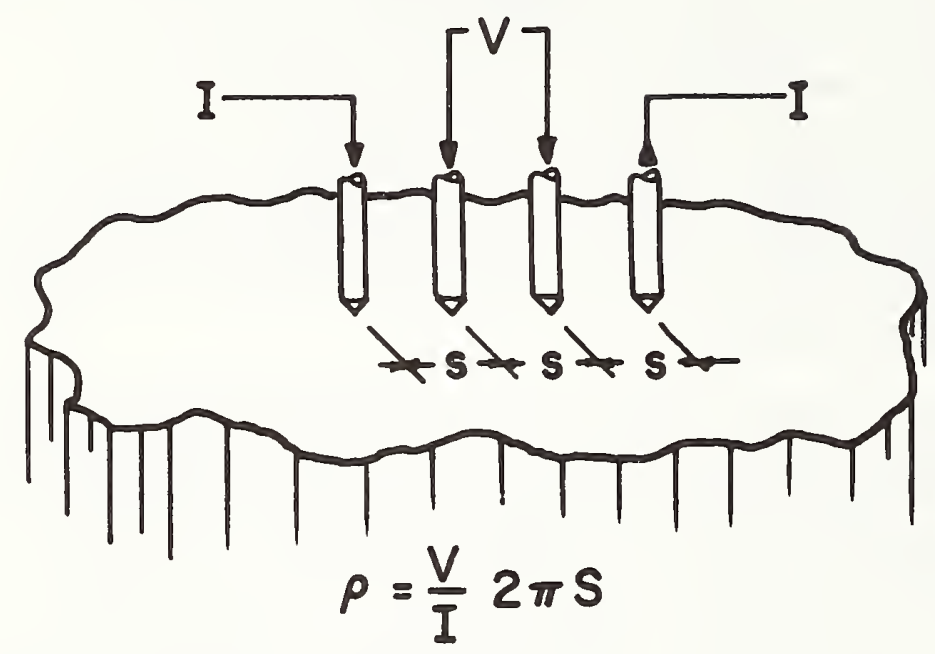

TWO-PROBE METHOD



Where:

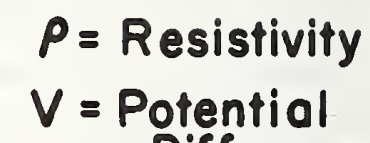

Difference

$I=$ Current

$S=$ Probe Spocing

$W=$ Width

$\dot{H}=$ Height

$L=$ Length

Figure 1. Probe Methods of Measurement of Resistivity. 
and geometrical correction factors appropriate to both circular and rectangular wafers were computed.

These studies resulted, in the development of an improved fourprobe method for measuring resistivity of semiconductor slices. A round-robin experiment on several silicon slices in the 5 to $20 \Omega-\mathrm{cm}$ range indicated that a precision over an order of magnitude better than that obtained using the earlier techniques could be achieved. Thus, it was demonstrated that the use of the expensive and destructive twoprobe method was not necessary to achieve the desired precision. The correction factor tables which were published as a part of the program have been widely used. These factors also enabled a significant im: provement in off-center resistivity measurements to be made. This improvement together with the increased precision of the method enabled the accuracy of the determination of radial variations of resistivity to be improved significantly.

The present project was undertaken in order to complete the development, writing, and publication of a standard method for the measurement of the resistivity of silicon wafers suitable for use throughout the electronics industry in cooperation with the ASTM and to provide the additional effort which was necessary to extend and refine the method for maximum usefulness. These added efforts involved: (1) extension of the application of the four-probe method to the most widely used resistivity ranges of silicon, (2) establishment of the precision of the method in the various resistivity ranges, (3) more precise establishment of the environmental control and geometrical requirements of the method, and (4) participation with ASTM in the writing of an industry standard for the measurement.

To accomplish these objectives the following tasks were performed:

1) Results of two round-robin experiments being carried out by the Resistivity Task Force of Subcommittee VI of ASTM Committee $\mathrm{F}-\mathrm{l}$ were analyzed. These experiments were in progress at the inception of this project and were completed in June 1967.

2) Experimental studies were carried out to establish the environmental control and geometrical requirements of the method and the relative influence of these factors on the precision of the method.

3) The procedure for making four-probe resistivity measurements on silicon slices was extended to include the entire resistivity range between 0.0005 and $2000 \Omega-\mathrm{cm}$.

4) A new draft of the resistivity standard based on the results of the above study was written and submitted to the Resistivity Task Force for review comment. 
This draft appeared as an ASTM Tentative Method

in the 1968 Book of Standards.

Work on these various tasks is reported in detail in the following sections. 


\section{ANALYSIS OF THE ROUND-ROBIN EXPERIMENTS}

\subsection{INTRODUCTION}

Two round-robin experiments covering a wide spectrum of resistivity were carried out between November 1966 and June 1967 by the Resistivity Task Force of Subcommittee VI, Committee F-l on Materials for Electron Devices and Microelectronics of the American Society for Testing and Materials to determine the limits of precision for a Method of Test for Resistivity of Silicon Slices Using Four-Point Probes. Earlier, a preliminary round-robin experiment consisting only of three specimens about $10 \Omega-\mathrm{cm}$ had been carried out to establish the feasibility of the method. In the near future a fourth round-robin experiment is planned in order to extend the method to lower resistivity $(\sim 0.001 \Omega-\mathrm{cm})$ and to recheck the precision in the $1000 \Omega-\mathrm{cm}$ range.

This section summarizes the results of the two wide-spectrum experiments. For completeness, the report on the preliminary experiment which was originally presented to the Task Force at the Chicago meeting June 1966 is included as Appendix A. Laboratories which had participated in the preliminary experiment participated in one of the new experiments:

Bell Telephone Labs., Allentown, Pa.,

Dow Corning Corp., Electronic Products Div., Hemlock, Mich., IBM Corp., Components Div., Hopewell Jcn., N. Y.

Monsanto Co., Inorganic Chemicals Div., St. Louis, Mo., and National Bureau of Standards, Washington, D. C.

Except for NBS, laboratories in the second had not participated in earlier experiments on resistivity:

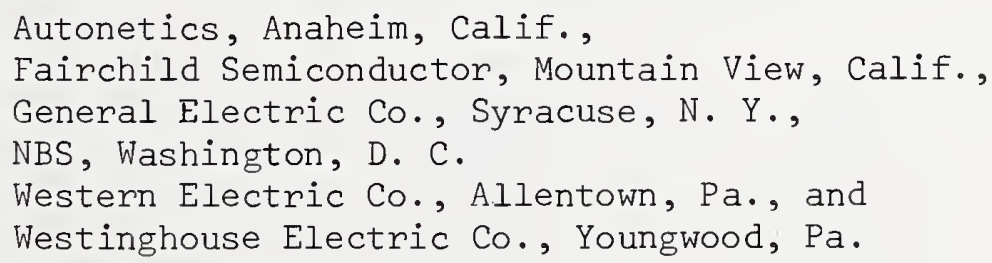

The original plan was to have 5 n-type and 5 p-type slices in each experiment. Each series was to include specimens with resistivity about $0.01,0.1,10,100$, and $1000 \Omega-\mathrm{cm}$. Except for the fact that the $10 \Omega$-cm n-type slices were improperly typed and turned out to be p-type, this plan was carried out. Three slices were broken during the tests; two were replaced so that data could be obtained. The $0.01 \Omega$-cm p-type slice in the second test was not replaced. Slices were prepared according to the test method (see Method F-84 - $\$ 9$ Preparation of Test Specimen) by the laboratory which supplied them. Analog circuits of resistance $0.001,0.01,0.1,10,100$, and $1000 \Omega$ were furnished for both tests. The 10, 100 , and $1000 \Omega$ analog circuits contained, as the standard, commercial precision ( \pm 0.05 per cent) resistors and, as the 
large series resistors, ordinary carbon composition ( \pm 10 per cent) resistors. The other standard resistors were fabricated from various wire of appropriate diameter and length.

\subsection{EXPERIMENT 1.}

In this experiment, the ten silicon wafers and six analog circuits were furnished to each of the participants in turn together with suitable data sheets. Wafers from crystals 605603, 601333, 71983, and 71166 were $n$-type; the remainder were p-type. The procedure governing the tests was "Proposed Method of Test for Resistivity of Silicon Slices Using Four Point Probes", Third Dnaft, December 1, 1966.1 Since this procedure pertained only to specimens in the 10 to $20 \Omega-\mathrm{cm}$ range a separate schedule of currents to be used in the test was also supplied:

$\begin{array}{lcccccc}\text { Range }(\Omega-\mathrm{cm} \text { or } \Omega) & 0.001 & 0.01 & 0.1 & 10 & 100 & 1000 \\ \text { Current }(\mathrm{mA}) & 50 & 50 & 30 & 0.3 & 0.1 & 0.02\end{array}$

2.2.1 Results. The method specifies tests to evaluate both the condition of the probe assembly and the accuracy of the electrical measuring equipment in addition to the resistivity measurement itself. All these facets of the method were studied as part of the round-robin experiments. The results are summarized in Tables I through X. The resistivity measurements themselves are considered first (Tables I through V), followed by the probe separation measurements (Table VI) and the electrical analog circuit measurements (Table VII.). Results presented in Tables VIII through $\mathrm{X}$ are used in the error analysis presented in paragraph 2.2.2.

2.2.1.1 Resistivity Tests. Table I lists the average resis- * tivity of each wafer (based on ten measurements in both the forward and reverse directions of current) reported by each laboratory. The grand average (Avg.), the sample standard deviation (s) (of the averages), and the relative sample standard deviation (s $(\%)$ ) (of the averages) were calculated for each wafer. Results of the preliminary round-robin had suggested that computation errors occur frequently. Hence, the reported raw data were used to recompute the averages with the use of an electronic desktop calculator programmed to yield average, sample standard deviation, and relative sample standard deviation. Results are shown in Table II, from which it can be seen that the relative sample standard deviation is less than 0.7 per cent in eight of the eleven cases. This would suggest that a precision of \pm 2 per cent (R3S\%) for these cases could be expected most of the time if the experiment were repeated with the same care as exercised in this test. Measurements on the $100 \Omega-\mathrm{cm}$ and $1000 \Omega-\mathrm{cm}$ p-type wafers and one of the $1000 \Omega$-cm $n$-type wafers had langer sample standard deviations. Only the $1000 \Omega$-cm p-type wafer significantly exceeded 1 per cent. Without additional experiments it is not possible to include the 1000 $\Omega-c m$ range in the \pm 2 per cent precision statement above. 
TABLE I - Average Resistivity $(\Omega-\mathrm{cm})$ at $23^{\circ} \mathrm{C}$ (as Reported)

\begin{tabular}{|c|c|c|c|c|c|c|c|c|}
\hline Specimen & Lab. 1 & Lab. 2 & Lab. 3 & Lab. 4 & Lab. 5 & Avg. & $\underline{s}$ & $\mathrm{~s}(\%)$ \\
\hline $605603-3$ & 0.008393 & 0.008378 & 0.008403 & 0.00834 & 0.0083343 & 0.008370 & 0.000031 & 0.37 \\
\hline $601333-2$ & 0.08540 & 0.08569 & 0.085058 & 0.08502 & 0.085577 & 0.08535 & 0.00030 & 0.35 \\
\hline $71983-2$ & 100.32 & 101.19 & 95.8052 & 101.725 & 100.65 & 99.94 & 2.37 & 2.37 \\
\hline $71166-2 a$ & 836.4 & 842.53 & & & 835.0 & 838.0 & 4.0 & 0.48 \\
\hline $71166-2 b$ & & & 1136.27 & 1044.13 & 932. & 1037.5 & 102.3 & 9.86 \\
\hline $600200-2$ & 0.007763 & 0.007824 & 0.007778 & 0.00777 & 0.0077426 & 0.007776 & 0.000030 & 0.39 \\
\hline $607075-2$ & 0.10927 & 0.10958 & 0.109189 & 0.10883 & 0.10881 & 0.10914 & 0.00032 & 0.30 \\
\hline $70877-3$ & 7.916 & 7.937 & 8.0403 & 8.0410 & 7.909 & 7.969 & 0.067 & 0.83 \\
\hline $49445-2$ & 11.857 & 11.97 & 12.0045 & 11.735 & 11.877 & 11.889 & 0.106 & 0.89 \\
\hline 66969-1 & 111.91 & 114.03 & 113.150 & 112.735 & 112.59 & 112.88 & 0.78 & 0.69 \\
\hline $16603-2$ & 940.3 & 979.83 & 981.740 & 967.31 & 941.6 & 962.2 & 20.1 & 2.09 \\
\hline
\end{tabular}

TABLE II - Average Resistivity $(\Omega-\mathrm{cm})$ at $23^{\circ} \mathrm{C}$ (Recomputed)

\begin{tabular}{|c|c|c|c|c|c|c|c|c|}
\hline Specimen & Lab. 1 & Lab. 2 & Lab. 3 & Lab. 4 & Lab. 5 & Avg. & $\underline{s}$ & $\underline{s(\%)}$ \\
\hline $605603-3$ & 0.008389 & 0.008452 & 0.008361 & 0.00830 & 0.0083343 & 0.008367 & 0.000058 & 0.69 \\
\hline $601333-2$ & 0.08540 & 0.08538 & 0.084723 & 0.08462 & 0.085577 & 0.08514 & 0.00044 & 0.51 \\
\hline $71983-2$ & 100.33 & 101.11 & 101.48 & 101.9 & 100.6 & 101.08 & 0.64 & 0.63 \\
\hline $71166-2 a$ & 836.4 & 842.61 & & & 835.0 & 838.0 & 4.0 & 0.48 \\
\hline $71166-2 b$ & & & 1122. & 1040. & 932. & 1031.3 & 95.3 & 9.24 \\
\hline $600200-2$ & 0.007761 & 0.007818 & 0.007743 & 0.007752 & 0.0077426 & 0.007763 & 0.000031 & 0.41 \\
\hline $607075-2$ & 0.10928 & 0.10964 & 0.10873 & 0.10901 & 0.10881 & 0.10909 & 0.00037 & .34 \\
\hline $70877-3$ & 7.915 & 7.930 & 7.991 & 8.0267 & 7.909 & 7.954 & 0.052 & .65 \\
\hline $49445-2$ & 11.859 & 11.94 & 11.92 & 11.747 & 11.877 & 11.869 & 0.075 & 0.63 \\
\hline 66969-1 & 111.90 & 114.09 & 112.5 & 114.20 & 112.59 & 113.06 & 1.03 & 0.91 \\
\hline $16603-2$ & 939.0 & 951.19 & 947.8 & 964.9 & 944.8 & 949.5 & 9.7 & 02 \\
\hline
\end{tabular}

TABLE III - Sample Standard Deviation in Per Cent (Recomputed)

Average Resistivity

\begin{tabular}{|c|c|c|c|c|c|c|c|}
\hline Specimen & $(\Omega-\mathrm{cm})$ & Lab. 1 & Lab. 2 & Lab. 3 & Lab. 4 & Lab. 5 & Avg. \\
\hline $605603-3$ & 0.008367 & 0.49 & 0.91 & 1.24 & $0.97^{\circ}$ & 0.71 & 0.69 \\
\hline $601333-2$ & 0.08514 & 0.10 & 0.19 & 0.30 & 0.29 & 0.32 & 0.51 \\
\hline $71983-2$ & 101.08 & 0.13 & 0.33 & 1.41 & 2.12 & 0.38 & 0.63 \\
\hline $71166-2 a$ & 838.0 & 0.27 & 0.33 & & & 1.53 & 0.48 \\
\hline $71166-2 b$ & 1031.3 & & & 8.82 & 0.30 & 1.24 & 9.24 \\
\hline $600200-2$ & 0.007763 & 0.15 & 0.08 & 0.18 & 0.08 & 0.20 & 0.41 \\
\hline $607075-2$ & 0.10909 & 0.16 & 0.25 & 0.16 & 0.02 & 0.16 & 0.34 \\
\hline $70877-3$ & 7.954 & 0.11 & 0.32 & 1.30 & 0.32 & 0.34 & 0.65 \\
\hline $49445-2$ & 11.869 & 0.14 & 0.12 & 1.08 & 0.21 & 0.19 & 0.63 \\
\hline $66969-1$ & 113.06 & 0.10 & 0.59 & 0.43 & 0.33 & 0.25 & 0.91 \\
\hline $16603-2$ & 949.5 & 0.23 & 0.87 & 0.82 & 0.68 & 1.15 & 1.02 \\
\hline
\end{tabular}


2.2.1.2 Relative Single Laboratory Deviation. The relative sample standard deviations obtained by each of the laboratories for the sequence of ten measurements for each wafer are shown in Table III together with the sample standard deviation of the grand average for each wafer repeated from Table II. There appears to be little correlation between the deviation reported for a wafer by a particular laboratory and the per cent difference between that laboratory's average resistivity value and the grand average. However, one of the limiting factors in obtaining reproducible resistivity measurements is the uniformity of the wafer being measured. Although the method requires that the measurements be made with the center of the probe array located within $\pm 0.25 \mathrm{~mm}$ of the center of the wafer, there is no way to verify from the data reported that this was actually done in every case. If uniform wafers were used in the experiment, this source of variation would not be present. That not all wafers used in the test were as uniform as would be desirable was shown by resistivity profiles of each wafer which were made at the end of the round-robin series. These were made at NBS with the use of a four-point probe which had the probe separation recommended in $\$ 6.3 .4$ of Method F-84 and which met the requirements of 110.1 of the method. Measurements were taken at intervals of about $1 \mathrm{~mm}$ along two perpendicular diameters. Comparison of the single laboratory deviations in Table III with these profiles which are shown in Fig. 2 suggests that more uniform wafers show generally smaller deviations. Differences in deviation between laboratories may be due as much to differences in locating the center of the wafer as to other errors.

2.2.1.3 Single Readings. The procedure being tested by this round robin calls for ten readings to be taken on each wafer measured. Although this procedure is acceptable for referee and other comparative measurements, single readings are much more practical in production control and inspection applications. Hence several single readings were analyzed to determine how the precision is affected in this case. The result of the analysis of the sixth, first, and tenth readings are shown in Table IV. In this table the per cent difference between individual resistivity values and the overall grand average value for that wafer are listed. The per cent difference between the value of resistivity of a wafer as determined by averaging the individual values reported by the various labs and the overall average value is Iisted in the column headed "Avg". The relative sample standard deviation determined for each wafer is listed in the last column. If the 1000 $\Omega-c m$ p-type wafer is excluded from the discussion it can be seen that over three-fourths of the values fall within 1 per cent of the appropriate grand average value. Less than 5 per cent of the values differ by 2 per cent or more. Comparison of the sample standard deviations with those in Table II shows that the reproducibility is only moderately degraded.

2.2.1.4 Median of Three Readings. Sometimes it is possible to improve the precision of a determination over that of a single 


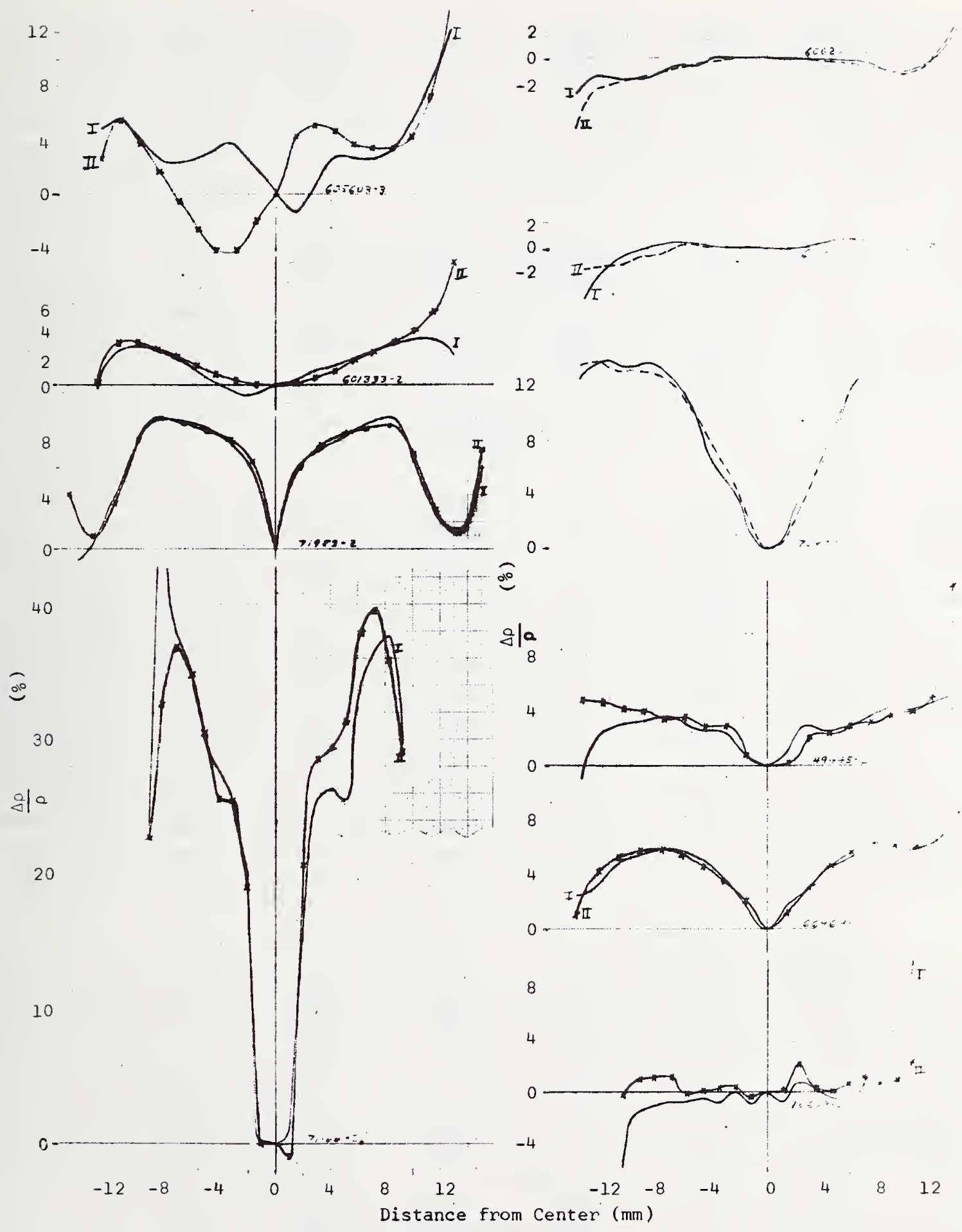

Figure 2. Specimen Resistivity Profiles for the Slices Used in Experiment 1. (No profile was made on Slice 71166-2a.) 
TABLE IV - Per Cent Difference of One Reading from Overall Average Resistivity

Average

a) Sixth Reading

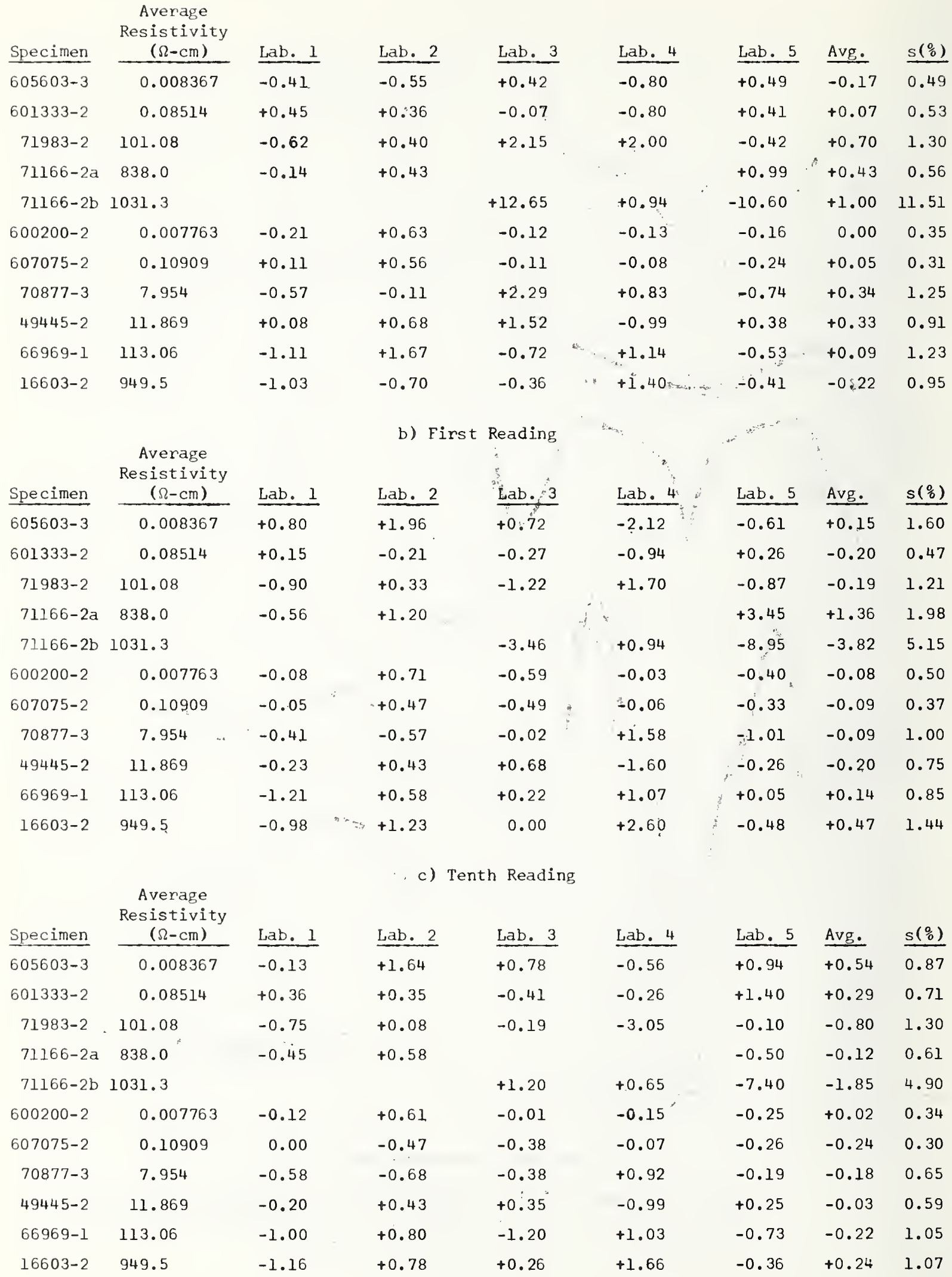


measurement by taking the median value of three measurements. This involves no arithmetic and only a small amount of extra measurement time while enabling isolated "wild" readings to be avoided. To test the usefulness of this approach, the median value of the sixth, seventh, and eighth readings was analyzed with the results shown in Table $V$. It can be seen by comparison with Table IV that the improvement is not consistent enough over the single reading case to justify the extra labor involved.

\subsubsection{Probe Separation Measurement. In the preliminary} experiment the test for probe quality was shown to be adequate. In that experiment each laboratory measured the separations on the same probe. As a result of this experiment, it was concluded that a single laboratory relative sample standard deviation greater than 0.25 per cent in any measurement of probe separation would be considered grounds for rejection of the probe. It was also concluded that the three separations must be equal within 2 per cent for the probe to be acceptable.

In the present experiment, each laboratory furnished its own probe. The results of the probe separation measurements on the five probes used are given in Table VI. The separation $\left(S_{i}\right)$, the sample standard deviation $\left(s_{i}\right)$, and the relative sample standard deviation $\left(s_{i}(\%)\right)$ are given for each of the three separations followed by the average separation ( $\bar{S})$ and the probe separation correction factor $\left(F_{s p}\right)$. Two probes did not meet the requirements of the method. The probe used by lab 2 had separations which differed by more than 2 per cent in addition to slightly greater than acceptable deviation in two of the three separations. The probe used by lab 4 had one separation with slightly greater than acceptable deviation. Note that the probe used by lab 2 had the probe separation correction factor nearest to unity of all the probes used. No increase in the measurement spread could be attributed definitely to either of these conditions. In neither case were the requirements missed by a large amount.

Details of the derivation of $F_{s p}$ are given in Appendix $C$. The 2 per cent requirement on probe separation difference is necessitated by the use of the approximate formula $(\mathrm{C}-7)$ for $\mathrm{F}_{\mathrm{sp}}$. Unless the exact formula $(C-5)$ is used to calculate $F_{S p}$, or (as in the case of the probe used by lab 2), $F_{S p}$ is within 0.1 per cent of unity, this requirement may not be relaxed. However, the results of this experiment suggest that the allowed relative sample standard deviation for probe separation can probably be increased to 0.30 per cent without producing an observable increase in the overall sample standard deviation.

\subsubsection{Electrical Equipment Tests. The electrical equip-} ment test in the preliminary round robin was successful in identifying one inadequate measuring system. The test circuit consisted of a precision resistor and four other resistors arranged as shown in Fig. 3 of the test method. The value of the other resistors, 300 times that 
TABLE V - Per Cent Difference of Median of Three Readings from Overall Average Resistivity

\begin{tabular}{|c|c|c|c|c|c|c|c|c|}
\hline Specimen & $\begin{array}{c}\text { Average } \\
\text { Resistivity } \\
(\Omega-\mathrm{cm}) \\
\end{array}$ & Lab. 1 & Lab. 2 & Lab. 3 & Lab. 4 & Lab. 5 & Avg. & $\mathrm{s}(\%)$ \\
\hline $605603-3$ & 0.008367 & +0.33 & +0.96 & +0.42 & -0.68 & -0.83 & +0.04 & 0.77 \\
\hline $601333-2$ & 0.08514 & +0.40 & +0.35 & -0.50 & -0.52 & +0.41 & +0.03 & 0.49 \\
\hline $71983-2$ & 101.08 & -0.62 & +0.23 & +0.148 & +1.90 & -0.40 & +0.32 & 0.99 \\
\hline $71166-2 a$ & 838.0 & -0.14 & +0.43 & & & -0.67 & -0.13 & 0.55 \\
\hline $71166-2 b$ & 1031.3 & & & +12.65 & +0.94 & -9.82 & +1.26 & 11.10 \\
\hline $600200-2$ & 0.007763 & -0.18 & +0.70 & -0.12 & -0.06 & -0.36 & -0.01 & 0.41 \\
\hline $607075-2$ & 0.10909 & +0.18 & +0.56 & -0.37 & -0.06 & -0.33 & 0 & 0.39 \\
\hline $70877-3$ & 7.954 & -0.54 & -0.11 & +2.29 & +0.78 & -0.54 & +0.38 & 1.19 \\
\hline $49445-2$ & 11.869 & +0.08 & +0.68 & +1.52 & -0.99 & +0.15 & +0.29 & 0.91 \\
\hline $66969-1$ & 113.06 & -1.03 & +1.67 & -0.66 & +1.14 & -0.60 & +0.10 & 1.21 \\
\hline $16603-2$ & 949.5 & -1.03 & +0.18 & +0.99 & +1.90 & -0.41 & +0.32 & 1.14 \\
\hline
\end{tabular}

TABLE VI - Probe Separation Measurement in Millimeters

\begin{tabular}{|c|c|c|c|c|c|}
\hline & Lab. 1 & Lab. 2 & Lab. 3 & Lab. 4 & Lab. 5 \\
\hline$S_{1}$ & 1.5933 & 1.5657 & 1.5926 & 1.5903 & 1.5890 \\
\hline$s_{1}$ & 0.00053 & 0.00145 & 0.00262 & 0.0010 & 0.0010 \\
\hline$s_{1}(\%)$ & 0.03 & 0.09 & 0.16 & 0.06 & 0.06 \\
\hline 2 & 1.5885 & 1.5850 & 1.5989 & 1.5938 & 1.5964 \\
\hline $\mathrm{s}_{2}$ & 0.00043 & 0.00409 & 0.00160 & 0.0033 & 0.0008 \\
\hline$s_{2}\left(\frac{0}{0}\right)$ & 0.03 & 0.26 & 0.10 & 0.21 & 0.05 \\
\hline $\mathrm{S}_{3}$ & 1.5936 & 1.6096 & 1.5941 & 1.5870 & 1.5865 \\
\hline$s_{3}$ & 0.00069 & 0.00447 & 0.00180 & 0.0041 & 0.0008 \\
\hline$s_{3}(\%)$ & 0.04 & 0.28 & 0.11 & 0.26 & 0.05 \\
\hline 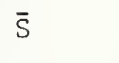 & 1.5918 & 1.5867 & 1.5951 & 1.5903 & 1.5905 \\
\hline sI & 1.0022 & 1.00107 & 0.99747 & 0.9976 & 0.99608 \\
\hline
\end{tabular}


of the precision resistors, is based on the work of Logan ${ }^{2}$ who estimated that if the contact force is $0.25 \mathrm{~N}$ (25 gf) the spreading resistance at an osmium probe point is about 300 times the resistivity of the specimen. Present conditions of tungsten carbide probe points and a contact force of $1.75 \mathrm{~N}$ would be expected to reduce this ratio by about a factor of two. The larger value was selected for the test in order to allow for uncertainties in the estimate.

The results of measurements are shown in Table VII. There were no problems encountered in measuring either the 10 or $100 \Omega$ resistors. Values reported by two labs ( 3 and 5 ) for the $1000 \Omega$ resistor fell outside the allowed band while three labs (1, 2, and 3 ) reported relative sample standard deviations in excess of the allowed 0.3 per cent. Comparison of the measurements on the $1000 \Omega$ resistor and measurements on specimens $71166-2$ and 16603-2 shows the following interesting but unexplained facts:

1) In measurements on the resistor lab 3 was low and lab 5 was high; in measurements on the wafers the reverse is true. (A possible explanation of this inversion is that the measurements were made by lab 5 closer to the center of the wafers.)

2) In measurements on the wafers, labs 1, 2, and 3 did not show significantly larger relative sample standard deviations than labs 4 and 5 except in one instance.

Problems of reproducibility were encountered in measuring the three smaller resistors. Since the scatter in the resistor measurements much exceeded that in the wafer measurements it is suspected that these analog test circuits were an inadequate test of the electrical measuring equipment in the 0.01 and $0.1 \Omega$ ranges because of unstable standard resistors. Further work will be required to eliminate this problem which probably arises from either thermally generated voltages or from temperature dependence of resistance or both. In addition to the larger deviation of average values reported for the $0.001 \Omega$ resistor, all labs had relative sample standard deviations in excess of 0.3 per cent. No specimens in this resistivity range were included in this experiment. A separate round-robin to test this range will be started as soon as an improved standard resistor in this range can be assembled and tested.

2.2.2 Error Analysis. The following quantities are measured in the experiment:

\author{
Voltage (V) \\ Current (I) \\ Temperature ( $\mathrm{T}$ ) \\ Wafer Diameter (D) \\ Wafer Thickness (w) \\ Probe Spacing ( $\mathrm{S}$ )
}


TABLE VII - Average Resistance (Recomputed)

a) Measured Values $(\Omega)$

\begin{tabular}{|c|c|c|c|c|c|c|c|c|}
\hline $\begin{array}{l}\text { Analog } \\
\text { Circuit }\end{array}$ & Lab. 1 & Lab. 2 & Lab. 3 & Lab. 4 & Lab. 5 & Avg. & $\underline{s}$ & $\mathrm{~s}(\%)$ \\
\hline No. 1 & 0.000939 & 0.000943 & 0.000920 & 0.00096 & 0.0009280 & 0.000938 & 0.000015 & 1.63 \\
\hline No. 2 & 0.010279 & 0.010254 & 0.00998 & 0.01027 & 0.010262 & 0.010209 & 0.000128 & 1.26 \\
\hline No. 3 & 0.10061 & 0.10056 & 0.0979 & 0.10048 & 0.10051 & 0.10001 & 0.00118 & 1.18 \\
\hline No. 5 & 10.015 & 10.012 & 10.00 & 10.000 & 10.013 & 10.008 & 0.007 & 0.07 \\
\hline No. 6 & 100.04 & 100.052 & 100.0 & 100.0 & 100.04 & 100.03 & 0.02 & 0.02 \\
\hline No. 7 & 1000.7 & 999.17 & 996. & 1000 & 1005 . & 1000.2 & 3.2 & 0.32 \\
\hline
\end{tabular}

b) Sample Standard Deviation (Per Cent)

\begin{tabular}{|c|c|c|c|c|c|c|}
\hline $\begin{array}{l}\text { Analog } \\
\text { Circuit }\end{array}$ & Lab. 1 & Lab. 2 & Lab. 3 & Lab. 4 & Lab. 5 & Avg. \\
\hline No. 1 & 1.02 & 0.60 & 1.09 & 1.05 & 0.36 & 1.63 \\
\hline No. 2 & 0.02 & 0.14 & 0.20 & 0.00 & 0.01 & 1.26 \\
\hline No. 3 & 0.02 & 0.02 & 0.16 & 0.00 & 0.01 & 1.18 \\
\hline No. 5 & 0.04 & 0.01 & 0.00 & 0.00 & 0.01 & 0.07 \\
\hline No. 6 & 0.03 & 0.12 & 0.00 & 0.00 & 0.02 & 0.02 \\
\hline No. 7 & 0.53 & 2.70 & 0.57 & 0.00 & 0.11 & 0.32 \\
\hline
\end{tabular}

TABLE VIII - V/I $(\Omega)$ corrected to $23^{\circ} \mathrm{C}$

\begin{tabular}{ccccccccc} 
Specimen & Lab. 1 & Lab. 2 & Lab. 3 & Lab. 4 & Lab. 5 & Avg. & $\underline{s}$ & $\frac{s(\%)}{0.47}$ \\
\hline $605603-3$ & 0.01665 & 0.01671 & 0.016654 & 0.01650 & 0.016650 & 0.016633 & 0.000785 & 0.47 \\
$601333-2$ & 0.16630 & 0.1658 & 0.165594 & 0.16515 & 0.16766 & 0.16610 & 0.000965 & 0.58 \\
$71983-2$ & 191.85 & 193.32 & 194.924 & 195.825 & 194.0 & 193.984 & 1.5221 & 0.78 \\
$71166-2 \mathrm{a}$ & 1701.3 & 1711. & & & 1718.8 & 1710.4 & 8.77 & 0.51 \\
$71166-2 \mathrm{~b}$ & & & 2323.89 & 2123.63 & 1915. & 2120.84 & 204.459 & 9.64 \\
$600200-2$ & 0.01483 & 0.01490 & 0.01485 & 0.014819 & 0.014888 & 0.014857 & 0.000354 & 0.24 \\
$607075-2$ & 0.21202 & 0.2115 & 0.211751 & 0.21207 & 0.21273 & 0.21201 & 0.00046 & 0.22 \\
$70877-3$ & 15.452 & 15.54 & 15.6199 & 15.7433 & 15.556 & 15.582 & 0.1082 & 0.69 \\
$49445-2$ & 23.538 & 23.72 & 23.7791 & 23.734 & 23.752 & 23.705 & 0.0957 & 0.40 \\
$66969-1$ & 221.31 & 225.07 & 223.169 & 226.628 & 224.03 & 224.04 & 1.998 & 0.89 \\
$16603-2$ & 1809. & 1831. & 1837.56 & 1862.62 & 1833.9 & 1834.82 & 19.121 & 1.04
\end{tabular}


With the use of the experience gained in the round-robin experiment and the limits of error specified in the measurement method, it is possible to estimate the contribution of error in each of these quantities to the overall measurement error.

The resistivity of a thin, homogenous semiconductor slice at a reference temperature $T_{0}$ is given by ${ }^{3}$

$$
\rho_{0}=\frac{V}{I} W F_{2} F(w / \bar{S}) F_{S P} F_{T}
$$

where the ratio of voltage $V$ to current $I$ is measured at a temperature $\mathrm{T}, \mathrm{W}$ is the slice thickness, $\mathrm{F}_{2}$ is a correction factor which accounts for finite slice diameter and which decreased from $\pi / \ln 2$ as the ratio $\bar{S} / D$ increases from $0, F(w / \bar{S})$ is a correction factor which accounts for finite thickness and which decreases from 1.0 as the ratio w/S increases, $F_{S P}$ is a correction factor which accounts for unequal probe separations, and $\mathrm{F}_{\mathrm{T}}$ is a temperature correction factor. The assumption that the first three independent correction factors may be multiplied together to obtain the total geometrical correction factor is valid only when the deviations from the factors in their limiting cases $\left(D \rightarrow \infty, w \rightarrow 0\right.$, and $\left.S_{1} \rightarrow S_{2} \rightarrow S_{3} \rightarrow \bar{S}\right)$ are small. This is the reason that certain geometrical restrictions ( $D \geq 10 \bar{S}, w \leq \bar{S}$ and $S_{1}, S_{2}, S_{3}$ equal to 2 per cent) are employed in the method. Smits ${ }^{4}$ has considered the factors $F_{2}$ and $F(w / \bar{S})$. More detailed tables of $F_{2}$ have appeared in the literature. 2,5 The factor $F_{S p}$ is discussed in Appendix C. The temperature correction factor is discussed in section 3 of this report. Tables or formulas for the four factors are given in the method.

For small deviations from equilibrium values:

$$
\frac{d \rho}{\rho}=\frac{d V}{V}-\frac{d I}{I}+\frac{d w}{w}+\frac{d F_{2}}{F_{2}}+\frac{d F(w / \bar{S})}{F(w / \bar{S})}+\frac{d F_{s p}}{F_{s p}}+\frac{d F_{T}}{F_{T}}
$$

Since $F_{T}=I-C_{T}\left(T-T_{0}\right) \approx I$, one may write $\left(d_{T} / F_{T}\right)=-C_{T} d T$. Then, with the use of $(D-1)$ and (D-2) of Appendix $D$ and $(C-9)$ of Appendix $C$ (1) becomes:

$$
\frac{d \rho}{\rho}=\frac{d V}{V}-\frac{d I}{I}-C_{T} d T-(a-b-c) \frac{d \bar{S}}{\bar{S}}-c \frac{d S}{\bar{S}}+(I-b) \frac{d w}{w}+a \frac{d D}{D},
$$

where the coefficients $a, b$, and $c$ are defined in Appendixes $D$ and $C$. If all these factors were independent, the analysis could procede in a straightforward manner. Uncertainty in the measured values of $\overline{\mathrm{s}}, \mathrm{S}_{2}$, $\mathrm{w}$, and $\mathrm{D}$ can be considered separately. However probe wander (resulting in changes in $\bar{S}$ and $S_{2}$ ) and uncertainty in temperature both affect the uncertainty in voltage. 
2.2.2.1 Errors in V, I, and T. These three quantities are lumped together since it is necessary to account for the temperature variation of resistivity when voltage readings at different temperatures are compared. Three factors contribute to the error in the V/I ratio corrected to the reference temperature:

1) direct measurement error of $V / I$ ratio

2) effect of probe wander on $V$, and

3) uncertainty of $T$.

The direct measurement error of the $V / I$ ratio can be estimated from the measurement of the resistor in the analog test circuit. The relative standard deviation in this measurement is limited to 0.15 per cent. Under good conditions, it is considerably smaller than this limit as can be seen from Table VII.

Probe wander will affect the $V / I$ ratio as discussed in Appendix $C$. Since the probe is raised and lowered between each of the ten independent readings of the ratio, the effect of probe wander on the uncertainty in the average value of the ratio is reduced to a negligible amount. Probe wander will be an important factor in the single reading procedure (cf. 12.2 .1 .3 ) but, as will be seen below, it is likely to be obscured by other effects.

Errors in temperature enter through uncertainties in the appropriate correction factor. If the maximum linear temperature coefficient is taken as 0.01 per deg uncertainties of temperature of $\pm 0.2^{\circ} \mathrm{C}$ will be reflected as an \pm 0.2 per cent error in temperature correction factor. In many cases the temperature coefficient is smaller so this error will also be smaller. Uncertainties in linear temperature coefficient $\left(C_{T}\right)$ of \pm 0.0001 are reflected as errors of about \pm 0.05 per cent at the extremes of the allowed temperature interval $\left[\left(23^{ \pm 5}\right)^{\circ} \mathrm{C}\right]$. This error is independent of and much smaller than the error due to uncertainty in temperature so it can be neglected. With these assumptions and the assumption that the three sources of error are random and independent, $\delta \mathrm{V} / \mathrm{V}$ becomes:

$$
\frac{\delta V}{V}=\sqrt{(0.15)^{2}+(0.2)^{2}}=0.25 \text { per cent }
$$

The data in Table VIII demonstrates that this small a deviation is seldom obtained even in those cases where the resistors in the analog test circuits were measured very accurately. The descrepancy probably arises from the inhomogeneity of the wafers. Note that the two wafers with the flattest resistivity profiles (Fig. 2) have the smallest $\mathrm{V} / \mathrm{I}$ standard deviations. The average observed value of $\delta \mathrm{V} / \mathrm{V}$ was 0.53 per cent if the $1000 \Omega$-cm slices are excluded. 
2.2.2.2 Errors in D. These errors enter into the calculation of resistivity only through the correction factor $\mathrm{F}_{2}$. The diameter of the wafer is required to be constant to $\pm D / 5 \bar{S}$ per cent of $D$. The average diameter was determined with an average relative standard deviation of less than 0.2 per cent as shown in Table IX. For the usual diameter of $25 \mathrm{~mm}$ ( $16 \overline{\mathrm{S}}$ for the recommended probe separation) $\delta \mathrm{F}_{2} / \mathrm{F}$ is only 0.013 per cent. The maximum uncertainty in the proper diameter correction factor to be used can be estimated by considering inscribed and circumscribed circles. In this case $\Delta D / D= \pm D / 5 \bar{S}$ per cent so the maximum $\triangle F / F_{2}$ becomes \pm 0.21 per cent for $D=16 \bar{S}$. Larger deviations will occur in smaller diameter wafers and smaller deviations in larger diameter wafers as discussed in Appendix D. The importance of using the diameter correction factor on wafers with $D \precsim 25 \bar{S}$ is also demonstrated in Appendix D.

2.2.2.3 Errors in $w$. These errors enter into the calculation of resistivity in two ways:

1) directly and

2) in the thickness correction factor $[F(w / \bar{S})]$.

The second of these, $\delta F / F$, is negative and has a value of $-0.27 \delta \mathrm{w} / \mathrm{w}$ when $w=\bar{S}$ (the maximum thickness allowed by the method) and decreases in magnitude to zero as the thickness decreases. Some intermediate values are listed in Appendix D. The permitted deviation on $w$ in the round-robin experiment was 0.16 per cent. From Table $X$ it can be seen that this was not achieved which suggests that instruments with the required accuracy were not used. The value achieved was on the average about 0.3 per cent so that the total contribution to the error arising from this source is between 0.3 per cent (for thin wafers) and 0.22 per cent (for the thickest wafer permitted). The wafers used in the round-robin had a w/S ratio of about 0.75 so that the appropriate value for the deviation due to thickness measurement errors is $(1-0.12)(\delta \mathrm{w} / \mathrm{s})=0.26$ per cent.

2.2.2.4 Errors in S. There are two forms of this error. First, there is an uncertainty in the measured values of the probe separations which will depend on both probe wander on the polished test wafer and the error in measuring the position of the impressions. Second, there is the effect of probe wander on the measured V/I ratio. The first of these will enter into the resistivity calculation through the three correction factors $F_{2}, F(w / \bar{S})$, and $F_{S P}$ as discussed in Appendixes $C$ and $D$. For typical slices $(D=16 \bar{S}, W=0.75 \bar{S})$ the contribution from $F_{2}$ and $F(w / \bar{S})$ can be neglected so the appropriate value is $1.14(\mathrm{~s} / \bar{S})=0.34$ per cent. The effect of probe wander on the voltage measurement has been considered in $\$ 2.2 .2 .1$ and Appendix $C$.

2.2.2.5 Summary. The total deviation may be found if it is assumed that each type of error discussed above is random and independent. With this assumption, the total deviation is the square root of the sum of the square of the individual deviations: 
TABLE IX - Specimen Diameter Measurement (Centimeters)

\begin{tabular}{|c|c|c|c|c|c|c|c|c|}
\hline Specimen & Lab. 1 & Lab. 2 & Lab. 3 & Lab. 4 & Lab. 5 & Avg. & $\underline{s}$ & $s(\%)$ \\
\hline $605603-3$ & 2.832 & 2.832 & 2.834 & 2.832 & 2.835 & 2.833 & 0.0014 & 0.05 \\
\hline $601333-2$ & 2.908 & 2.895 & 2.902 & 2.891 & 2.888 & 2.897 & 0.0082 & 0.28 \\
\hline $71983-2$ & 3.343 & 3.360 & 3.3437 & 3.350 & 3.347 & 3.349 & 0.0069 & 0.21 \\
\hline $71166-2 a$ & 2.047 & 2.051 & & & 2.06 & 2.053 & 0.0067 & 0.32 \\
\hline $71166-2 b$ & & & 2.0713 & 2.070 & 2.071 & 2.071 & 0.0007 & 0.03 \\
\hline $600200-2$ & 3.099 & 3.096 & 3.104 & 3.099 & 3.103 & 3.100 & 0.0033 & 0.11 \\
\hline $607075-2$ & 2.972 & 2.969 & 2.9696 & 2.967 & 2.971 & 2.970 & 0.0019 & 0.06 \\
\hline $70877-3$ & 3.048 & 3.045 & 3.062 & 3.058 & 3.051 & 3.053 & 0.0070 & 0.23 \\
\hline $49445-2$ & 2.997 & 3.000 & 3.003 & 3.000 & 3.006 & 3.001 & 0.0034 & 0.11 \\
\hline 66969-1 & 3.086 & 3.0911 & 3.10 & 3.086 & 3.094 & 3.091 & 0.0059 & 0.19 \\
\hline $16603-2$ & 2.337 & 2.344 & 2.349 & 2.347 & 2.343 & 2.344 & 0.0046 & 0.20 \\
\hline
\end{tabular}

TABLE X - Specimen Thickness Measurement (Centimeters)

$\begin{array}{ccccccccc}\text { Specimen } & \text { Lab.1 } & \text { Lab. 2 } & \text { Lab. 3 } & \text { Lab. 4 } & \text { Lab. 5 } & \text { Avg. } & \frac{s}{5} & \frac{s(\%)}{0.23} \\ 605603-3 & 0.1168 & 0.1173 & 0.1168 & 0.1171 & 0.11662 & 0.1169 & 0.0003 & 0.23 \\ 601333-2 & 0.1191 & 0.1197 & 0.1191 & 0.1194 & 0.11909 & 0.1193 & 0.0003 & 0.23 \\ 71983-2 & 0.1207 & 0.1209 & 0.1207 & 0.1206 & 0.12043 & 0.1207 & 0.0002 & 0.14 \\ 71166-2 \mathrm{a} & 0.1166 & 0.11696 & & & 0.11581 & 0.1165 & 0.0006 & 0.50 \\ 71166-2 \mathrm{~b} & & & 0.1158 & 0.1166 & 0.11597 & 0.1161 & 0.0004 & 0.36 \\ 600200-2 & 0.1214 & 0.1218 & 0.1214 & 0.1219 & 0.12121 & 0.1215 & 0.0003 & 0.24 \\ 607075-2 & 0.1194 & 0.1203 & 0.1194 & 0.1196 & 0.11920 & 0.1196 & 0.0004 & 0.36 \\ 70877-3 & 0.1184 & 0.1181 & 0.1188 & 0.1184 & 0.11821 & 0.1184 & 0.0003 & 0.22 \\ 49445-2 & 0.1163 & 0.1163 & 0.1163 & 0.1145 & 0.11610 & 0.1159 & 0.0008 & 0.68 \\ 66969-1 & 0.1166 & 0.11709 & 0.1168 & 0.1167 & 0.11659 & 0.1168 & 0.0002 & 0.18 \\ 16603-2 & 0.1224 & 0.1227 & 0.1222 & 0.1227 & 0.12222 & 0.1224 & 0.0002 & 0.20\end{array}$




$$
\begin{aligned}
\frac{\delta \rho}{\rho} & =\sqrt{(0.53)^{2}+(0.013)^{2}+(0.26)^{2}+(0.34)^{2}} \\
& =\sqrt{0.481}=0.69 \text { per cent. }
\end{aligned}
$$

This value is remarkably close to the value frequently found in the round-robin experiment. It would appear to indicate that the errors in the experiment can be accounted for by the various factors above. Since the dominant error occurs in the V/I measurement, and since much of this can be attributed to wafer non-uniformity, more uniform slices must be available if increased precision is to be obtained.

\subsection{EXPERIMENT 2 .}

This experiment was modeled after, the preliminany experiment described in Appendix A. The procedure given in Appendix B was used with the addition of the table of currents described in connection with Experiment 1 . In addition to the ten silicon wafers and six analog circuits the following equipment was furnished to each participant in turn: (1) four-point probe and holder, (2) micrometer stage with copper heat sink, mica insulator, and silicone heat-sink compound, (3) calibrated thermometer, and (4) polished silicon blanks for the probe separation measurement.

The analog circuits were similar to those used in Experiment 1. Resistivity profiles made on the wafers at the end of the test are shown in Fig. 3. In most cases each is similar to the profiles of the equivalent wafer used in Experiment 1 .

2.3.1 Results. The results of the test are summarized in Table

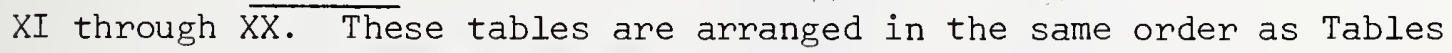
$I$ through $X$ and present the data in a similar fashion. Much of the discussion related to Experiment 1 can be carried over to the present case. However, it is immediately obvious that the precision of the measurement is considerably less ( $i . e$. , has a higher numerical value) in Experiment 2. Examination of Tables XVII and XVIII shows that significant difficulties with the electrical measuring apparatus were encountered in several of the labs. Unfortunately, these difficulties render a quantitative analysis of the experiment meaningless.

It can be noted that geometrical measurements on the wafers ( Tables XIX and $X X$ ) were made with nearly the precision attained in Experiment 1. Since the same probe was supplied to all participants, the data (Table XVI) yields an indication of the precision of the measurement of probe separation. Labs 1, 2, and 3 appeared to have problems in this area. The same probe was used in the preliminary experiment. Comparison of Table XVI with Tables III and IV of Appendix A shows that much of the spread in the present experiment is due to measurement problems rather than probe problems. 

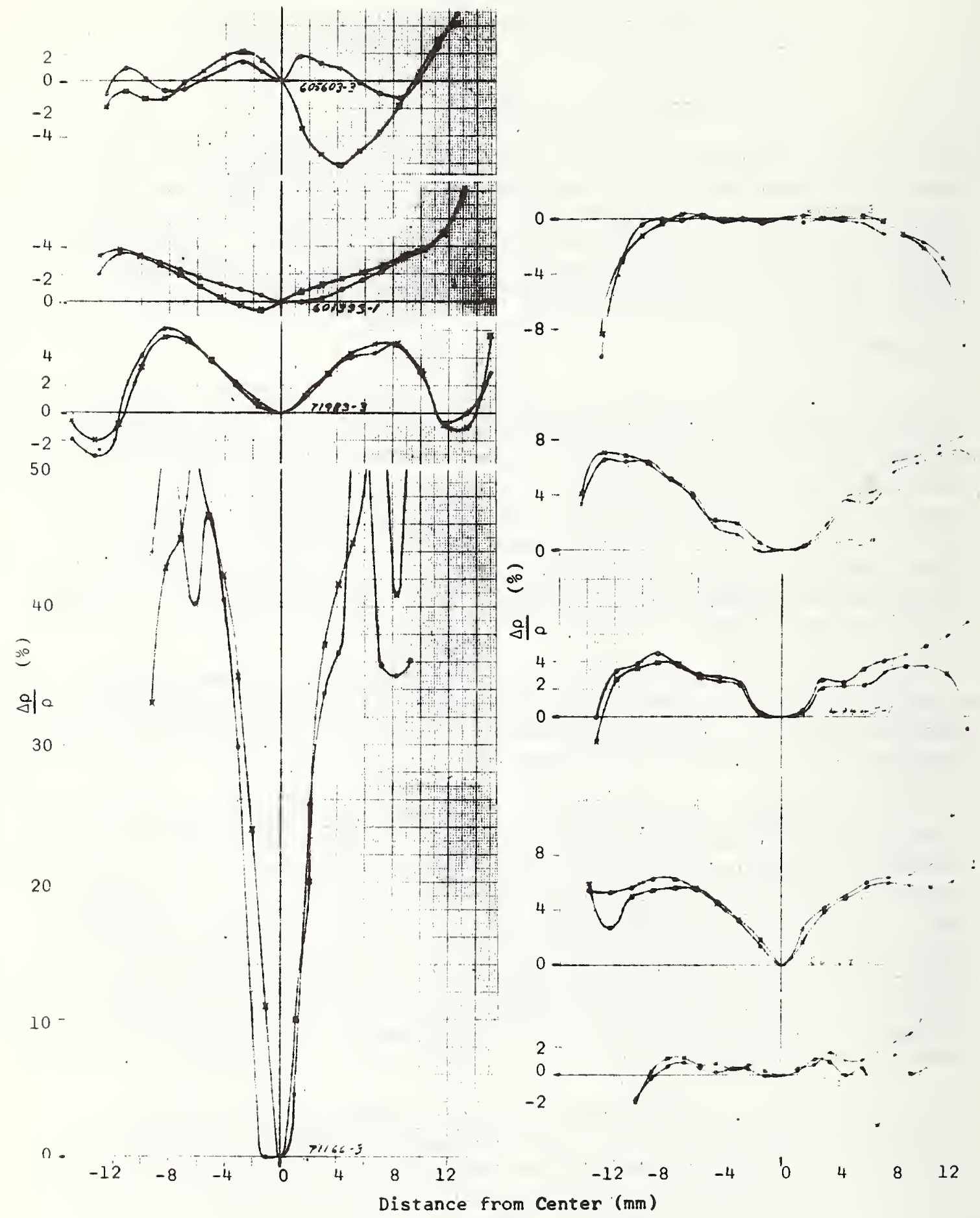

Figure 3. Specimen Resistivity Profiles for the Slices Used in Experiment 2. (No profile was made on Slice 600200-3.) 
TABLE XI - Average Resistivity $(\Omega-\mathrm{cm})$ at $23^{\circ} \mathrm{C}$ (as Reported)

\begin{tabular}{|c|c|c|c|c|c|c|c|c|c|}
\hline Specimen & Lab. 1 & Lab. 2 & Lab. 3 & Lab. 4 & Lab. 5 & Lab. 6 & Avg. & $\underline{s}$ & $s(\%)$ \\
\hline $605603-2$ & 0.0079680 & 0.008 & 0.0082 & 0.00808 & 0.00821 & 0.0081977 & $17 \quad 0.008109$ & 0.000108 & 81.34 \\
\hline $601333-1$ & 0.084034 & 0.086 & 0.08436 & 0.08449 & 0.0851 & 0.084731 & 0.08479 & 0.000694 & $4 \quad 0.82$ \\
\hline $71983-3$ & 96.693 & 136.8 & 100.76 & 106.1 & 86.64 & 96.78 & 103.96 & 17.31 & 16.65 \\
\hline $71166-3$ & 1264.3 & 3373. & & 1067.9 & 704.6 & 1152. & 1512. & 1061. & 70.16 \\
\hline $600200-3$ & 0.0077248 & 0.008 & & & & & 0.00786 & 0.00019 & 2.48 \\
\hline $607075-3$ & 0.10800 & 0.103 & 0.1074 & 0.1059 & 0.107 & 0.10688 & 0.1064 & 0.00179 & 1.68 \\
\hline BTL-4 & 10.187 & 10.0 & 10.220 & 10.50 & 9.68 & 10.134 & 10.12 & 0.271 & 2.68 \\
\hline $49445-1$ & 11.822 & 11.8 & 11.7959 & 12.10 & 11.83 & 11.800 & 11.86 & 0.119 & 1.01 \\
\hline $66969-2$ & 110.53 & 102.3 & 109.02 & 119.2 & 108.3 & 110.47 & 110.0 & 5.4 & 4.95 \\
\hline $16603-3$ & 939.42 & & & 914.1 & 735.07 & 936.9 & 881.4 & 98.2 & 11.14 \\
\hline
\end{tabular}

TABLE XII - Average Resistivity $(\Omega-\mathrm{cm})$ at $23^{\circ} \mathrm{C}$ (Recomputed)

\begin{tabular}{|c|c|c|c|c|c|c|c|c|c|}
\hline Specimen & Lab. I & Lab. 2 & Lab. 3 & Lab. 4 & Lab. 5 & Lab. 6 & Avg. & & $\mathrm{s}(\%)$ \\
\hline $605603-2$ & 0.0079895 & 0.0080 & 0.0082 & 0.00823 & 0.00822 & 0.0081977 & $\begin{array}{ll}7 & 0.008140\end{array}$ & 0.000113 & 31.39 \\
\hline 601333-1 & 0.084201 & 0.086 & 0.0849 & 0.08501 & 0.0850 & 0.084731 & 0.08497 & 0.000586 & 60.69 \\
\hline $71983-3$ & 97.112 & 137. & 101.2 & 107.6 & 86.6 & 96.78 & 104.38 & 17.39 & 16.66 \\
\hline $71166-3$ & 1268.3 & 3360 . & & 1075 . & 704. & 1161. & 1514. & 1054 . & 69.62 \\
\hline $600200-3$ & 0.0077600 & 0.0078 & & & & & 0.00778 & 0.000028 & 80.36 \\
\hline $607075-3$ & 0.10745 & 0.103 & 0.1079 & 0.1067 & 0.1070 & 0.10688 & 0.1065 & 0.00176 & 1.66 \\
\hline BTL -4 & 10.188 & 10.0 & 10.23 & 10.55 & 9.70 & 10.134 & 10.13 & 0.280 & 2.76 \\
\hline $49445-1$ & 11.855 & 11.8 & 11.85 & 12.26 & 11.83 & 11.811 & 11.90 & 0.177 & 1.49 \\
\hline $66969-2$ & 110.84 & 102. & 110.8 & 119.0 & 107.9 & 110.47 & 110.2 & 5.5 & 4.99 \\
\hline $16603-3$ & 940.80 & & & 923.4 & 734. & 936.9 & 883.8 & 100.1 & 11.33 \\
\hline
\end{tabular}

TABLE XIII- Sample Standard Deviation in Per Cent (Recomputed)

\begin{tabular}{|c|c|c|c|c|c|c|c|c|}
\hline Specimen & 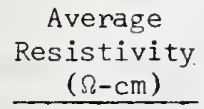 & Lab. 1 & Lab. 2 & Lab. 3 & Lab. 4 & Lab. 5 & Lab. 6 & Avg. \\
\hline $605603-2$ & 0.008140 & 0.25 & 0.6 & 0.39 & 1.19 & 0.73 & 0.55 & 1.39 \\
\hline $601333-1$ & 0.08497 & 0.31 & 0.6 & 0.08 & 0.34 & 0.42 & 0.13 & 0.69 \\
\hline $71983-3$ & 104.38 & 0.38 & 2.6 & 0.89 & 1.22 & 4.31 & 0.24 & 16.66 \\
\hline $71166-3$ & 1514. & 1.64 & 14.0 & & 3.30 & 4.44 & 1.23 & 69.62 \\
\hline $600200-3$ & 0.00778 & 0.15 & 0.0 & & & & & .36 \\
\hline $607075-3$ & 0.1065 & 0.15 & 0.0 & 1.17 & 0.50 & 0.32 & 0.08 & 1.66 \\
\hline BTL-4 & 10.13 & 0.34 & 1.2 & 0.88 & 0.89 & 5.05 & 0.30 & 2.76 \\
\hline $49445-1$ & 11.90 & 0.15 & 0.7 & 0.28 & 0.24 & 0.21 & 0.10 & 1.49 \\
\hline $66969-2$ & 110.2 & 0.14 & 2.5 & 0.25 & 1.74 & 0.69 & 0.18 & 4.99 \\
\hline $16603-3$ & 883.8 & 0.31 & & & 1.66 & 0.71 & 0.14 & 11.33 \\
\hline
\end{tabular}


TABLE XIV - Per Cent Difference of One Reading from Overall Average Resistivity Average Resistivity

\begin{tabular}{|c|c|c|c|c|c|c|c|c|c|}
\hline Specimen & $(\Omega-\mathrm{cm})$ & Lab. 1 & Lab. 2 & Lab. 3 & Lab. 4 & Lab. 5 & Lab. 6 & Avg. & $s(\%)$ \\
\hline $605603-2$ & 0.008140 & -1.65 & -1.72 & +0.74 & +1.35 & +0.98 & +0.18 & 0.00 & 1.34 \\
\hline $601333-1$ & 0.08497 & -0.50 & +0.04 & +0.04 & +0.39 & +0.04 & -0.11 & -0.02 & 0.29 \\
\hline $71983-3$ & 104.38 & -6.96 & +8.26 & -3.81 & +5.19 & -25.66 & -7.14 & -5.02 & 12.60 \\
\hline $71166-3$ & 1514 & -16.49 & +162.88 & & -29.66 & -54.76 & -23.18 & +7.73 & 81.59 \\
\hline $600200-3$ & 0.00778 & -0.40 & +0.26 & 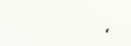 & & & & -0.13 & 0.46 \\
\hline $607075-3$ & 0.1065 & +0.90 & -3.29 & +0.56 & +0.66 & +0.19 & +0.38 & -0.09 & 1.58 \\
\hline $\mathrm{BTL}-4$ & 10.13 & +0.69 & +0.69 & +1.28 & +3.95 & -0.99 & +0.51 & +0.99 & 1.61 \\
\hline $49445-1$ & 11.90 & -0.35 & -1.68 & -0.42 & +3.28 & -0.76 & -0.83 & -0.17 & 1.74 \\
\hline $66969-2$ & 110.2 & +0.67 & -4.72 & -8.53 & +7.89 & -2.27 & +0.19 & -1.09 & 5.64 \\
\hline $16603-3$ & 883.8 & +6.40 & & & +4.66 & -16.27 & +5.83 & +0.16 & 10.96 \\
\hline
\end{tabular}

TABLE XV - Per Cent Difference of Median of Three Reedings from Overall Average Resistivity Average Resistivity

\begin{tabular}{|c|c|}
\hline Specimen & $(\Omega-\mathrm{cm})$ \\
\hline $605603-2$ & 0.008140 \\
\hline $601333-1$ & 0.08497 \\
\hline $71983-3$ & 104.38 \\
\hline $71166-3$ & 1514. \\
\hline $600200-3$ & 0.00778 \\
\hline $607075-3$ & 0.1065 \\
\hline BTL-4 & 10.13 \\
\hline $49445-1$ & 11.90 \\
\hline $66969-2$ & 110.2 \\
\hline $16603-3$ & 883.8 \\
\hline
\end{tabular}

\begin{tabular}{|c|c|c|c|c|c|c|c|}
\hline Lab. 1 & $\underline{\mathrm{Lab}} \cdot 2$ & Lab. 3 & Lab. 4 & Lab. 5 & Lab. 6 & Avg. & $\mathrm{s}(\%)$ \\
\hline-1.84 & -1.72 & +0.74 & +0.98 & +1.84 & +0.54 & +0.12 & 1.52 \\
\hline-0.84 & +1.80 & +0.04 & -0.20 & +0.04 & -0.31 & +0.08 & 0.90 \\
\hline-7.05 & +27.42 & -3.81 & +3.56 & -15.88 & -7.30 & -0.56 & 15.13 \\
\hline-16.06 & +132.50 & & -29.66 & -54.76 & -23.65 & +1.65 & 73.33 \\
\hline-0.29 & +0.26 & & & & & 0.00 & 0.39 \\
\hline+0.89 & -3.29 & +0.56 & +0.47 & +0.47 & +0.39 & -0.09 & 1.58 \\
\hline+0.35 & -0.30 & +1.97 & +3.95 & -0.99 & +0.08 & +0.89 & 1.80 \\
\hline-0.35 & -1.68 & -0.42 & +3.03 & -0.59 & -0.80 & -0.17 & 1.62 \\
\hline+0.67 & -5.63 & +0.54 & +7.71 & -2.27 & +0.33 & +0.18 & 4.39 \\
\hline+6.80 & & & +4.66 & -16.72 & +5.83 & +0.14 & 11.26 \\
\hline
\end{tabular}

TABLE XVI - Probe Separation Measurement in Millimeters

\begin{tabular}{|c|c|c|c|c|c|c|c|}
\hline & Lab. 1 & Lab. 2 & Lab. 3 & Lab. 4 & Lab. 5 & Lab. 6 & Avg. \\
\hline$s_{1}$ & $1.59156^{\circ}$ & 1.5951 & 1.5888 & 1.58966 & 1.5908 & 1.58775 & 1.5905 \\
\hline$s_{1}$ & 0.01387 & 0.0020 & 0.00729 & 0.00122 & 0.0015 & 0.001090 & 0.00259 \\
\hline$s_{1}(\%)$ & 0.87 & 0.13 & 0.46 & 0.08 & 0.10 & 0.07 & 0.16 \\
\hline $\mathrm{s}_{2}$ & 1.58692 & 1.5916 & 1.58534 & 1.58671 & 1.5867 & 1.58796 & 1.5875 \\
\hline $\mathrm{s}_{2}$ & 0.01651 & 0.0046 & 0.00658 & 0.001168 & 0.0008 & 0.001123 & 0.00213 \\
\hline$s_{2}\left(\frac{c}{6}\right)$ & 1.04 & 0.29 & 0.41 & 0.07 & 0.05 & 0.07 & 0.13 \\
\hline $\mathrm{S}_{3}$ & 1.59720 & 1.5961 & 1.60528 & 1.60099 & 1.6063 & 1.60210 & 1.6012 \\
\hline $\mathrm{s}_{3}$ & 0.01852 & 0.0056 & 0.00267 & 0.00086 & 0.0023 & 0.001199 & 0.00411 \\
\hline $\mathrm{s}_{3}(\%)$ & 1.16 & 0.35 & 0.17 & 0.05 & 0.14 & 0.07 & 0.26 \\
\hline$\overline{\mathrm{S}}$ & 1.59189 & 1.5944 & 1.59314 & 1.59245 & 1.5946 & 1.59261 & 1.59319 \\
\hline $\mathrm{F}_{\mathrm{sp}}$ & 1.0034 & 1.0018 & 1.0053 & 1.0039 & 1.0053 & 1.0031 & 1.0038 \\
\hline
\end{tabular}


TABLE XVII - Average Resistance (Recomputed)

a) Measured Values $(\Omega)$

\begin{tabular}{|c|c|c|c|c|c|c|c|c|c|}
\hline $\begin{array}{l}\text { Analog } \\
\text { Circuit }\end{array}$ & Lab. 1 & Lab. 2 & Lab. 3 & Lab. 4 & Lab. 5 & Lab. 6 & Avg. & $\underline{s}$ & $s(\%)$ \\
\hline No. 1 & 0.0010032 & 0.00107 & 0.00100 & 0.001025. & & 0.0009799 & 90.001016 & 0.000034 & 3.38 \\
\hline No. 2 & 0.010102 & 0.0102 & 0.01001 & 0.00996 & 0.01001 & 0.0101023 & 30.01006 & 0.00009 & 0.87 \\
\hline No. 3 & 0.10025 & 0.101 & 0.1003 & 0.1017 & 0.0995 & 0.10022 & 0.1005 & 0.00076 & 0.75 \\
\hline No. 5 & 10.015 & 0.3 & 10.00 & 10.155 & 9.96 & 10.017 & 10.07 & 0.129 & 1.28 \\
\hline No. 6 & 99.853 & 100. & 100.0 & 106.2 & 93.8 & 99.94 & 99.97 & 3.92 & 3.92 \\
\hline No. 7 & 990.75 & 880 . & 1001. & 963.0 & & 1003.5 & 967.6 & 51.6 & 5.33 \\
\hline
\end{tabular}

b) Sample Standard Deviation (Per Cent)

\begin{tabular}{|c|c|c|c|c|c|c|c|}
\hline $\begin{array}{l}\text { Analog } \\
\text { Circuit }\end{array}$ & Lab. 1 & Lab. 2 & Lab. 3 & Lab. 4 & Lab. 5 & Lab. 6 & Avg. \\
\hline No. 1 & 0.11 & 4.7 & 0.80 & 0.32 & & 0.08 & 3.38 \\
\hline No. 2 & 0.02 & 0.3 & 0.28 & 0.55 & 0.22 & 0.01 & 0.87 \\
\hline No. 3 & 0.00 & 0.0 & 0.2 & 0.26 & 0.13 & 0.00 & 0.75 \\
\hline No. 5 & 0.01 & 0.8 & 0.0 & 0.19 & 0.28 & 0.00 & 1.28 \\
\hline No. 6 & 0.05 & 0.0 & 0.0 & 0.12 & 0.04 & 0.03 & 3.92 \\
\hline No. 7 & 0.11 & 0.0 & 0.33 & 0.48 & & 0.05 & 5.33 \\
\hline
\end{tabular}

TABLE XVIII - V/I $(\Omega)$ Corrected to $23^{\circ} \mathrm{C}$

\begin{tabular}{|c|c|c|c|c|c|c|c|c|c|}
\hline Specimen & Lab. 1 & Lab. 2 & Lab. 3 & Lab. 4 & Lab. 5 & Lab. 6 & Avg. & $\underline{s}$ & $s(\%)$ \\
\hline $605603-2$ & 0.015798 & 0.0159 & 0.01629 & 0.0164 & 0.0163 & 0.016306 & 0.01617 & 0.000251 & 11.55 \\
\hline $601333-1$ & 0.16365 & 0.1669 & 0.1652 & 0.166 & 0.166 & 0.16533 & 0.1655 & 0.00110 & 0.66 \\
\hline $71983-3$ & 185.30 & 261.1 & 192.7 & 206.6 & 165. & 185.2 & 199.3 & 33.13 & 16.62 \\
\hline $71166-3$ & 2583.0 & 6842.0 & & 2194. & 1438 & 2370 & 3085 . & 2144 . & 69.48 \\
\hline $600200-3$ & 0.014799 & 0.015 & & & & & 0.014810 & 0.000142 & 20.95 \\
\hline $607075-3$ & 0.20849 & 0.201 & 0.2095 & 0.208 & 0.208 & 0.20821 & 0.2072 & 0.00309 & 1.49 \\
\hline BTL-4 & 21.990 & 21.8 & 22.078 & 23.01 & 21.0 & 22.020 & 21.98 & 0.643 & 2.92 \\
\hline $49445-1$ & 23.432 & 23.5 & 23.563 & 24.52 & 23.5 & 23.54 & 23.68 & 0.416 & 1.76 \\
\hline $66969-2$ & 217.72 & 201.0 & 217.0 & 234.5 & 212. & 217.34 & 216.6 & 10.83 & 5.00 \\
\hline $16603-3$ & 1808.3 & & & 1782 . & 1411. & 1805 . & 1702 . & 194.1 & 11.40 \\
\hline
\end{tabular}


TABLE XIX - Specimen Diameter Measurement (Centimeters)

\begin{tabular}{|c|c|c|c|c|c|c|c|c|c|}
\hline Specimen & Lab. 1 & Lab. 2 & Lab. 3 & Lab. 4 & Lab. 5 & Lab. 6 & Avg. & $\underline{s}$ & $\mathrm{~s}(\%)$ \\
\hline $605603-2$ & 2.8313 & 2.81783 & & 2.837 & 2.835 & 2.835 & 2.831 & 0.0078 & 0.27 \\
\hline $601333-1$ & 2.893 & 2.858 & & 2.903 & 2.903 & 2.901 & 2.892 & 0.0192 & 0.67 \\
\hline $71983-3$ & 3.340 & 3.3338 & & 3.338 & 3.340 & 3.331 & 3.337 & 0.0040 & 0.12 \\
\hline $71166-3$ & 2.065 & 2.064 & & 2.068 & 2.064 & 2.068 & 2.066 & 0.0020 & 0.10 \\
\hline $600200-3$ & 3.0803 & 3.09562 & & & & & 3.088 & 0.0108 & 0.35 \\
\hline $507075-3$ & 2.9634 & 2.93687 & & 2.967 & 2.965 & 2.965 & 2.959 & 0.0127 & 0.43 \\
\hline BTL- 4 & 3.228 & 3.175 & & 3.226 & 3.236 & 3.238 & 3.221 & 0.0260 & 0.81 \\
\hline $49445-1$ & 3.0015 & 3.0162 & & 3.018 & 3.005 & 3.0038 & 3.009 & 0.0076 & 0.25 \\
\hline $66909-2$ & 3.081 & 3.01625 & & 3.086 & 3.084 & 3.087 & 3.071 & 0.0306 & 1.00 \\
\hline $16603-3$ & 2.340 & & & 2.355 & 2.347 & 2.350 & 2.348 & 0.0063 & 0.27 \\
\hline
\end{tabular}

TABLF XX - Specimen Thickness Measurement (Centimeters)

\begin{tabular}{|c|c|c|c|c|c|c|c|c|c|}
\hline Specimen & Lab. 1 & Lab. 2 & Lab. 3 & Lab. 4 & Lab. 5 & Lab. 6 & Avg. & $\underline{\mathrm{s}}$ & $\mathrm{s}(\%)$ \\
\hline $605603-2$ & 0.117057 & 0.1166 & & 0.1158 & 0.1161 & 0.11625 & 0.11636 & 0.00048 & 0.42 \\
\hline $601333-1$ & 0.119168 & 0.1189 & & 0.11836 & 0.1186 & 0.11865 & 0.11874 & 0.00031 & 0.26 \\
\hline $71983-3$ & 0.12082 & 0.1209 & & 0.11989 & 0.1204 & 0.12051 & 0.12050 & 0.00040 & 0.33 \\
\hline $71166-3$ & 0.11618 & 0.1166 & & 0.11582 & 0.1156 & 0.11589 & 0.11602 & 0.00039 & 0.33 \\
\hline $600200-3$ & 0.121376 & 0.1212 & & & & & 0.12129 & 0.00012 & 0.10 \\
\hline $607075-3$ & 0.119228 & 0.1191 & & 0.11836 & 0.1184 & 0.11873 & 0.11876 & 0.00040 & 0.33 \\
\hline BTL-4 & 0.105537 & 0.1054 & & 0.10439 & 0.1049 & 0.10480 & 0.10500 & 0.00047 & 0.44 \\
\hline $49445-1$ & 0.11668 & 0.1156 & & 0.11506 & 0.1156 & 0.11561 & 0.11571 & 0.00059 & 0.51 \\
\hline $66909-2$ & 0.11734 & 0.1176 & & 0.11684 & 0.1171 & 0.11716 & 0.11721 & 0.00028 & 0.24 \\
\hline $16603-3$ & 0.12257 & & & 0.12192 & 0.1222 & 0.12219 & 0.12222 & 0.00027 & 0.22 \\
\hline
\end{tabular}


It should also be noted that some of the observed difficulties arose because of inadequate resolution in the measuring equipment. As a result, specific resolution requirements were added to the revision of the method.

\subsection{CONCLUSIONS}

From the results of these experiments, it can be concluded that resistivity measurements can be made according to the procedures of the method under test with a precision of \pm 2 per cent ( 3 standard deviations). Relaxation of the requirement of averaging 10 pairs of readings to permit a single pair to be used increases the 3 standard deviation interval to \pm 4 per cent. It was shown that errors in the six quantities measured during the test account for the overall deviation obtained if effects of wafer inhomogeneity are included. It was found that much of the error which entered in the determination of the potential difference between the inner probes arose from this source.

This precision was not achieved over the entire resistivity range. No very low $(\sim 0.001 \Omega-\mathrm{cm})$ resistivity wafers were included in the experiments. In addition gross inhomogeneity in the $1000 \Omega$-cm p-type wafers used in the tests prevented the acquisition of good data. Accordingly, additional tests at both extremes are still needed. The low resistivity test is scheduled to begin soon; in addition several high resistivity wafers will be included in this test.

The poor precision achieved in Experiment 2 serves to emphasize the need for adequate equipment and control procedures if precise measurements are desired. Although resistivity is probably the most widely measured semiconductor characteristic, the precise determination of resistivity can only be done with facilities which are well maintained, accurately calibrated, and properly used.

The control procedures outlined in the test method appear to be adequate to identify problems associated with the probe or electrical measuring equipment. Additional study of the low resistance analog circuits will be required before their usefulness can be fully documented. This will be done in connection with the forthcoming roundrobin experiment.

The results of the analysis indicate that aside from the single measurement pair modification discussed above relaxation of the various requirements of the method will reduce the precision of the measurement to a value which is generally unacceptable. In particular if the permitted standard deviation were doubled the probe separation uncertainty would become the dominant factor contributing to the variation in measured resistivity. Furthermore, difficulties in thickness determination at the $1.1 \mathrm{~mm}$ level suggest that uncertainty in this deminsion will also become a dominant factor if slices 0.25 to $0.5 \mathrm{~mm}$ are measured. Where \pm 10 per cent measurements are sufficient, some relaxation in the geometrical requirements on the wafer would be feasible 
even if only a single pain of readings is taken. It is possible to incorporate the various geometrical correction factors into a direct reading instrument. 6 It is also possible to include circuits which incorporate the correction for temperature and unequal probe separations.

The method can be extended for use in sheet resistance measurements and for production control of slices. In order to determine the limits of validity and the precision which might be anticipated in such applications, additional studies of the effects of decreased probe pressure and different surface conditions must be carried out.

\subsection{NOTES AND REFERENCES}

1. This draft version of the method differs only slightly from the version published for information only in the back of Part 8 of the 1967 ASTM Book of Standards. In subsequent revisions some paragraph numbers have been changed; references to paragraph numbers given in this printing are appropriate to the current standard, F-84-73.

2. M. A. Logan, "An AC Bridge for Semiconductor Resistivity Measurement Using a Four-Point Probe," Bell System Tech. J. 40, 885-919 (1961).

3. Note that this formula is appropriate to a thin slice while the formula shown in Fig. $l$ is appropriate to a semi-infinite volume.

4. F. M. Smits, "Measurement of Sheet Resistivities with the Four-Point Probe," Bell System Tech. J. 37, 711-718 (1958).

5. L. J. Swartzendruber, "Correction Factor Tables for FourPoint Probe Resistivity Measurements on Thin Circular Semiconductor Samples," NBS Technical Note 199, April I5, 1964 .

6. L. J. Swartzendruber, F. H. Ulmer, and J. A. Coleman, "Direct-Reading Instrument for Silicon and Germanium Resistivity Measurement," Rev. Sci. Instrum. 39, 18581863 (1968). 


\subsection{INTRODUCTION}

An experimental study of the temperature coefficient of resistivity of silicon and germanium was concluded during the project. A report describing this work has been prepared for publication. The data obtained are attached as Appendix E. In addition, initial experimental work was undertaken to establish thermal equilibration time, the effect of non-uniform thickness, and the effect of probe needle wobble.

\subsection{THERMAL EQUILIBRATION TIME}

Two sets of experiments were run. In the first, a $0.1 \Omega$-cm n-type germanium wafer cut into a "clover-leaf" shape for van der Pauw measurements was cooled below or heated above room temperature. After reaching a suitable temperature it was placed on the copper heat sink of the four-probe apparatus. The temperature of the wafer determined from its resistivity was monitored as a function of time. It was found that the wafer always approached a temperature somewhat greater than the heat sink temperature but that it was within $0.5^{\circ} \mathrm{C}$ of the heat sink temperature in less than 3 minutes when initially at $-50^{\circ} \mathrm{C}$ and in less than 7 minutes when initially at $+35^{\circ} \mathrm{C}$.

These results emphasize the importance of the use of proper current levels when measuring resistivity. The current used (about $100 \mathrm{~mA}$ ) was large enough to cause sufficient joule heating in the wafer to raise the temperature above the heat sink temperature. An auxiliary experiment, in which the wafer was not placed directly on the copper heat sink but instead, inside a plastic box at the heat sink temperature, showed that, in the absence of the heat sink, the wafer rises to a temperature nearly $9 \mathrm{deg}$ above that of the heat sink in about 20 minutes. This current, which is larger than would normally be used on wafers of this resistivity, was selected in order to allow more rapid measurements to be made.

Even with the larger current, it was not possible to follow the initial stages of decay. Hence, a second series of measurements on a silicon wafer about $1.2 \mathrm{~mm}$ thick were made in which the temperature difference between the top of the wafer and the copper block was measured with a differential copper-constantan thermocouple. One junction of the thermocouple was attached to the wafer with galliumindium eutectic; mechanical support was provided by gluing the wires just behind the junction to the wafer. The wafer was cooled or heated to the desired initial temperature. After the reference junction of the thermocouple was immersed in an oil-filled well in the copper heat sink and the leads were connected to a recorder with a maximum sensitivity of $1 \mu \mathrm{V} / \mathrm{mm}$, the wafer was placed on a $12 \mu \mathrm{m}$ thick mica sheet on the heat sink and the probes were lowered. No current was passed through the 
probes. In all cases the wafer temperature had reached within 0.2 deg of the heat sink temperature in less than $30 \mathrm{~s}$. Noise on the thermocouple leads prevented determination of smaller temperature differences. In an auxiliary experiment, the wafer was placed near but not on the heat sink; about 11 min elapsed before the wafer reached within 0.3 deg of the heat sink.

\subsection{EFFECT OF NON-UNIFORM THICKNESS}

These experiments were carried out on an aluminum-doped silicon wafer of about $0.245 \Omega-\mathrm{cm}$. The thickness was initially $1.022 \mathrm{~mm}$ and the diameter, $26.85 \mathrm{~mm}$. After measuring the resistivity with parallel faces on the wafer, one side was angle lapped to 11 min., then $22 \mathrm{~min}$, then 33 min., and finally parallel again. The average thickness in each case was determined from five measurements, one at the center of the wafer, and four on perpendicular radii about half way between the center and the edge of the wafer. The resistivity was determined by averaging the results of ten measurements at the center of the wafer, five on each side. Between readings, the wafer was rotated about $15^{\circ}$. Although a small increase in average resistivity was detected as the taper angle was increased, the value in each case did not depart from the average of the two parallel cases by more than $0.33 \%$. The spread on the averages of the two parallel cases was about $0.2 \%$. Although the dependence on taper angle may be statistically significant, it would appear that it may be ignored as a practical matter at least under conditions similar to those of this test. The results are summarized in Table XXI.

Table XXI

Angle lapped wafer: thickness and resistivity

\begin{tabular}{|c|c|c|c|c|c|c|}
\hline Condition & $\begin{array}{l}\text { thickness } \\
(\mathrm{mm})\end{array}$ & \multicolumn{2}{|c|}{$\begin{array}{c}\text { thickness } \\
\text { variation } \\
\text { (edge-to-edge) }\end{array}$} & \multicolumn{2}{|c|}{$\begin{array}{l}\text { thickness } \\
\text { variation } \\
\text { (measured) }\end{array}$} & $\begin{array}{c}\text { resistivity } \\
(\Omega-\mathrm{cm})\end{array}$ \\
\hline parallel & 1.0223 & - & - & 0.024 & 0.23 & $0.24496 \pm 0.00047$ \\
\hline 11 min. & 0.9670 & 0.0860 & 8.9 & 0.0356 & 3.7 & $0.24534 \pm 0.00066$ \\
\hline 22 min. & 0.8899 & 0.1718 & 19.3 & 0.1103 & 12.4 & $0.24585 \pm 0.00047$ \\
\hline $33 \mathrm{~min}$. & 0.8449 & 0.2577 & 30.4 & 0.1350 & 16.0 & $0.24626 \pm 0.00069$ \\
\hline parallel & 0.6083 & - & - & 0.032 & 0.38 & $0.24594 \pm 0.00054$ \\
\hline
\end{tabular}

Nevertheless, uncertainty in thickness in very thin wafers causes equal uncertainty in resistivity. When the wafer has flat (though nonparallel) faces the uncertainty in thickness can be reduced considerably below the variation in thickness over the wafer; however, this can not be assumed always to be the case. As an example of an irregular shape, a ring $2.674 \mathrm{~mm}$ wide and $0.130 \mathrm{~mm}$ deep was cut ultrasonically from the 
outer edge of the wafer, leaving a "top-hat" structure. If the full diameter and maximum thickness are used in the resistivity computation, a value about $1 \%$ larger than the average of the two parallel cases was obtained. A weighted value of average thickness yielded a resistivity about $4 \%$ lower; a $3 \%$ avercorrection. No convenient means of obtaining the effective diameter or thickness in this case has been found.

\subsection{EFFECT OF PROBE NEEDLE WANDER}

Studies of the effect of probe needle wander require the use of probes with different amounts of needle wander. Several probe assemblies were tested during this reporting period but none which had a sample standard deviation on probe spacing larger than that allowed in the test method (cf. Method F-84, I10.1.3.1) was found.

Computations of expected effects of probe needle wander on thin wafers were carried out as part of the error analysis of Experiment 1 . The results of these computations have been summarized in Section 2 . 


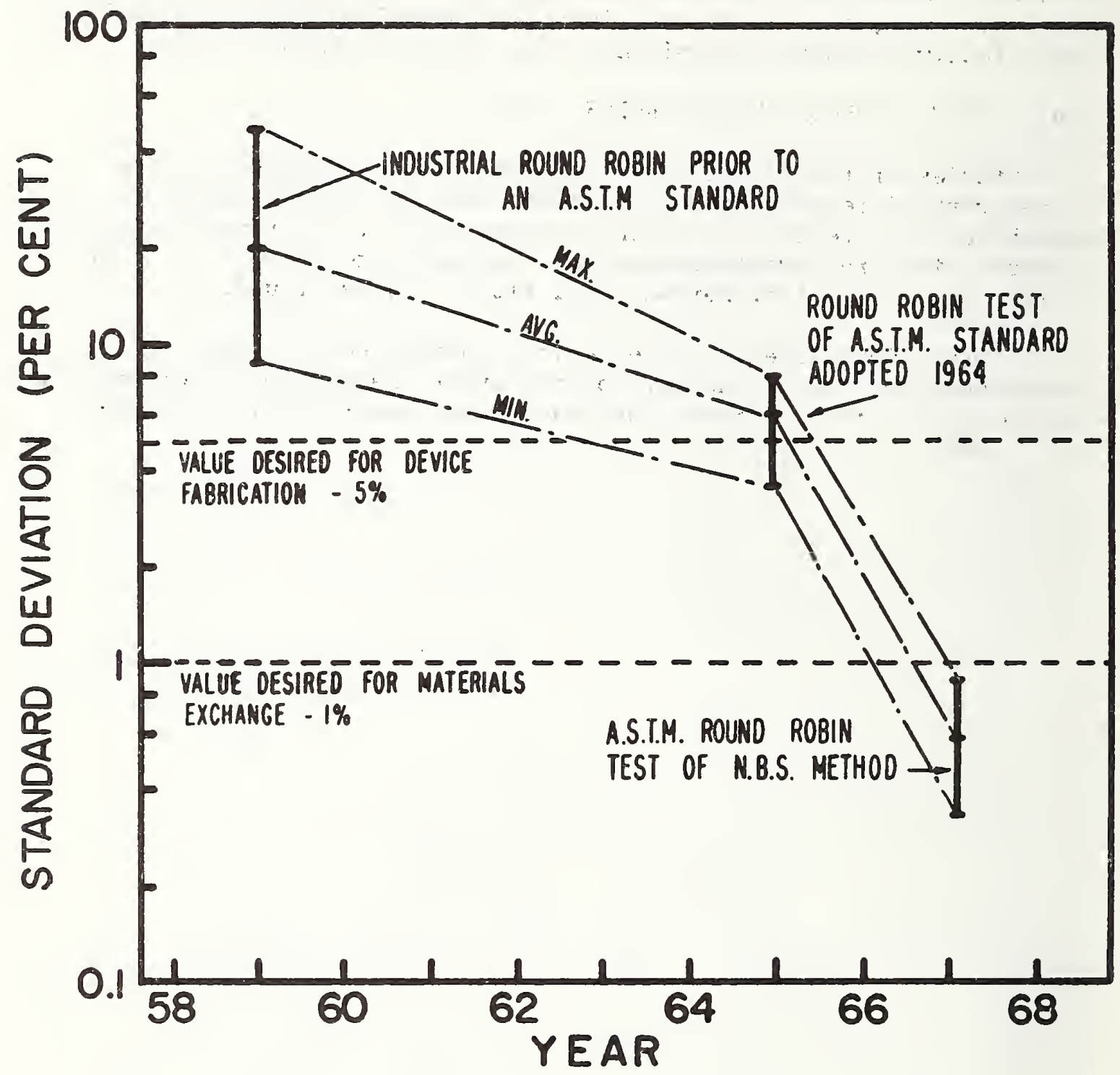

Figure 4. History of the Interlaboratory Precision of Measurement of Silicon Resistivity in the Range 0.01 to $100 \Omega-\mathrm{cm}$, by the Four-Probe Method, Showing the Spread of Sample-Dependent Standard Deviations by the Vertical Bars. 


\section{SUMMARY}

During the period covered by this project, the Method of Test for Resistivity of Silicon Slices Using Four Point Probes has been extended to cover the useful resistivity range. The precision which can now be obtained in the resistivity range between 0.005 and $120 \mathrm{ohm}-\mathrm{cm}$ is \pm 2 per cent ( 3 standard deviations). This is significantly better than was possible with earlier methods as shown by the plot of single standard deviation against time in Fig. 4.

Detailed analysis of the round-robin experiments leads to the following conclusions:

1) The desired precision can be obtained if correct procedures are followed and if the equipment used in the test meets the requirements of the test method. The importance of a well maintained, accurately calibrated, and properly used test system can not be overemphasized.

2) The major contribution to measurement error appears to be resistivity non-uniformity in the specimen under study.

3) If a single pair of readings is taken rather than the average of 10 pairs as required by the method, the precision is degraded somewhat; the relative standard deviation may double.

4) Relaxation of the geometrical requirements of the method would be expected to reduce the precision significantly. Some difficulty in maintaining the required precision in the determination of the thickness is expected if thin $(0.25$ to $0.5 \mathrm{~mm})$ slices are measured.

The importance of knowing the temperature of the slice being measured and the effectiveness of the large copper heat sink in establishing this temperature were also demonstrated. Slices initially maintained at temperature well above or below the heat sink temperature reached a temperature within $0.2^{\circ} \mathrm{C}$ of the heat sink temperature less than $30 \mathrm{~s}$ after being placed on the mica insulator which electrically isolates the slice being measured from the heat sink.

Slices with flat, but non-parallel, sides could be measured precisely at the center if the average thickness was used. However, an appropriate correction could not be found for a slice with a "top-hat" configuration. 
Difficulties with the low resistance analog circuits were attributed to instabilities in the circuits. New analog circuits of improved design are being assembled but they have not yet been tested to verify this conclusion. These tests are expected to be carried out soon in connection with an additional round-robin experiment designed to establish precision figures for very high and very low resistivity slices.

Determination of the precision to be expected from the method in non-referee applications such as routine production and quality control will require additional study of such factors as surface conditions, probe force, current levels, etc. Nevertheless, use of the various procedures of the method, in particular the sections on probe and measuring circuit evaluations and on thermal sinking of the wafer, would be expected to yield significantly improved precision in such applications. Use of these procedures on a regular and widespread basis should be encouraged. 


\author{
Report to the ASTM F-1 \\ Subcommittee VI Semiconductor \\ Resistivity Task Force on \\ a Special Round Robin
}

\title{
$\underline{\text { Introduction }}$
}

This is a report on a special round robin on 4-point probe resistivity measurements held March 1 to June 1, 1966. The report was originally made to the Task Force in a preliminary form at the Chicago meeting in June 1966.

The idea for this round robin originated at a meeting of the Task Force in Dallas in February. Final plans were formulated at a later one-day meeting held at the National Bureau of Standards. The following laboratories participated (listed in alphabetical order):

Bell Telephone Labs., Allentown, Pennsylvania

Dow Corning Corp., Electronic Products Div., Hemlock, Michigan

International Business Machines Corp., East Fishkill Facility,

Hopewell Junction, New York

Monsanto Chemical Co., Inorganic Chemicals Div., St. Louis, Mo.

National Bureau of Standards, Washington, D. C.

A special vote of thanks go to $K$. Benson and $C$. Paulnak at BTL for providing much of the material used and for making a special box to facilitate shipping. Thanks also go to all the participants for their expeditious handling of the measurements, allowing much useful data to be obtained and analyzed between two Sub-VI meetings!

\section{Purpose}

Before F43-64T $\mathrm{T}^{1}$ (Tentative Methods of Test for Resistivity of Semiconductor Materials) can be properly revised, the need exists to determine the contribution of each of the factors affecting the multilaboratory precision of resistivity measurements. The factors selected for investigation in this round robin were the precision of the probe spacing measurement and precision of electrical measuring equipment when doing four-point probe measurements at the $10 \Omega-\mathrm{cm}$ level. The measuring process was to be that typical of a good industrial standards laboratory. Future round robins including such factors as sample temperature measurement and sample preparation will be necessary.

Method

The procedure that was used for the round robin is given in Appendix B. As many of the variables as possible were controlled. The 
mechanical equipment required for the measurement was supplied along with silicon slices in the $10 \Omega-\mathrm{cm}$ range that had been prepared. Procedures for measuring the spacing of the probes in the furnished fourpoint probe and for determining the suitability of electrical equipment (supplied by each laboratory) were specified. Independent measurements of probe spacing, electrical equipment, 'slice diameter, and slice thickness in each lab provided a means of evaluating the reproducibility obtainable in such measurements. Since the thermal sink and thermometer were both supplied and since the sample surfaces were prepared at the beginning of the test, these conditions were not varied. A round robin "kit" encased in a sturdy wood box was shipped to each laboratory in turn. This kit' contained:

(a) a four-point probe,

(b) a micrometer stage,

(c) a copper heat sink,

(d) a calibrated thermometer,

(e) mica for use as an insulator on the copper block,

(f) chemically polished silicon blanks for needle impressions,

(g) a four-point probe analog circuit,

(h) heat sink compound for making good thermal contact between the heat sink and specimen, and

(i) three lapped silicon slices on which to measure resistivity.

\section{Results}

First a word about notation. The abbreviation AVG will be used to denote the sample mean and the symbol s to denote the square root of the sample estimate of variance. (A capital S will be used to denote probe spacing.) Also, the idea of a confidence interval will be used. ${ }^{2}$

Let us first.look at the resistivity results as taken directly from the data sheets which are shown in Table A-I. At first glance this is discouraging; even disregarding lab. 5 the most probable multilaboratory precision is no better than \pm 2 per cent (R2S\%). 3 Lab. 5 is obviously in error but this was probably due to difficulty in interpreting the instructions for use with direct reading equipment.

After finding out exactly how lab. 5 proceeded and recalculating their results, and also correcting obvious errors on the rest of the data sheets (e.g. misreading correction factors or errors like 49.9 mils $=0.1277 \mathrm{~cm}$ ), the resistivities shown in Table A-II were obtained. If we disregard lab. 5 we can assert that: 1) under the conditions of this round robin, the most probable multi-lab precision for resistivity measurement is \pm 0.7 per cent (R2S\%), and 2) the multi-laboratory precision for resistivity measurement using the methods of this round robin is better than $\$ 2$ per cent (R2S\%) at a confidence level of 95 per cent. The latter statement means that if we were to repeat the round robin a very large number of times, there is only a 5 per cent 
Table A-I - Average Resistivity $(\Omega-\mathrm{cm})$ at $23^{\circ} \mathrm{C}$ (as Reported)

\begin{tabular}{|c|c|c|c|}
\hline Lab. No. & $\begin{array}{l}\text { Sample } \\
\text { BTL-2 } \\
\end{array}$ & $\begin{array}{l}\text { Sample } \\
\text { BTL-4 }\end{array}$ & $\begin{array}{c}\text { Sample } \\
\mathrm{KN}-4 \\
\end{array}$ \\
\hline 1 & 10.24 & 10.36 & 14.80 \\
\hline 2 & 10.083 & 10.209 & 14.763 \\
\hline 3 & 10.065 & 10.137 & 14.545 \\
\hline 4 & 10.036 & 10.125 & 14.648 \\
\hline 5 & 1.853 & 1.778 & 3.261 \\
\hline AVG & 8.455 & 8.522 & 12.403 \\
\hline $\mathrm{s}$ & $\begin{array}{l}3.691 \\
(44 \%)\end{array}$ & $\begin{array}{l}3.77 \\
(44 \%)\end{array}$ & $\begin{array}{l}5.11 \\
(41 \%)\end{array}$ \\
\hline $\operatorname{AVG}^{(a)}$ & 10.106 & 10.208 & 14.689 \\
\hline$s^{(a)}$ & $\begin{array}{c}0.091 \\
(0.90 \%)\end{array}$ & $\begin{array}{r}0.108 \\
(1.1 \%)\end{array}$ & $\begin{array}{c}0.116 \\
(0.79 \%)\end{array}$ \\
\hline $\begin{array}{l}\text { One-sided, }(\text { a ) } \\
95 \% \text { confidence } \\
\text { upper bound on } \sigma\end{array}$ & $\begin{array}{l}1.22 \\
(2.2 \%)\end{array}$ & $\begin{array}{c}0.26 \\
(2.5 \%)\end{array}$ & $\begin{array}{c}0.27 \\
(1.9 \%)\end{array}$ \\
\hline
\end{tabular}

Table A-II - Average Resistivity $(\Omega-\mathrm{cm})$ at $23^{\circ} \mathrm{C}$ (Recomputed)

\begin{tabular}{|c|c|c|c|}
\hline Lab. No. & $\begin{array}{l}\text { Sample } \\
\text { BTL-2 } \\
\end{array}$ & $\begin{array}{l}\text { Sample } \\
\text { BTL-4 } \\
\end{array}$ & $\begin{array}{c}\text { Sample } \\
\mathrm{KN}-4 \\
\end{array}$ \\
\hline 1 & 10.042 & 10.148 & 14.513 \\
\hline 2 & 10.081 & 10.209 & 14.538 \\
\hline 3 & 10.055 & 10.148 & 14.557 \\
\hline 4 & 10.036 & 10.125 & 14.523 \\
\hline 5 & 9.899 & 10.036 & 14.338 \\
\hline AVG & 10.023 & 10.133 & 14.494 \\
\hline s & $\begin{array}{c}0.071 \\
(0.71 \%)\end{array}$ & $\begin{array}{c}0.063 \\
(0.62 \%)\end{array}$ & $\begin{array}{c}0.089 \\
(0.61 \%)\end{array}$ \\
\hline $\operatorname{AVG}^{(a)}$ & 10.054 & 10.158 & 14.533 \\
\hline$s^{(a)}$ & $\begin{array}{r}0.020 \\
(0.2 \%)\end{array}$ & $\begin{array}{c}0.036 \\
(0.36 \%)\end{array}$ & $\begin{array}{c}0.019 \\
(0.13 \%)\end{array}$ \\
\hline $\begin{array}{l}\text { One-sided, } \\
95 \% \text { confidence } \\
\text { upper bound on } \sigma(a)\end{array}$ & $\begin{array}{l}0.058 \\
(0.6 \%)\end{array}$ & $\begin{array}{r}0.105 \\
(1.0 \%)\end{array}$ & $\begin{array}{r}0.045 \\
(0.3 \%)\end{array}$ \\
\hline
\end{tabular}


chance that the final precision obtained would be worse than \pm 2 per cent (R2S\%).

\section{Discussion}

We wish to analyze and compare the relative magnitudes of the sources of error. The sources to be analyzed are:

(1) probe separation,

(2) $\mathrm{V} / \mathrm{I}$ measurement,

(3) temperature measurement, and

(4) slice thickness measurement.

(1) Probe separation measurement. Probe separation was measured in each lab according to the specified procedure. The results, shown in Table A-III, show that this is an excellent procedure for measuring probe spacing, there being only a 5 per cent chance that the multi-lab precision is worse than \pm 0.5 per cent (R2S\%). What part of this precision is due to needle-wobble, what part to needle-tip condition, and what part to the measuring apparatus is not certain.

Good probes can be selected by placing a maximum allowable singlelab $s$ for the series of 10 determinations performed by each lab. The values for $s$ obtained by the individual labs in this round robin, using a "good" probe, are given in Table A-IV. If we accept 0.16 per cent as the "true" standard deviation for the probe used, and if we want only a 5 per cent chance of rejecting a "good" probe (i.e. one at least as good as the one used in this round robin) we should require a singlelab $s$ measurement of less than 0.26 per cent (see page 4-3 of Handbook $91) .2$

In a measurement of the resistivity of a slice a probe spacing error will show up in three places. The ratio $\mathrm{S}_{2} / r$, where $r$ is the sample radius, is used to determine the correction factor for finite diameter, $\mathrm{F}_{2}$. The ratio $\mathrm{w}^{4} / \mathrm{S}_{2}$, where $\mathrm{w}$ is the slice thickness, is used to determine the correction factor, $\mathrm{F}(\mathrm{w} / \mathrm{S})$. The individual values $\mathrm{S}_{1}$, $S_{2}$, and $S_{3}$ are used to determine a correction for unequal probe spacing, $\mathrm{F}_{\mathrm{sp}}=1+0.721\left(1-\mathrm{s}_{2} / 2 \mathrm{~S}_{1}-\mathrm{S}_{2} / 2 \mathrm{~S}_{3}\right) .5$

For the slice diameter and thickness used, an error of 0.1 per cent in measuring $S$ would cause,

(1) an error of 0.01 per cent in $\mathrm{F}_{2}$,

(2) an error of 0.02 per cent in $F(w / S)$,

(3) an error of 0.08 per cent in $\mathrm{F}_{\mathrm{Sp}}$.

Adding the effect of these errors directly (since they are not independent) gives a total error of 0.11 per cent.

Note the following about $F_{S p}$, a correction factor which has not been previously used. In this round robin the average value was 1.004 . This is a 0.4 per cent correction and thus should not be neglected. 
Table A-III - Probe Separation Measurement in Millimeters

\begin{tabular}{cccc} 
Lab & \multicolumn{1}{c}{$\mathrm{S}_{1}$} & $\mathrm{~S}_{2}$ & $\mathrm{~S}_{3}$ \\
1 & 1.60160 & 1.58572 & 1.58572 \\
2 & 1.60396 & 1.58590 & 1.58882 \\
3 & 1.60134 & 1.58354 & 1.58496 \\
4 & 1.6027 & 1.5857 & 1.5862 \\
5 & 1.6050 & 1.5880 & 1.5875 \\
AVG & 1.60294 & 1.58577 & 1.58664 \\
S & 0.00157 & 0.00157 & 0.00152 \\
& $(0.10 \%)$ & $(0.10 \%)$ & $(0.10 \%)$ \\
One-sided, 95\% & & & 0.00361 \\
confidence upper & 0.00373 & 0.00373 & $(0.23 \%)$ \\
bound on $\sigma$ & $(0.23 \%)$ & $(0.23 \%)$ &
\end{tabular}

Table A-IV - Single Laboratory Relative Standard Deviation

$\begin{array}{llll}\text { Lab } & \frac{S_{1}}{1} & \frac{S_{2}}{S_{3}} & -12 \% \\ 1 & 0.10 \% & 0.06 \% & 0.12 \% \\ 3 & 0.17 & 0.10 & 0.21 \\ 4 & 0.08 & 0.07 & 0.06 \\ 5 & 0.04 & 0.04 & 0.04 \\ & 0.27 & 0.24 & 0.19\end{array}$

Overall AVG of

table above

0.12

Overall s of

table above

0.08

One sided, 95\%

confidence upper

bound on AVG

0.16 
(2) $\mathrm{V} / \mathrm{I}$ measurement. The justification for disregarding the lab. 5 results for V/I comes from measurement of the four-point probe analog circuit. The resistor in the black box was a $10 \Omega \pm 0.5 \%$ resistor. The four other resistors were $3000 \Omega \pm 5 \%$ resistors. The measured values are given in Table A-V. Note that lab. 5 measured a resistance about 3 per cent low and was also low on the slice resistivity measurement, ( 1.5 per cent, 1.2 per cent, and 1.2 per cent for the 3 slices, respectively). This could have been caused by using a measuring system with an input impedance a little too low. Note that a quantitative correction can not be determined from the analog circuit measurement, but that a wrong measurement indicates that an incorrect resistivity will probably be obtained.

The $\mathrm{V} / \mathrm{I}$ values, in ohms corrected to $23^{\circ} \mathrm{C}$, obtained by the first four labs are shown in Table A-VI. Again this is good agreement, with only a 5 per cent chance that the multi-lab precision is worse than \pm 0.9 per cent (R2S\%), the most probable value being \pm 0.3 per cent $(\mathrm{R} 2 \mathrm{~S} \%)$. One of the major aources of error here is probably specimen nonuniformity although an attempt was made to reduce this as much as possible by selecting uniform slices and by recentering after each of ten measurements in each lab, thus tending to average out the nonuniformity.

(3) Temperature measurement. This factor was largely eliminated as a source of error by sending around the same thermometer and same heat sink to every lab. Thus thermometer calibration and thermometer specimen heat path were uniform. Correction for temperature was quite important, however, corrections ranging as high as 3 per cent. A future round robin should help determine the effect of using different thermometers and heat sinks.

(4) Slice thickness measurement. The reported thicknesses are listed in Table A-VII. The thickness plays a double role in introducing error. For the sample thickness used an error of 0.11 per cent in w should cause,

(a) an error of 0.02 per cent due to the change of $F(w / S)$, and

(b) an error of 0.11 per cent because $w$ is a direct multiplier in the formula for calculating resistivity.

These two errors are in opposite directions; this gives a resultant error of about 0.09 per cent.

(5) Slice diameter measurement. The slices were not perfectly round so everyone did not measure the same diameter. The reported values, are listed in Table A-VIII. The last line shows the standard deviation in the correction factor, $F_{2}$, corresponding to the $s$ in the diameter measurement. It is smaller because, at the diameter used, the correction factor is a slowly varying function of the diameter. 


\section{Table A-V - Average Resistance $(\Omega$ ) (Recomputed)}

$\begin{array}{cc}\text { Lab. } & \underline{R} \\ 1 & 10.002 \\ 2 & 10.004 \\ 3 & 10.003 \\ 4 & 10.006 \\ 5 & 9.71\end{array}$

Table A-VI - V/I $(\Omega)$ Corrected to $23^{\circ} \mathrm{C}$

\begin{tabular}{cccc} 
Lab. No. & $\begin{array}{c}\text { Sample } \\
\text { BTL-2 }\end{array}$ & $\begin{array}{c}\text { Sample } \\
\text { BTL-4 }\end{array}$ & $\begin{array}{c}\text { Sample } \\
\text { KN-4 }\end{array}$ \\
\hline 1 & 21.743 & 22.045 & 26.616 \\
2 & 21.752 & 22.083 & 26.544 \\
3 & 21.796 & 22.035 & 26.644 \\
4 & 21.718 & 21.970 & 26.602 \\
AVG & 21.752 & 22.033 & 26.602 \\
S & 0.032 & 0.047 & 0.042
\end{tabular}

One sided, $95 \%$

$(0.15 \%)$

$(0.21 \%)$

$(0.16 \%)$

confidence upper

0.093

0.137

0.123

bound on $\sigma$

$(0.44 \%)$

$(0.61 \%)$

$(0.47 \%)$ 
Table A-VII - Slice Thickness (cm)

\begin{tabular}{clll} 
Lab. No. & $\begin{array}{l}\text { Sample } \\
\text { BTL-2 }\end{array}$ & $\begin{array}{l}\text { Sample } \\
\text { BTL -4 }\end{array}$ & $\begin{array}{c}\text { Sample } \\
\text { KN-4 }\end{array}$ \\
\cline { 1 - 2 } 1 & 0.1054 & 0.1049 & 0.1267 \\
2 & 0.1054 & 0.1052 & 0.1270 \\
3 & 0.10511 & 0.10481 & 0.12672 \\
4 & 0.1052 & 0.1049 & 0.1267 \\
5 & 0.1052 & 0.1049 & 0.1267 \\
AVG & 0.10522 & 0.10494 & 0.12676 \\
S & 0.00011 & 0.00015 & 0.00013 \\
& $(0.10 \%)$ & $(0.14 \%)$ & $(0.10 \%)$
\end{tabular}

One sided,

$95 \%$ confidence $\quad 0.00032$

0.00044

0.00038

upper bound on $\sigma$

$(0.29 \%)$

$(0.41 \%)$

$(0.29 \%)$

Table A-VIII - Slice Diameter ( $\mathrm{cm}$ )

\begin{tabular}{clll} 
Lab. No. & $\begin{array}{l}\text { Sample } \\
\text { BTL-2 }\end{array}$ & $\begin{array}{l}\text { Sample } \\
\text { BTL-4 }\end{array}$ & $\begin{array}{c}\text { Sample } \\
\text { KN -4 }\end{array}$ \\
\hline 1 & 3.216 & 3.236 & 3.292 \\
2 & 3.228 & 3.236 & 3.294 \\
3 & 3.223 & 3.2322 & 3.297 \\
4 & 3.236 & 3.238 & 3.302 \\
5 & 3.221 & 3.241 & 3.299 \\
AVG & 3.224 .8 & 3.2367 & 3.2969 \\
s & 0.0076 & 0.0033 & 0.0041 \\
Resultant s in & $(0.23 \%)$ & $(0.10 \%)$ & $(0.12 \%)$ \\
correction factor & $(0.02 \%)$ & $(0.01 \%)$ & $(0.01 \%)$ \\
$\begin{array}{l}\text { One sided, 95\% } \\
\text { confidence upper } \\
\text { bound on in in } \\
\text { correction factor }\end{array}$ & $(0.05 \%)$ & & $(0.02 \%)$ \\
\end{tabular}


(6) Total. If each source of error is assumed to be random and independent, an estimate of the overall standard deviation may be found as the square root of the sum of the measured sample variances $\left[\left(\sum s^{2}\right)^{1 / 2}\right]:$

$\begin{array}{ll}\text { Probe spacing: } & s=0.11 \% \\ \text { V/I measurement: } & s=0.15 \% \\ \text { Thickness measurement: } & s=0.09 \% \\ \text { Diameter measurement: } & s=0.02 \% \\ \text { Total } & s=0.21 \%\end{array}$

Conclusions

The following conclusions can be drawn from the round robin results:

(1) We have a good method for the measurement of probe spacing.

(2) Using the black box analog circuit procedure is a good test of the electrical equipment being used to measure resistivity, at least for samples in the $10 \Omega$-cm range finished with a 5 micron lapping compound.

(3) For an "industrial standards lab" procedure at the $10 \Omega-\mathrm{cm}$ level, the contribution of the electrical measurement associated with a four-point probe method is on the order of $\pm 1 / 2$ per cent (R2S\%).

(4) The necessity for detailed, explicit instructions covering every important detail of the measurement can not be overemphasized. Neither can the need for detailed data sheets that show all the data taken, all the correction factors used, and all the computations made in arriving at the final values of the resistivity. When two laboratories are comparing resistivity measurements, these data sheets should be exchanged along with the samples.

\section{Notes and References}

1. ASTM Book of Standards, Part 8 .

2. For a full explanation of the statistical terms and the method of computation used, see NBS Handbook 91, "Experimental Statistics", by M. G. Natrella, Chapters 1 through 4 .

3. (R2S\%) is the two-sigma precision index expressed in relative per cent. 
4. There is an ambiguity in the method of Appendix $B$ because it is not specified whether to use $S_{1}, S_{2}, S_{3}$ or the average in determining $\mathrm{F}_{2}$ and $\mathrm{F}(\mathrm{w} / \mathrm{S})$. This is important since the difference in the spacings is larger than the precision in their measurement. This will affect the $s$ in the final resistivity values, but not the $s$ for each factor.

5. Note that $\mathrm{F}_{\mathrm{SP}}$ applies to slice measurement only. A more convenient form of $F_{S p}$ is: $F_{S P}=1+1.082\left(1-S_{2} / \bar{S}\right)$, where $\bar{S}$ is the average of $\mathrm{S}_{1}, \mathrm{~S}_{2}$, and $\mathrm{S}_{3}$. 


\section{APPENDIX B}

Special Round Robin Procedure

1. Measurement of Probe Spacing:

1.I Measure the spacing of the probe provided (serial no. SI 62-1440C) using the method below. If any deviations in this technique are used, describe the deviations.

1.2 The technique used for measuring probe spacings is that of observing and measuring the probes indentations in a polished silicon surface.

1.3 Apparatus: The following apparatus is needed:

(1) A flat polished silicon surface. Some are provided but use your own if desired.

(2) A micrometer movement to move the probe or silicon in a direction perpendicular to a line through the probe points.

(3) A toolmaker's microscope for measuring distances between the indentations.

The silicon surface can be that of a slice or block which can be conveniently placed under the probe. The surface should be polished and reasonably flat. The micrometer movement for moving the probe or silicon surface should be capable of moving increments of 10 to $15 \mathrm{mils}(0.25$ to 0.375 $\mathrm{mm}$ ) in a direction perpendicular to a line through the probe points. The toolmaker's microscope should be capable of measuring increments of $0.1 \%$ of the probe spacing $S(0.06$ $\mathrm{mils}(1.5 \mu \mathrm{m})$ for a $62.5 \mathrm{mil}(1.59 \mathrm{~mm})$ probe spacing).

1.4 Procedure: With the four-point probe make a series of indentations on a polished silicon surface. These indentations are made by applying the probe to the surface using normal point pressures and measurement routine. The probes are then lifted and the silicon surface or probe is moved 10 to $15 \mathrm{mils}(0.25$ to $0.375 \mathrm{~mm})$ in a direction perpendicular to a line through the probe points. Again the probe is applied to the silicon surface and the procedure repeated until a series of 30 indentation sets is obtained. The indentations obtained are often irregular in shape and may show several areas of contact for each probe. Place the silicon sample in the toolmaker's microscope. For 10 of the 30 indentation sets record the readings $A$ through 
$\mathrm{H}$ on the $\mathrm{X}$ axis of the toolmaker's microscope and the readings $Y_{A}$ and $Y_{B}$ on the $Y$ axis for the locations shown in the figure below:
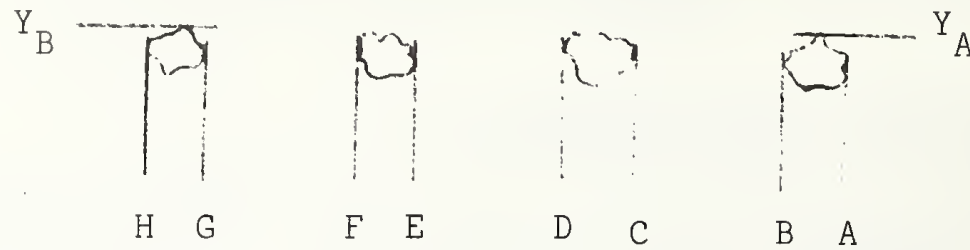

The angle of placement of the silicon sample on the microscope should be such that the $Y$ axis readings do not differ more than $6 \mathrm{mils}(0.125 \mathrm{~mm})$. Record all readings on the data sheet provided. Calculate $\mathrm{S}_{1}, \mathrm{~S}_{2}$, and $\mathrm{S}_{3}$ using the data sheet provided and the formulas:

$$
\begin{aligned}
& S_{1}=\frac{C+D}{2}-\frac{A+B}{2} \\
& S_{2}=\frac{E+F}{2}-\frac{C+D}{2} \\
& S_{3}=\frac{G+H}{2}-\frac{E+F}{2}
\end{aligned}
$$

2. Measurements of the analog circuit.

2. I In the apparatus to be used to measure sample resistivity connect the four leads of the analog circuit. Leads A, $B, C$, and D correspond to the four leads of a four-point probea, $\mathrm{b}, \mathrm{c}$, and $\mathrm{d}$ as shown below:

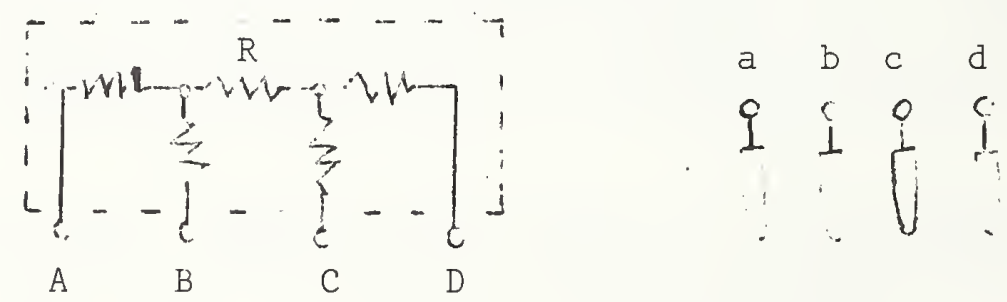

with $A$ and $D$ being the current leads and $B$ and $C$ being the leads between which the voltage is measured.

2.2 At a current level of approximately one milliampere measure the current and voltage first in one direction (the "forward" direction) and then with current reversed (the "reverse" direction). Record these values on the data sheet provided. If the instrument being used measures $V / I$ directly, record this instead of currents and voltages. Repeat for ten determinations. For each determination calculate V/I for forward and reverse direction and the averages and record on the data sheet provided. 
PROBSE SPCIIC ISTA

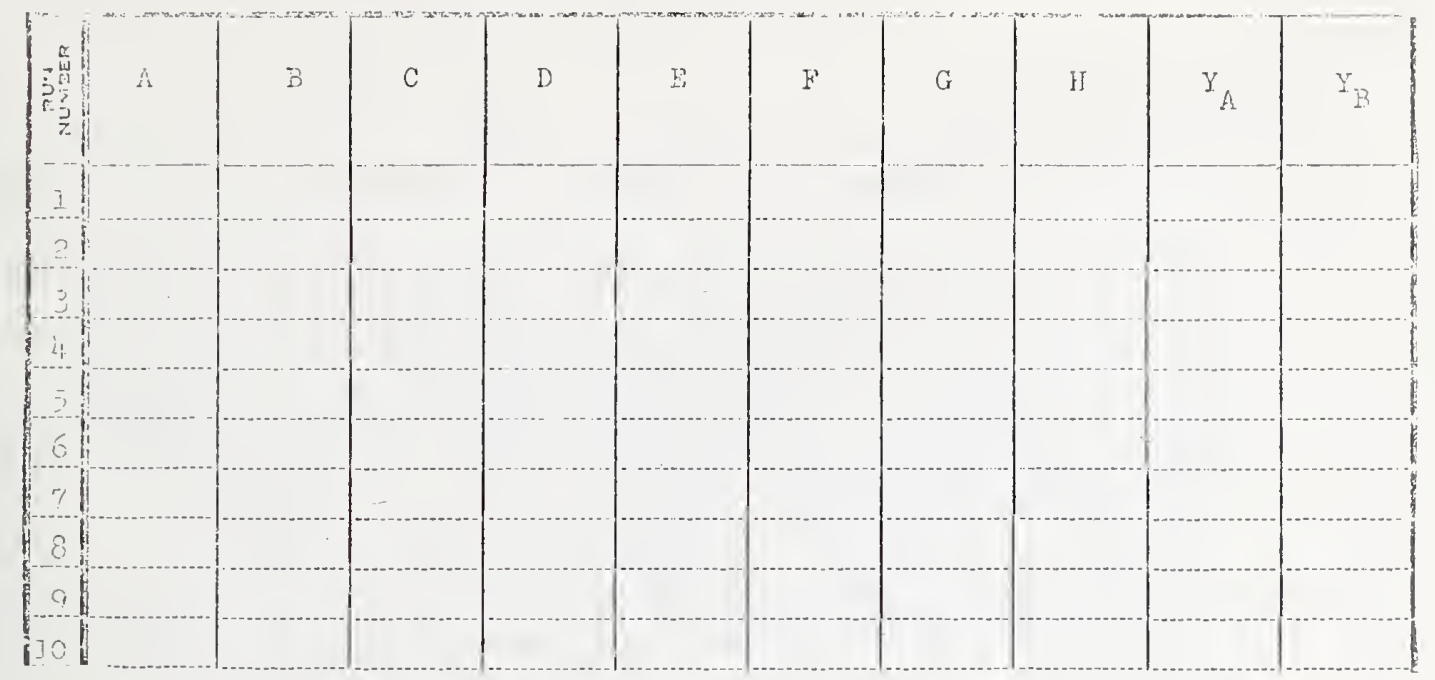

PHOBE SPACTIE CAICUIATIOH

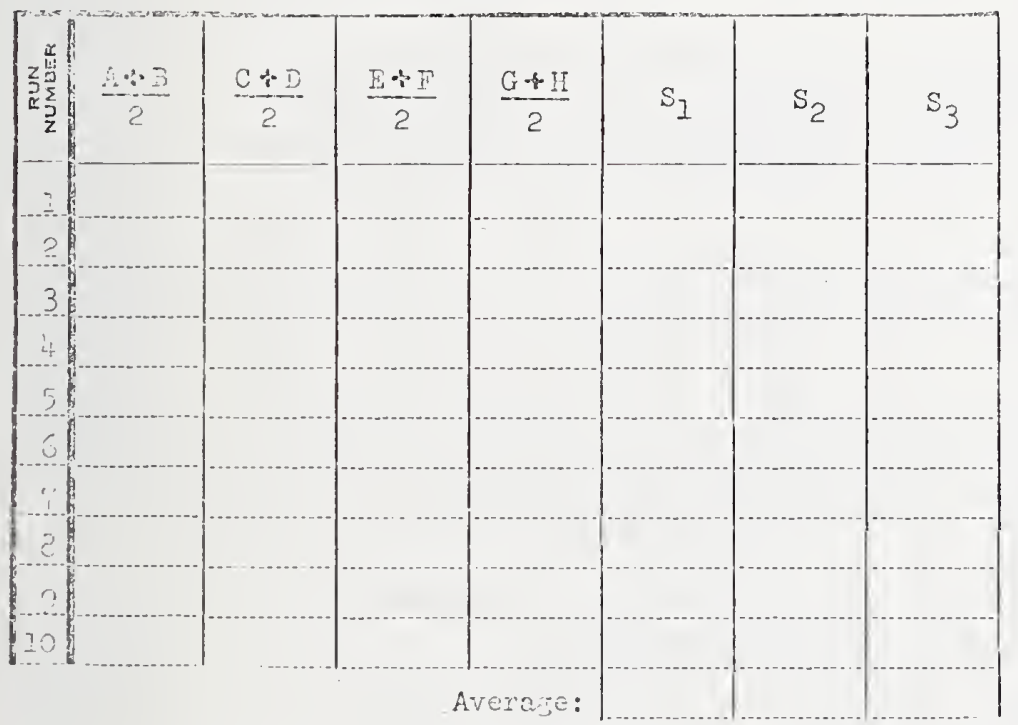

IAPOAREY:

DAPE:

PROBI SEETAL No.:-

$$
\begin{aligned}
& S_{1}=\frac{C+D}{2}-\frac{A+B}{2} \\
& S_{2}=\frac{B+B}{2}-\frac{C-D}{2} \\
& S_{3}=\frac{G+F}{2}-\frac{D+F}{2}
\end{aligned}
$$

\begin{tabular}{|c|c|c|c|c|c|c|}
\hline 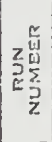 & $\begin{array}{c}\text { Driard } \\
\text { current } \\
\text { me. }\end{array}$ & $\begin{array}{c}\text { Onvard } \\
\text { voltege } \\
\mathrm{V}_{-} \\
\text {riv }\end{array}$ & $\begin{array}{c}\text { roverse } \\
\text { current } \\
I \\
\text { ma }\end{array}$ & $\mid \begin{array}{c}\text { reverse } \\
\text { volta } \\
v_{r} \\
n v\end{array}$ & $\begin{array}{l}\text { for } \\
\text { readin } \\
v / I \\
\text { oh }\end{array}$ & $\begin{array}{l}\text { irect } \\
\text { cguio. } \\
V / I \\
\text { vans }\end{array}$ \\
\hline & & & & & & \\
\hline & & & & & & \\
\hline & & & & & & \\
\hline & & & & & & \\
\hline & & & & & & \\
\hline & & & & & & \\
\hline & & & & & & \\
\hline & & & & & & \\
\hline & & & & & & \\
\hline & & & & & & \\
\hline
\end{tabular}

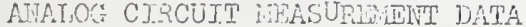

CALCUTAPITOIS

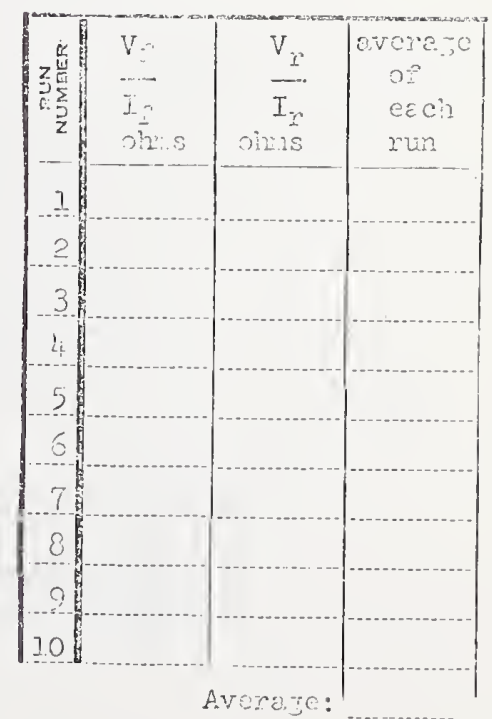


3.1 Measure each of the three samples by the method that follows.

3.2 Use the heat sink and micrometer stage provided. Make sure each sample is electrically isolated from the heat sink by measuring the resistance between sample and heat sink with an ohmeter. Electrical isolation is accomplished with a mica layer (provided with heat sink). Measure the sample temperature by placing one of the thermometers provided in the hole in the heat sink. Two thermometers are provided. Please use thermometer NBS 63 (tagged with an $H$ ) unless it has been broken during the round robin, in which case use thermometer NBS 64 (tagged with an L). Note on the data sheet which thermometer was used.

3.3 Before measuring each sample, clean ultrasonically ir warm water and detergent, then rinse with flowing deionized water. Then ultrasonically degrease in acetone, rinse with alcohol and air dry.

3.4 Center the four point probe within $0.010^{\prime \prime}(0.25 \mathrm{~mm})$ of the center of the sample being measured.

3.5 Using the probe provided make ten determinations of current, voltage, and temperature. Remove, replace, and recenter the sample between each determination. Record the following data in the data sheet provided:

(a) $T$, the temperature of the sample as measured by the thermometer placed in the heat sink.

(b) If, the current through the two outer probes.

(c) $V_{f}$, the voltage across the two inner probes with current in the direction of $\mathrm{I}_{\mathrm{f}}$.

(d) $I_{r}$, the current through the two outer probes when the current direction is reversed.

(e) $V_{r}$, the voltage across the two inner probes with the current in the direction of $I_{r}$.

(f) For direct reading equipment only record $V / I$ in both forward and reverse directions instead of $I_{f}, V_{f}, I_{r}$, and $V_{r}$.

3.6 Carry out the calculations on the data sheet. Obtain $\mathrm{C}_{\mathrm{T}}$ from Figure $\mathrm{B}-1, \mathrm{~F}_{2}$ by linear interpolation of Table B-I and $F(w / S)$ (where $W$ is the slice thickness) by linear interpolation of Table B-II. Use the data on slice thickness and diameter provided. 
LABORTOHE:

DAIV:

SAYPIS İO.:
Thiclnoes=

Dienctex =

Inewarioter lin:

$D$ LTA
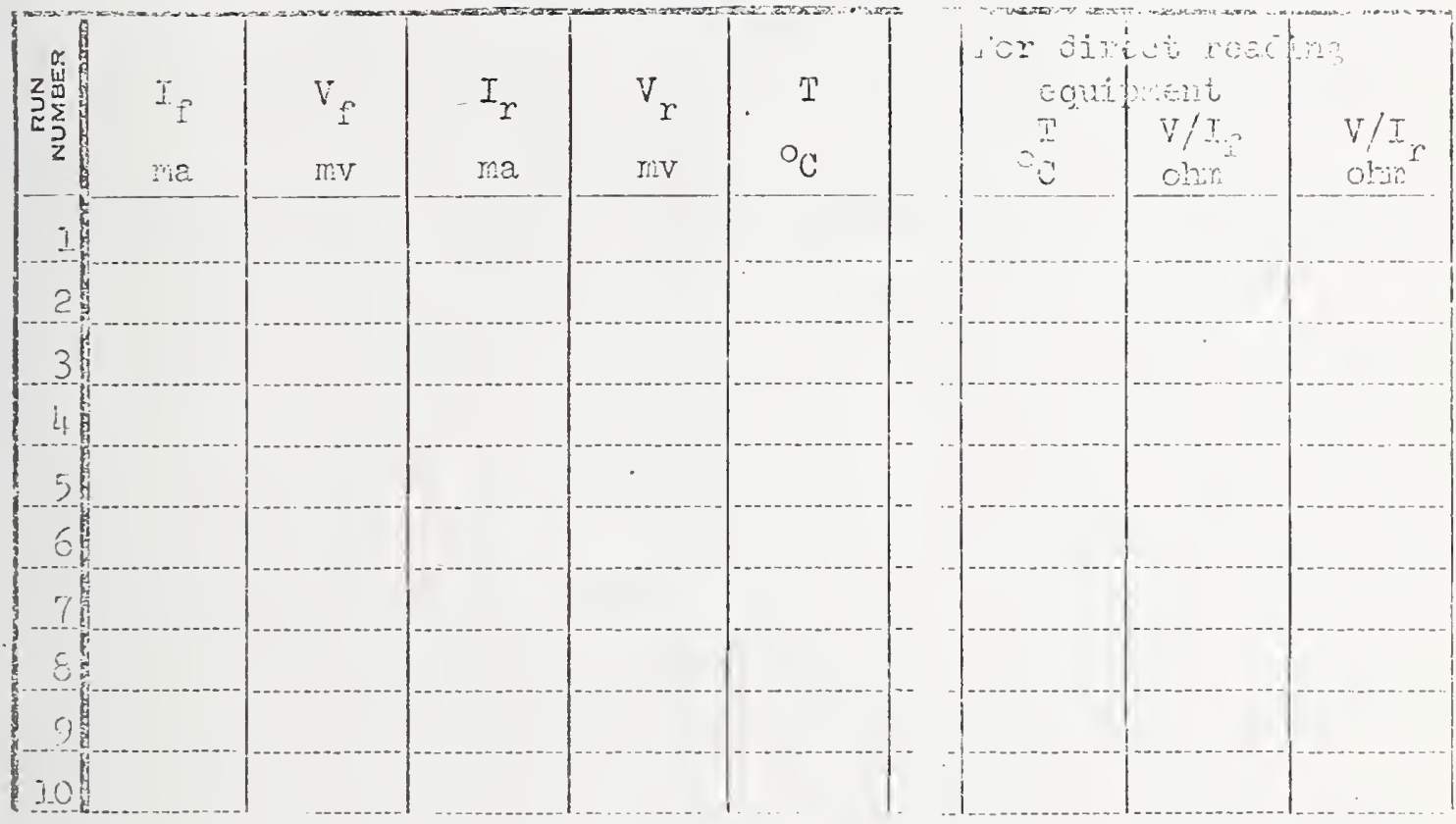

CATOUIDATOHS

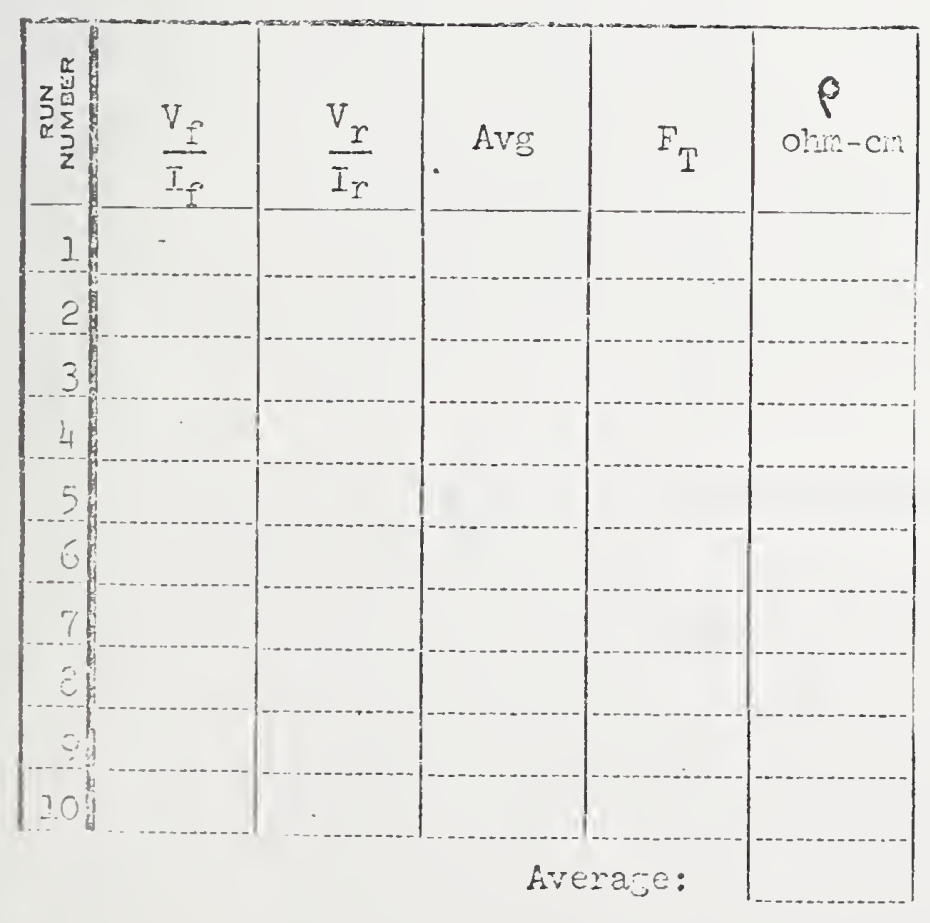

$$
\begin{aligned}
& C_{I}= \\
& F_{T}=I-C_{T I}(I-23) \\
& F_{S P}= \\
& I * 0.721\left(1 * 3_{2} / 2 S_{1}-3 S_{2} / 2 s_{3}\right)
\end{aligned}
$$

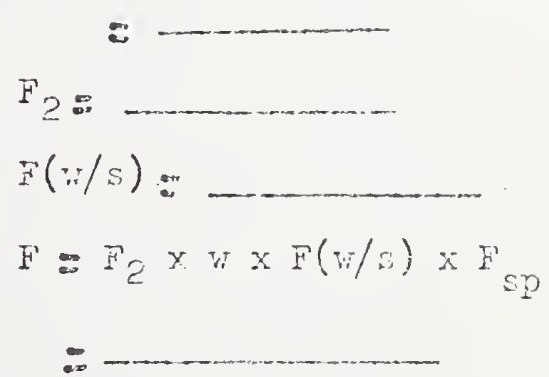

$P=A V B F_{I} \times F^{2}$ 


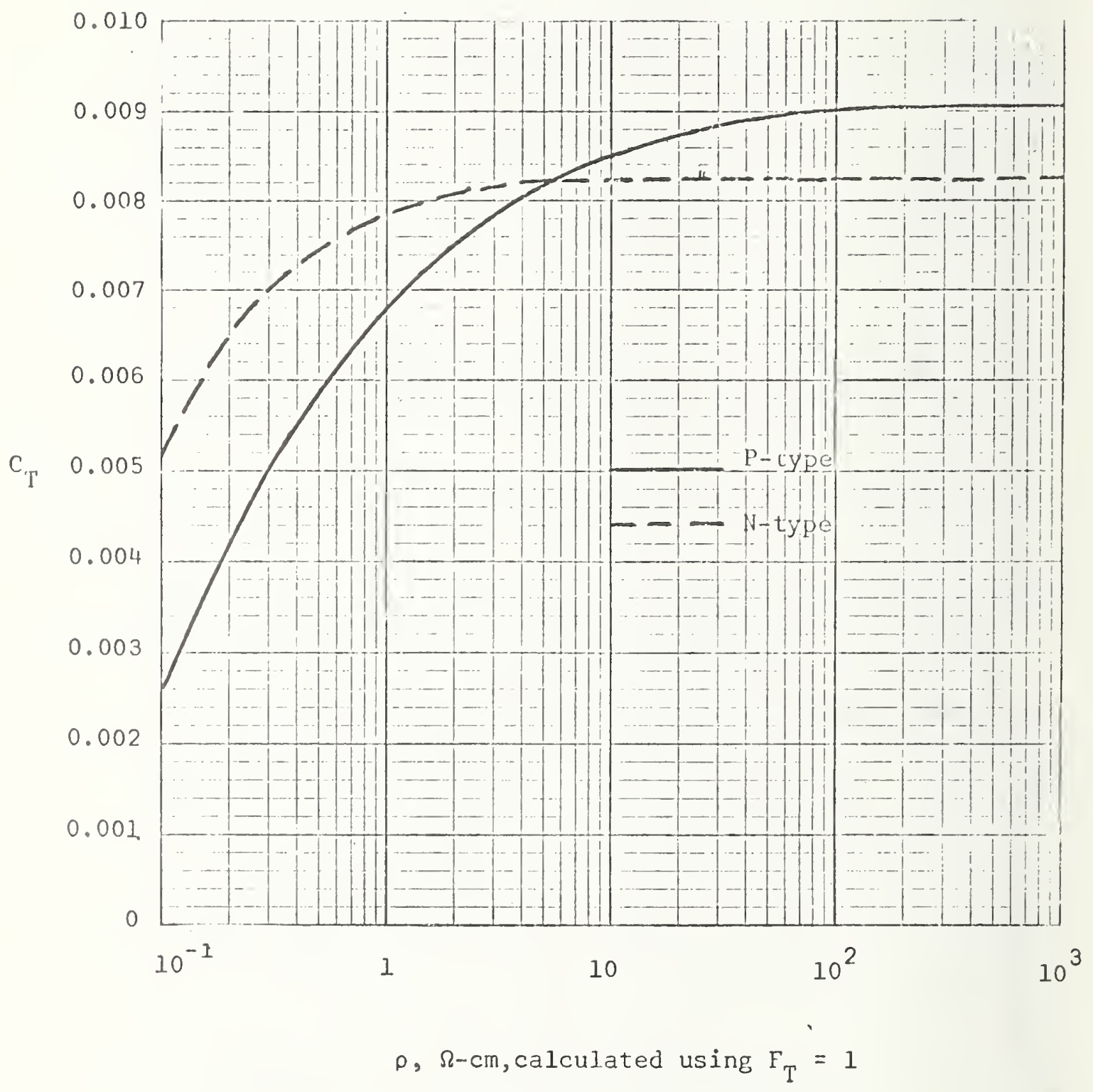

Figure $B-1$. 
Table B-I

$\begin{array}{lccccc}\text { s/r } & \mathrm{F}_{2} & \mathrm{~s} / \mathrm{r} & \mathrm{F}_{2} & \mathrm{~s} / \mathrm{r} & \mathrm{F}_{2} \\ 0 & 4.532 & 0.07 & 4.485 & 0.14 & 4.348 \\ 0.01 & 4.531 & 0.08 & 4.470 & 0.15 & 4.322 \\ 0.02 & 4.528 & 0.09 & 4.454 & 0.16 & 4.294 \\ 0.03 & 4.524 & 0.10 & 4.436 & 0.17 & 4.265 \\ 0.04 & 4.517 & 0.11 & 4.417 & 0.18 & 4.235 \\ 0.05 & 4.508 & 0.12 & 4.395 & 0.19 & 4.204 \\ 0.06 & 4.497 & 0.13 & 4.372 & 0.20 & 4.171\end{array}$

Table B-II

$\begin{array}{ll}\text { w/s } & F(w / s) \\ 0.5 & 0.997 \\ 0.6 & 0.992 \\ 0.7 & 0.982 \\ 0.8 & 0.966 \\ 0.9 & 0.944 \\ 1.0 & 0.921\end{array}$


Probe Separation Correction Factor for Thin Slices

The resistivity of large, thin sheets of homogeneous material when measured with an in-line four-point probe is given by:

$$
\rho=\frac{V}{I} \frac{\pi}{\ln 2} \mathrm{wF}_{\mathrm{sp}} \text {, }
$$

where $\mathrm{V}$ is the potential difference between the inner probes, $I$ is the current through the outer probes, $w$ is the slice thickness, and

$$
\mathrm{F}_{\mathrm{Sp}}=\frac{2 \ln 2}{\ln \left[\frac{\left(\mathrm{S}_{1}+\mathrm{S}_{2}\right)\left(\mathrm{S}_{2}+\mathrm{S}_{3}\right)}{\mathrm{S}_{1} \mathrm{~S}_{3}}\right]}
$$

is the factor which corrects for unequal separations $S_{1}, S_{2}$, and $S_{3}$ between adjacent probes. If the separations differ from their mean value, $S$, by no more than a few per cent the expression can be simplified to: ${ }^{1}$

$$
F_{S p}=1+\frac{1}{\ln 4}\left[1-\frac{S_{2}}{2 S_{3}}-\frac{S_{2}}{2 S_{1}}\right]=1+0.721\left[1-\frac{S_{2}}{2 S_{3}}-\frac{S_{2}}{2 S_{1}}\right] \text {, }
$$

where $S_{2}$ is the separation between the inner probes. This expression was the one used in the Proposed Method. With the same assumptions it is also possible to transform $(\mathrm{C}-2)$ into an equivalent form which involves only $\mathrm{S}_{2}$ and $\overline{\mathrm{s}}$ :

$$
F_{\text {SP }}=1+\frac{3}{2 \ln 4}\left(1-\frac{S_{2}}{\bar{S}}\right)=1+1.082\left(1-\frac{S_{2}}{\bar{S}}\right) \text {. }
$$

If the slice thickness $w$ exceeds $\bar{S} / 2$ or if the slice diameter is less than $50 \bar{S}$ additional correction factors must be used with (C-1). The effect of unequal probe separation on these factors has not been investigated. If the probe separations do not differ from their means by more than a few per cent (as required in the derivations above) it is thought that significant error will not be introduced into the result by multiplying the appropriate factors together for the w/S and $\bar{S} / D$ ratios allowed by the method. Correction factors appropriate to semi-infinite volumes have been discussed by Valdes ${ }^{2}$ and Hargreaves and Millard. 3

The magnitude of $F_{S p}$ will be affected by uncertainty in the measured values of the probe separations. This effect can be 
determined from the differential:

$$
\mathrm{dF}_{\mathrm{sp}}=-\frac{3}{2 \bar{S}^{2} \ln 4}\left(\overline{\mathrm{S}} \mathrm{d} \mathrm{S}_{2}-\mathrm{s}_{2} \mathrm{~d} \overline{\mathrm{S}}\right)
$$

If the measured positions of the four probes differ from their correct values by small amounts $\mathrm{dx}_{1}, \mathrm{dx}_{2}, \mathrm{dx}_{3}, \mathrm{dx}_{4}$ (as a result either of probe wander or error in measurement of an impression) then $\mathrm{dS}_{2}=$ $d x_{3}-d x_{2}, d \bar{S}=\left(d x_{4}-d x_{1}\right) / 3$ and $(C-5)$ becomes:

$$
d F_{s p}=-\frac{1}{2 \bar{S}^{2} \ln 4}\left(S_{2} d x_{1}-3 \bar{S} d x_{2}+3 \bar{S} d x_{3}-S_{2} d x_{4}\right) \cdot \quad(C-6)
$$

If it is assumed that the probe displacements are random and independent each with standard deviation $\delta x$ and that $S_{2} \approx \bar{s}$, then $F_{s p} \approx 1$ and the relative standard deviation in $\mathrm{F}_{\mathrm{sp}}$ becomes:

$$
\frac{\delta F_{s p}}{F_{s p}}=\frac{\sqrt{5}}{\ln 4} \frac{\delta x}{\bar{s}}
$$

One measures the standard deviation, s, of the probe separation rather than the standard deviation of the probe displacement. These are related by $s=\sqrt{2} \delta \mathrm{x}$ and $(\mathrm{C}-7)$ becomes:

$$
\frac{\delta F_{\text {sp }}}{F_{\text {sp }}}=\frac{\sqrt{10}}{2 \ln 4} \frac{\mathrm{s}}{\overline{\mathrm{S}}}=1.14 \frac{\mathrm{s}}{\overline{\mathrm{s}}}
$$

It should be noted that the standard deviation of the mean probe separation is $\delta \bar{S}=\mathrm{s} / 3$ because only the first and last probe displacements enter into the calculation. If the variation of $\bar{S}$ and $S_{2}$ are considered to be independent, the following form of ( $C-5)$ is convenient in the error analysis of 112.2 .2 :

$$
\frac{d F_{s p}}{F_{s p}}=-c \frac{d S_{2}}{\bar{S}}+c \frac{d \bar{S}}{\bar{S}} \text {, }
$$

where $c=3 / 2$ In $4=1.082$. In this form, the second term may be combined directly with terms in $d \bar{S} / \bar{S}$ from Appendix $D$. (C-8) follows directly since $\sqrt{10} / 2$ ln $4=3 \sqrt{1+(1 / 9)} / 2$ ln 4 .

Probe wander will also influence the measured voltage. If all other factors are held constant:

$$
\frac{d V}{V}=(a-b-c) \frac{d \bar{S}}{\bar{S}}+c \frac{d S_{2}}{\bar{s}}
$$


where $\mathrm{a}$ and $\mathrm{b}$ are coefficients associated with the factors $\mathrm{F}_{2}$ and $\mathrm{F}(\mathrm{w} / \overline{\mathrm{S}})$ discussed in Appendix D. For typical slices $(\mathrm{D}=16 \overline{\mathrm{S}}, \mathrm{w}=0.75 \overline{\mathrm{S}}$ )

$\mathrm{a}=0.07$ and $\mathrm{b}=0.12$. Therefore $(\mathrm{C}-10)$ becomes:

$$
\frac{d V}{V}=1.13 \frac{d \bar{S}}{\bar{S}}+1.08 \frac{\mathrm{dS}_{2}}{\bar{S}}
$$

and the relative standard deviation in the voltage reading is:

$$
\frac{\delta V}{V}=\sqrt{\frac{(1.13)^{2}}{9}+(1.08)^{2}} \frac{\delta S_{2}}{\bar{s}} \approx 1.14 \frac{\delta S_{2}}{\bar{s}} \cdot(C-12)
$$

It can be seen that the principal contribution to the deviation in $V$ comes from $F_{S P}$. Although $(\mathrm{C}-8)$ and $(\mathrm{C}-12)$ are similar in form, the former refers to the uncertainty in measured probe separation which is characterized by $s$ while the latter refers to probe wander which is characterized by $\delta S_{2}$. In general one would expect that $\delta S_{2}<s$. If data from a series of measurements are averaged to obtain the value of voltage, the contribution to the uncertainty which arises from probe wander is reduced significantly. For a single reading, it could be as much as 0.34 per cent for the conditions of the method, but in general would be expected to be significantly less than this.

\section{REFERENCES}

1. L.“J. Swartzendruber, unpublished work.

2. L. B. Valdes, "Resistivity Measurements on Germanium for Transistors," Proc. IRE 42, 420-427 (1954).

3. J. K. Hargreaves and D. Millard, "The Accuracy of Four-Probe Resistivity Measurements on Silicon," Brit., J. Appl. Phys. 13, 231-234 (1962). 


\section{APPENDIX D}

Errors Introduced Through Diameter and Thickness

Correction Factors

The correction factors $\mathrm{F}_{2}$ and $\mathrm{F}(\mathrm{w} / \overline{\mathrm{S}})$ are tabulated in Tables 1 and 2 of the Special Round Robin Procedure (see Appendix B). These factors approach constant values as $\bar{S} / D$ and $w / \bar{S}$, respectively, become small. Hence the error introduced into the calculation for resistivity will be a function of these ratios.

Consider first the factor $\mathrm{F}_{2}$. The diameter, $\mathrm{D}$, is permitted to go from $10 \bar{S}$ to infinity. The effect of error in the determination of $\mathrm{D}$ or $\overline{\mathrm{S}}$ on $\mathrm{F}_{2}$ is given by

$$
\frac{\mathrm{dF}_{2}}{\mathrm{~F}_{2}}=\mathrm{a} \frac{\mathrm{dD}}{\mathrm{D}}=-\mathrm{a} \frac{\mathrm{d} \overline{\mathrm{S}}}{\overline{\mathrm{S}}} .
$$

The coefficient, $a$, varies from 0.154 at $D=10 \bar{S}$ to 0.0 at $D=\infty$. The following table lists several quantities of interest:

\begin{tabular}{|c|c|c|c|c|c|c|c|c|c|}
\hline D & $\underline{\mathrm{F}_{2}}$ & $a$ & $\delta \mathrm{F}_{2} / \mathrm{F}_{2}(\%)$ & $\delta D$ & $\Delta \mathrm{F}_{2} / \mathrm{F}_{2}(\%)$ & $\Delta \mathrm{D}$ & $\delta F_{2} / F_{2}(\%)$ & $\delta \bar{S}$ & $E(\%)$ \\
\hline $10 \bar{S}$ & 4.171 & 0.154 & 0.031 & & 0.31 & & -0.015 & & +8.7 \\
\hline $16 \overline{\mathrm{S}}$ & 4.383 & 0.066 & 0.013 & & 0.21 & & -0.006 & & +3.4 \\
\hline $25 \bar{S}$ & 4.470 & 0.028 & 0.006 & & 0.14 & & -0.003 & & +1.4 \\
\hline $100 \bar{S}$ & 4.528 & 0.0015 & 0.0003 & & 0.03 & & -0.000 & & +0.1 \\
\hline
\end{tabular}

The first three columns list the diameter, the correction factor, and the coefficient respectively. The fourth column lists the relative deviation due to deviations in the measurement of average diameter obtained in the round-robin experiment ( 0.2 per cent). The fifth column lists the maximum uncertainty in the correction factor due to permitted eccentricity of the wafer; the diameter is required to be constant to within $\mathrm{D} / 5 \overline{\mathrm{S}}$ per cent. The sixth column lists the relative sample standard deviation due to deviation in the measurement of average probe separation ( 0.1 per cent). The seventh column lists the error in computed resistivity if the diameter correction factor is not used and clearly demonstrates the importance of using it if $\mathrm{D} \lesssim 25 \bar{s}$. It should be noted that this correction factor is appropriate only for measurements taken at the center of the wafer. Additional factors are required if measurements are made elsewhere on the wafer. These have been incorporated into an extended table of $\mathrm{F}_{2} \cdot 1$ 
The factor $F(w / \bar{S})$ is discussed in detail by Smits. ${ }^{2}$ The thickness, $\mathrm{w}$, is permitted in the present method to vary from $\overline{\mathrm{S}}$ to as small a value as can be accurately controlled and measured. The effect of error in the determination of $\mathrm{w}$ or $\overline{\mathrm{S}}$ on $\mathrm{F}(\mathrm{w} / \overline{\mathrm{S}})$ is given by:

$$
\frac{\mathrm{dF}}{\mathrm{F}}=-\mathrm{b} \frac{\mathrm{dw}}{\mathrm{w}}=\mathrm{b} \frac{\mathrm{d} \overline{\mathrm{S}}}{\overline{\mathrm{S}}}
$$

The coefficient, $\mathrm{b}$, varies from 0.27 for $\mathrm{w}=\overline{\mathrm{S}}$ to 0.018 for $\mathrm{w}=\overline{\mathrm{S}} / 2$. The following table lists several quantities of interest:

$\begin{array}{ccccc}W & F(w / \bar{S}) & b & \delta F / F(\%) \mid \delta w & \delta F / F(\%) \mid \delta \bar{S} \\ \overline{\bar{S}} & \frac{0.921}{0} & 0.27 & -0.081 & 0.027 \\ 0.75 \bar{S} & 0.974 & 0.12 & -0.036 & 0.012 \\ 0.65 \bar{S} & 0.987 & 0.066 & -0.0020 & 0.0007 \\ 0.5 \bar{S} & 0.997 & 0.018 & -0.00054 & 0.0002\end{array}$

The first three columns list the thickness, the correction factor and the coefficient. The fourth column lists the relative deviation due to deviations in the measurement of thickness obtained in the roundrobin experiment ( 0.3 per cent). The fifth column lists the column deviation due to deviations in the measurement of average probe separation ( 0.1 per cent).

\section{REFERENCES}

1. L. J. Swartzendruber, "Correction Factor Tables for Four-Point Probe Resistivity Measurements on Thin Circular Semiconductor Samples," NBS Technical Note 199, April 15, 1964.

2. F. M. Smits, "Measurement of Sheet Resistivities with the FourPoint Probe," Bell System Tech. J. 37, 711-718 (1958). 


\section{APPENDIX E}

Resistivity of Silicon over the Temperature Range

0 to $50^{\circ} \mathrm{C}$

The data in the following tables were taken on a selection of $n-$ and p-type silicon specimens in order to compute the temperature coefficient of resistivity of silicon at room temperature. Resistivity was measured over the temperature range 0 to $50^{\circ} \mathrm{C}$ on clover-leaf specimens immersed in a bath of silicone oil by means of the van der Pauw method as described in ASTM Method F-76. The calculations were made as described in the paper, Temperature Coefficient of Resistivity of Silicon and Germanium near Room Temperature, the abstract of which is reproduced following the data tables. Curves showing the temperature coefficient of resistivity of silicon, valid between 18 and $28^{\circ} \mathrm{C}$ are also included following the abstract.

Specimens were obtained from a wide variety of sources. All p-type specimens were doped with boron except those identified with the symbol (AL) which were doped with aluminum. There appears to be a significant difference in temperature variation of resistivity between the boronand aluminum-doped specimens. No such difference in temperature variation was observed for the n-type specimens, most of which were doped with phosphorus.

The data tables are arranged in the following fashion. The upper, two-column table lists the resistivity calculated from the measured resistances. These data were fitted by the least squares method to the relation:

$$
\log \rho=\log A+\alpha \log \mathrm{T}
$$

and the resistivity calculated at decade intervals from 0 to $50^{\circ} \mathrm{C}$ and at $23^{\circ} \mathrm{C}$ to yield the second table. The range in resistivity given in this table is that associated with uncertainty in $\alpha$ only; the uncertainty in the constant A was not computed since the study was concerned with temperature variation only. 


\begin{tabular}{|c|c|}
\hline$t,{ }^{\circ} \mathrm{C}$ & $\rho, \Omega \cdot \mathrm{cm}$ \\
\hline-.19 & $7.444-04$ \\
3.73 & $7.496-04$ \\
9.05 & $7.563-04$ \\
14.90 & $7.048-04$ \\
20.48 & $7.721-04$ \\
25.00 & $7.736-04$ \\
30.10 & $7.851-04$ \\
34.83 & $7.918-04$ \\
40.12 & $7.954-04$ \\
45.49 & $8.070-04$ \\
50.04 & $8.136-04$ \\
\hline
\end{tabular}

$\log \rho=\log A+a \log T$

$T=t+273.16$

\begin{tabular}{|c|c|c|c|c|}
\hline$t,{ }^{\circ} \mathrm{C}$ & $p, \sqrt{2} \cdot \mathrm{cm}$ & \multicolumn{3}{|c|}{ range of $p$} \\
\hline .0 & $7.439-04$ & $7.40 \mathrm{~B}-04$ & 10 & $7.470-04$ \\
\hline 10.0 & $7.580-04$ & $7.557-04$ & 10 & $7.6 \cap 4-04$ \\
\hline 20.0 & $7.720-04$ & $7.702-04$ & TO & $7.738-04$ \\
\hline 23.0 & $7.761-04$ & $7.744-04$ & TO & $7.779-04$ \\
\hline 30.0 & $7.857-04$ & $7.63 H-04$ & 10 & $7.876-04$ \\
\hline 40.0 & $7.992-04$ & $7.967-04$ & TO & $8.016-04$ \\
\hline so.o & $8.125-04$ & $8.092-04$ & TO & $8.158-04$ \\
\hline
\end{tabular}

$$
A=3.915-05
$$

ALPHA $=.52485$

$W 4=\overline{3.1962-02}$

$\alpha=A L P H A \pm W 4$

ranges given are $95 \%$ confidence limits

SAMPLE NUMBER- 3

DAIA CULPUTEU ON 28 NOV 67

P-TYPE ST

DATA TAKE'S ORJ DEC 29, 1965

\begin{tabular}{|c|l|}
\hline$t,{ }^{\circ} \mathrm{C}$ & $\rho, 32 \cdot \mathrm{cm}$ \\
\hline .21 & $1.454-02$ \\
5.113 & $1.453-02$ \\
10.74 & $1.452-02$ \\
15.04 & $1.453-02$ \\
20.25 & $1.454-02$ \\
24.98 & $1.455-02$ \\
29.78 & $1.457-02$ \\
34.95 & $1.460-02$ \\
39.65 & $1.463-02$ \\
44.74 & $1.466-02$ \\
49.44 & $1.469-02$ \\
\hline
\end{tabular}

$\log \rho=\log A+\alpha \log T$

$T=t+273.16$

\begin{tabular}{|c|c|c|c|c|}
\hline$t,{ }^{\circ} \mathrm{C}$ & $p, \Omega \cdot \mathrm{cm}$ & \multicolumn{3}{|c|}{ range of $\rho$} \\
\hline .0 & $1.449-02$ & $1.445-02$ & TO & $1.454-0 ?$ \\
\hline 10.0 & $1.453-02$ & $1.450-02$ & 10 & $1.456-02$ \\
\hline 20.0 & $1.456-02$ & $1.454=012$ & TO & $1.459-0 ?$ \\
\hline 23.0 & $1.457-02$ & $1.455-02$ & TO & $1.460-02$ \\
\hline 30.0 & $1.460-02$ & $1.457-02$ & TO & $1.462-02$ \\
\hline 41).0 & $1.463-02$ & $1.459-02$ & TO & $1.466-0 ?$ \\
\hline 50.0 & $1.466-02$ & $1.461-02$ & TU & $1.470-02$ \\
\hline
\end{tabular}

$$
A=9.970-03
$$

ALPHA $=\frac{9.970-03}{.06671}$

$W 4 = 2 \longdiv { 2 . 5 3 4 8 - n 2 }$

$\alpha=A L P H A \pm W 4$

ranges given are $95 \%$ confidence limits

\begin{tabular}{|c|c|}
\hline$t,{ }^{\circ} \mathrm{C}$ & $\rho, \Omega \cdot \mathrm{cm}$ \\
\hline-.71 & $1.072-02$ \\
5.14 & $1.07 c-02$ \\
9.95 & $1.072-02$ \\
14.57 & $1.073-02$ \\
20.59 & $1.074-02$ \\
25.14 & $1.075-02$ \\
30.97 & $1.077-02$ \\
34.95 & $1.079-02$ \\
39.92 & $1.081-02$ \\
44.92 & $1.064-02$ \\
49.62 & $1.086-02$ \\
\hline
\end{tabular}

$\log \rho=\log A+\alpha \log T$

\begin{tabular}{|c|c|c|c|c|}
\hline$t,{ }^{\circ} \mathrm{C}$ & $\rho, \Omega \cdot c m$ & \multicolumn{3}{|c|}{ range of $\rho$} \\
\hline .0 & $1.069-02$ & 1. $065-02$ & ro & $1.073-0 ?$ \\
\hline 10.0 & $1.072-02$ & $1.070-112$ & 10 & $1.075-0 ?$ \\
\hline 20.0 & $1.075-02$ & $1.073-02$ & TO & $1.077-02$ \\
\hline 23.0 & $1.076-02$ & $1.074-02$ & TO & $1.078-02$ \\
\hline 30.0 & $1.078-02$ & $1.076-02$ & Tu & $1.080-0 ?$ \\
\hline 40.0 & $1.081-02$ & $1.078-02$ & Tu & $1.084-02$ \\
\hline 50.0 & $1.084-02$ & $1.080-02$ & TO & 1. $0 \Omega 37-02$ \\
\hline
\end{tabular}

$T=t+273.16$

$$
\begin{aligned}
A & =\frac{6.821-03}{.01014} \\
\text { ALPHA } & =\frac{.18014}{2.5203-02} \quad \alpha=\text { ALPHA } \pm W 4 \\
W 4 & =W
\end{aligned}
$$

ranges given are $95 \%$ confidence limits

SAMPLE NUMBER- 4

WATA COMPUTEIJ ON 29 NOV G7

P-TYPE SI

\begin{tabular}{|c|c|c|c|c|}
\hline$t,{ }^{\circ} \mathrm{C}$ & $\rho, \Omega \cdot \mathrm{cm}$ & \multicolumn{3}{|c|}{ range of $p$} \\
\hline .0 & $1.454-02$ & $1.449-02$ & TO & $1.459-0 ?$ \\
\hline 10.0 & $1.1458-02$ & $1.454-02$ & TO & $1.461-02$ \\
\hline 20.0 & $1.461-02$ & $1.458-02$ & TO & $1.464-02$ \\
\hline 23.10 & $1.462-02$ & $1.459-112$ & TO & $1.46,5-0 ?$ \\
\hline 30.0 & $1.464-02$ & $1.462-02$ & TO & $1.407-0 ?$ \\
\hline 40.0 & 1. $467-02$ & $1.464-02$ & TO & $1.471-0 ?$ \\
\hline 50.0 & $1.470-02$ & 1. $465-02$ & TO & $1.475-0 ?$ \\
\hline
\end{tabular}

UAFA TAKEW OII OEC. 21.1965

\begin{tabular}{|c|c|}
\hline$t,{ }^{\circ} \mathrm{C}$ & $\rho, \Omega \cdot \mathrm{cm}$ \\
\hline .61 & $1.459-02$ \\
5.47 & $1.458-02$ \\
10.23 & $1.457-02$ \\
15.29 & $1.458-02$ \\
20.19 & $1.459-02$ \\
24.97 & $1.460-02$ \\
29.78 & $1.402-02$ \\
34.73 & $1.464-02$ \\
39.90 & $1.457-02$ \\
45.90 & $1.471-02$ \\
50.02 & $1.475-02$ \\
\hline
\end{tabular}

$\log \rho=\log A+\alpha \log T$

$T=t+273.16$

$$
\begin{aligned}
A & =\frac{1.003-02}{.06613} \\
\text { ALPHA } & =\frac{2.5895-12}{W 4}=
\end{aligned}
$$$$
a=A L P H A \pm W A
$$

ranges given are $95 \%$ confidence limits 
SAMPLE NUMBEK $=5$

UAIA CUMAUILU ON $2 H$ NOV 67

UATA TAKEIN ON DEC 21. $196^{\circ}$

\begin{tabular}{|c|c|}
\hline $\mathrm{t},{ }^{\circ} \mathrm{C}$ & $\rho, \Omega \cdot \mathrm{cm}$ \\
\hline 1.11 & $2.511-02$ \\
5.87 & $2.515-02$ \\
10.51 & $2.520-02$ \\
15.45 & $2.527-02$ \\
20.25 & $2.535-02$ \\
25.06 & $2.543-02$ \\
29.70 & $2.553-02$ \\
34.68 & $2.564-02$ \\
39.72 & $2.576-02$ \\
44.72 & $2.589-02$ \\
49.63 & $2.603-02$ \\
\hline
\end{tabular}

$\log p=\log A+\alpha \log T$

$T=t+273.16$

\begin{tabular}{|c|c|cc|}
\hline$t,{ }^{\circ} \mathrm{C}$ & $\rho, \Omega \cdot \mathrm{cm}$ & \multicolumn{2}{|c|}{ range of $\rho$} \\
\hline.$U$ & $2.500-02$ & $2.490-02$ & T0 $2.511-02$ \\
$11 . U$ & $2.520-02$ & $2.513-02$ & TO $2.528-02$ \\
20.0 & $2.540-02$ & $2.534-02$ & TO $2.545-02$ \\
23.0 & $2.545-02$ & $2.540-02$ & T0 $2.551-02$ \\
30.0 & $2.558-02$ & $2.553-02$ & TO $2.564-02$ \\
$40 . U$ & $2.577-02$ & $2.569-02$ & TO $2.585-02$ \\
$b u . U$ & $2.595-02$ & $2.585-02$ & TO $2.605-02$ \\
\hline
\end{tabular}

\footnotetext{
$A=7.213-03$

ALPHA $=.22158$

$W 4=3.1995-12$

$\alpha=\mathrm{ALPHA} \pm W 4$
}

ranges given are $95 \%$ confidence limits

SAMPLE NUMGER - 7

DAIA CUIPUTEU ON 28 NOV 67

P-TYPE SI

DATA TAKEI: ON MAKCH 27, 1967

\begin{tabular}{|c|c|}
\hline$t,{ }^{\circ} \mathrm{C}$ & $\rho, \Omega \cdot \mathrm{Cm}$ \\
\hline-.98 & $3.765-02$ \\
4.92 & $3.792-02$ \\
9.73 & $3.817-02$ \\
14.32 & $3.843-02$ \\
19.23 & $3.8370-02$ \\
24.30 & $3.900-02$ \\
29.66 & $3.934-02$ \\
34.67 & $3.968-02$ \\
39.84 & $4.004-02$ \\
44.80 & $4.040-02$ \\
49.70 & $4.077-02$ \\
\hline
\end{tabular}

$\log \rho=\log A+\alpha \log T$

$T=t+273.16$

\begin{tabular}{|c|c|cc|}
\hline$t,{ }^{\circ} \mathrm{C}$ & $\rho, \Omega \cdot \mathrm{cm}$ & \multicolumn{3}{|c|}{ range of } \\
\hline .0 & $3.757-02$ & $3.739-02$ & TO $3.774-02$ \\
10.0 & $3.820-02$ & $3.802-02$ & TO $3.833-02$ \\
20.0 & $3.883-02$ & $3.873-02$ & TO $3.893-0 ?$ \\
$<3.11$ & $3.901-02$ & $3.892-02$ & TO $3.911-02$ \\
30.0 & $3.944-02$ & $3.934-02$ & TO $3.955-0 ?$ \\
40.0 & $4.005-02$ & $3.991-02$ & TO $4.019-02$ \\
50.0 & $4.064-02$ & $4.046-02$ & TO $4.083-0 ?$ \\
\hline
\end{tabular}

$\begin{aligned} A & =\frac{2.720-03}{.46803} \\ \text { ALPHA } & =\frac{3.5649-n 2}{W 4}=\frac{3.5}{}\end{aligned}$

$\alpha=A L P H A \pm W 4$

ranges given are $95 \%$ confidence limits
SAMPLE NUMBER - 6

DATA COMNUTED ON $2 B$ HOV 67

\begin{tabular}{|c|c|}
\hline$t,{ }^{\circ} \mathrm{C}$ & $\rho, \Omega \cdot \mathrm{cm}$ \\
\hline .37 & $2.849-02$ \\
5.11 & $2.854-02$ \\
10.81 & $2.842-02$ \\
15.08 & $2.809-02$ \\
20.26 & $2.879-02$ \\
24.98 & $2.886-02$ \\
29.76 & $2.899-02$ \\
34.91 & $2.912-02$ \\
39.58 & $2.925-02$ \\
44.67 & $2.941-02$ \\
49.36 & $2.956-02$ \\
\hline
\end{tabular}

$\log \rho=\log A+\alpha \log T$

$T=t+273.16$

\begin{tabular}{|c|c|c|c|}
\hline$t,{ }^{\circ} \mathrm{C}$ & $\rho, \Omega \cdot \mathrm{cm}$ & \multicolumn{2}{|c|}{ range of $\rho$} \\
\hline 10.0 & $2.838-02$ & $2.8127-02$ & To $2.850-0 ?$ \\
20.0 & $2.861-02$ & $2.853-02$ & To $2.870-02$ \\
$23 . u$ & $2.884-02$ & $2.877-02$ & To $2.890-0 ?$ \\
$30 . u$ & $2.890-02$ & $2.8814-02$ & To $2.896-02$ \\
$40 . u$ & $2.906-02$ & $2.899-02$ & To $2.912-0 ?$ \\
$50 . u$ & $2.927-02$ & $2.918-02$ & TO $2.935-0 ?$ \\
\hline
\end{tabular}

$A=8.064-03$

ALPHA $=.22432$

$44=\overline{3.1516-02}$

$\alpha=\mathrm{ALPHA} \pm \mathrm{HL}$

ränges given are $95 \%$ confidence limits

SAMPLE NUMBER- 8

P-TYPE $5 T$

DATA COAPUTED ON $2 B$ NUV 67

DATA TAKEN ON OCT 6, 1966

\begin{tabular}{|c|c|}
\hline$t,{ }^{\circ} \mathrm{C}$ & $\rho, \Omega \cdot \mathrm{cm}$ \\
\hline .42 & $8.844-02$ \\
5.67 & $9.012-02$ \\
10.23 & $9.161-02$ \\
14.11 & $9.292-02$ \\
19.87 & $9.486-02$ \\
24.80 & $9.659-02$ \\
29.68 & $9.834-02$ \\
34.36 & $1.000-01$ \\
39.24 & $1.019-01$ \\
44.17 & $1.037-01$ \\
49.31 & $1.057-01$ \\
\hline
\end{tabular}

$\log \rho=\log A+\alpha \log T$

$T=t+273.16$

\begin{tabular}{|c|c|cc|}
\hline$t,{ }^{\circ} \mathrm{C}$ & $\rho, \Omega \cdot \mathrm{Cm}$ & \multicolumn{2}{|c|}{ range of $\rho$} \\
\hline $10 . U$ & $8.806-02$ & $8.779-02$ & To $9.833-0 ?$ \\
$20 . U$ & $9.156-02$ & $9.136-02$ & T0 $9.176-02$ \\
23.0 & $9.507-02$ & $9.492-02$ & T0 $9.523-0 ?$ \\
$30 . U$ & $9.613-02$ & $9.593-02$ & T0 $9.628-02$ \\
$40 . U$ & $9.860-02$ & $9.843-02$ & T0 $9.876-0 ?$ \\
50.0 & $1.021-01$ & $1.019-01$ & TO $1.024-01$ \\
& $1.057-01$ & $1.054-01$ & T0 $1.060-01$ \\
\hline
\end{tabular}

$$
A=2.007-04
$$

ALPHA $=1.08450$

$\alpha=A L P H A \pm W 4$

$W 4=2.3529-12$

ranges given are $95 \%$ confidence 1 imits 
SAMPLE NUMBER- 9 (AL)

LATA CUMPUTEU ON $2 \mathrm{H}$ 1.OV 67

P-TYPE SI

UATA ThKEI UII NUV 27,1964

\begin{tabular}{|c|c|}
\hline$t,{ }^{\circ} \mathrm{C}$ & $\rho, \Omega \cdot \mathrm{cm}$ \\
\hline .30 & $2.070-01$ \\
4.15 & $2.096-01$ \\
9.23 & $2.139-01$ \\
15.02 & $2.161-01$ \\
20.35 & $2.234-01$ \\
25.29 & $2.275-01$ \\
30.01 & $2.317-01$ \\
34.06 & $2.361-01$ \\
39.96 & $2.412-01$ \\
45.29 & $2.462-01$ \\
49.78 & $2.310-01$ \\
\hline
\end{tabular}

$\log \rho=\log A+\alpha \log T$

$T=t+273.16$

\begin{tabular}{|c|c|cc|}
\hline$t,{ }^{\circ} \mathrm{C}$ & $\rho, \Omega \cdot \mathrm{cm}$ & \multicolumn{2}{|c|}{ range of } \\
\hline .0 & $2.057-01$ & $2.047-11$ & TO $2.068-01$ \\
10.0 & $2.145-01$ & $2.137-01$ & TO $2.153-01$ \\
20.0 & $2.234-01$ & $2.227-01$ & TO $2.240-01$ \\
23.0 & $2.260-01$ & $2.254-01$ & TO $2.256-01$ \\
30.0 & $2.322-01$ & $2.316-01$ & TO $2.329-01$ \\
40.0 & $2.412-01$ & $2.403-01$ & TO $2.421-01$ \\
50.0 & $2.502-01$ & $2.489-01$ & TO $2.514-01$ \\
\hline
\end{tabular}

$A=3.022-04$

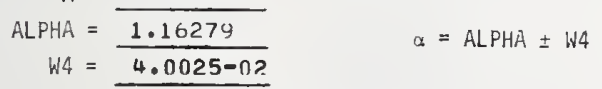

ranges given are $95:$ confidence limits

SAMPLE NUMBER-, ,

DATA CUMPUTED ON 283 HOV 67

P-TYPF SI

DATA TAKEI. ON OCT 31, 1966

\begin{tabular}{|c|c|}
\hline$t,{ }^{\circ} \mathrm{C}$ & $\rho, \Omega \cdot \mathrm{cm}$ \\
\hline-.22 & $2.010-01$ \\
4.80 & $2.673-01$ \\
10.16 & $2.733-01$ \\
15.06 & $2.739-01$ \\
19.69 & $2.843-01$ \\
25.08 & $2.908-01$ \\
29.47 & $2.962-01$ \\
34.37 & $3.025-01$ \\
39.54 & $3.093-01$ \\
44.33 & $3.157-01$ \\
48.99 & $3.222-01$ \\
\hline
\end{tabular}

$\log \rho=\log A+\alpha \log T$

$T=t+273.16$

\begin{tabular}{|c|c|c|c|c|}
\hline$t,{ }^{\circ} \mathrm{C}$ & $p, 8 . \mathrm{cm}$ & \multicolumn{3}{|c|}{ range of $p$} \\
\hline .6 & $2.611-01$ & $2.599-01$ & & $2.624-01$ \\
\hline 10.0 & $2.731-01$ & $2.722-111$ & TO & $2.741-01$ \\
\hline $20 \cdot 11$ & $2.853-01$ & $2.1345-01$ & TO & $2.860-01$ \\
\hline 23.0 & 2. $889-01$ & $2.802-01$ & TO & $2.897-01$ \\
\hline 30.0 & $2.975-01$ & 2. $907-01$ & TO & $2.993-01$ \\
\hline 40.0 & $3.099-01$ & 3. $08 B-01$ & TO & $3.110-01$ \\
\hline 50.0 & $3.223-01$ & $3.208-01$ & TO & $3.238-01$ \\
\hline
\end{tabular}

$A=2.313-04$

ALPHA $=1.25294$

$W 4=3.7154-n 2$

$\alpha=A L P H A \pm W 4$

ranges given are $95 \%$ confidence limits
SAMPLE NUMHEK - 10

P-TYI'F. ST

DAIA CUINPUIEU UIN 2 B INOV 67

UAIA TAKEIS ON FEI3 2, 1965

\begin{tabular}{|r|l|}
\hline$t,{ }^{\circ} \mathrm{C}$ & $\rho, \Omega \cdot \mathrm{cm}$ \\
\hline .05 & $2.236-01$ \\
5.35 & $2.296-01$ \\
10.14 & $2.356-01$ \\
14.41 & $2.414-01$ \\
20.58 & $2.496-01$ \\
25.43 & $2.502-01$ \\
30.09 & $2.628-01$ \\
34.92 & $2.690-01$ \\
39.59 & $2.764-01$ \\
44.76 & $2.840-01$ \\
49.26 & $2.907-01$ \\
\hline
\end{tabular}

$\log \rho=\log A+\alpha \log T$

$T=t+273.16$

\begin{tabular}{|c|c|cc|}
\hline$t,{ }^{\circ} \mathrm{C}$ & $\rho, \Omega \cdot \mathrm{cm}$ & \multicolumn{2}{|c|}{ range of } \\
\hline .0 & $2.224-01$ & $2.214-01$ & T0 $2.235-01$ \\
10.0 & $2.356-01$ & $2.348-01$ & To $2.364-01$ \\
20.0 & $2.491-01$ & $2.485-01$ & T0 $2.498-01$ \\
23.0 & $2.532-01$ & $2.526-01$ & To $2.538-01$ \\
30.0 & $2.629-01$ & $2.622-01$ & TO $2.636-01$ \\
40.0 & $2.769-01$ & $2.760-01$ & To $2.779-01$ \\
50.0 & $2.913-01$ & $2.899-01$ & To $2.926-01$ \\
\hline
\end{tabular}

$A=2.749-05$

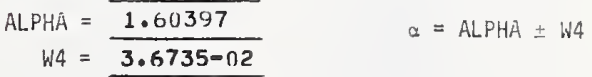

ranges given are $95 \%$ confidence limits

SAMPLE INUMBER- $i 1-\vec{R}-1$ (AU)

DATA CUMPUTEU ON $2 B$ HOV 67

DATA TAKE W ON AUG 16, 1967

P-TYPE ST

\begin{tabular}{|c|c|}
\hline$t,{ }^{\circ} \mathrm{C}$ & $\rho, \Omega \cdot \mathrm{cm}$ \\
\hline .00 & $2.023-01$ \\
5.36 & $2.075-01$ \\
10.53 & $2.732-01$ \\
15.22 & $2.736-01$ \\
19.92 & $2.842-01$ \\
24.08 & $2.899-01$ \\
20.50 & $2.966-01$ \\
34.04 & $3.025-01$ \\
39.52 & $3.009-01$ \\
44.10 & $3.150-01$ \\
49.56 & $3.226-01$ \\
\hline
\end{tabular}

$\log \rho=\log A+\alpha \log T$

$T=t+273.16$

\begin{tabular}{|c|c|cc|}
\hline$t,{ }^{\circ} \mathrm{C}$ & $\rho, \Omega \cdot \mathrm{cm}$ & \multicolumn{3}{|c|}{ range of $\rho$} \\
\hline 10.0 & $2.606-01$ & $2.595-01$ & T0 $2.618-01$ \\
20.0 & $2.727-01$ & $2.713-01$ & T0 $2.736-01$ \\
23.0 & $2.849-01$ & $2.842-01$ & T0 $2.855-01$ \\
30.0 & $2.885-01$ & $2.879-01$ & TO $2.892-01$ \\
41.0 & $3.071-01$ & $2.904-01$ & To $2.979-01$ \\
20.0 & $3.220-01$ & $3.206-01$ & TO $3.234-01$ \\
\hline
\end{tabular}

$A=2 \cdot 242=04$

$\begin{aligned} \text { ALPHA } & =\frac{1.25814}{3.4339-12} \\ \text { W4 } & =\frac{2.242-04}{3.45}\end{aligned}$

$x=$ ALPHA $\pm W 4$

ranges given are $95 \%$ confidence limits 
SAMPLE NUMBER- $11-4-2$ (AL)

DATA COMPUTEU ON 28 NOV 67

P-TYPE SI

UAIA TAKE. ON AUG 16, 1967

\begin{tabular}{|r|l|}
\hline$t,{ }^{\circ} \mathrm{C}$ & $\rho, \Omega \cdot \mathrm{cm}$ \\
\hline .60 & $2.008-01$ \\
5.36 & $2.660-01$ \\
10.53 & $2.717-01$ \\
15.22 & $2.771-01$ \\
19.92 & $2.826-01$ \\
24.68 & $2.803-01$ \\
29.50 & $2.943-01$ \\
34.64 & $3.009-01$ \\
39.52 & $3.072-01$ \\
44.10 & $3.133-01$ \\
49.56 & $3.2063-01$ \\
\hline
\end{tabular}

$\log \rho=\log A+\alpha \log T$

$T=t+273.16$

\begin{tabular}{|c|c|cc|}
\hline$t,{ }^{\circ} \mathrm{C}$ & $\rho, \Omega \cdot \mathrm{cm}$ & \multicolumn{2}{|c|}{ range of $\rho$} \\
\hline .0 & $2.592-01$ & $2.581-01$ & T0 $2.603-01$ \\
10.0 & $2.712-01$ & $2.703-01$ & T0 $2.720-01$ \\
20.0 & $2.833-01$ & $2.8326-01$ & TO $2.840-01$ \\
2.50 & $2.869-01$ & $2.863-01$ & To $2.876-01$ \\
30.0 & $2.955-01$ & $2.948-01$ & To $2.962-01$ \\
40.0 & $3.078-01$ & $3.069-01$ & TO $3.088-01$ \\
50.0 & $3.202-01$ & $3.189-01$ & TO $3.216-01$ \\
\hline
\end{tabular}

\footnotetext{
$A=2 \cdot 229-04$

ALPHA $=1.25817$

$W 4=\overline{3.358 R-02}$

$\alpha=A L P H A \pm W 4$
}

ranges given are $95 \%$ confidence limits

SAMPLE NUMBER- 1.3 (AL) P-TYPE ST

DATA COMPUTEU ON 29 INOV 07

UATA TAKEID ON FEIS 20, 1965

\begin{tabular}{|r|l|}
\hline$t,{ }^{\circ} \mathrm{C}$ & $\rho, \Omega \cdot \mathrm{cm}$ \\
\hline .78 & $8.39 t-01$ \\
5.42 & $8.665-01$ \\
10.31 & $8.965-01$ \\
14.86 & $9.246-01$ \\
20.69 & $9.010-01$ \\
25.29 & $9.906-01$ \\
30.11 & $1.021+00$ \\
35.13 & $1.054+00$ \\
39.838 & $1.086+00$ \\
44.82 & $1.119+00$ \\
49.56 & $1.151+00$ \\
\hline
\end{tabular}

$\log \rho=\log A+\alpha \log T$

$T=t+273.16$

\begin{tabular}{|c|c|cc|}
\hline$t,{ }^{\circ} \mathrm{C}$ & $\rho, \Omega \cdot \mathrm{cm}$ & \multicolumn{2}{|c|}{ range of $\rho$} \\
\hline $10 . U$ & $8.348-01$ & $8.319-01$ & T0 $8.377-01$ \\
$20 . U$ & $8.947-01$ & $1.925-01$ & T0 $8.970-01$ \\
23.0 & $9.567-01$ & $9.549-01$ & TO $9.545-01$ \\
30.0 & $9.756-01$ & $9.739-01$ & TO $9.774-01$ \\
40.0 & $1.021+00$ & $1.013+00$ & TO $1.023+00$ \\
50.0 & $1.087+00$ & $1.084+00$ & TO $1.089+00$ \\
& $1.154+00$ & $1.151+00$ & TO $1.158+00$ \\
\hline
\end{tabular}

$$
A=1.669-05
$$

ALPHA $=\frac{1.92872}{1.962}$

$W 4=2.6704-n 2$

$\alpha=A L P H A \pm W A$

ranges given are $95 \%$ confidence limits
SAMPLE NUMBER- /2. (AL) P-TYPF 5 I LAAIA COMPUTED ON 28 INUV 67

UATA TAKEII ON NOV 27, 1964

\begin{tabular}{|c|c|}
\hline$t,{ }^{\circ} \mathrm{C}$ & $\rho, \Omega \cdot \mathrm{cm}$ \\
\hline .40 & $6.251-01$ \\
4.27 & $6.401-01$ \\
9.28 & $6.602-01$ \\
15.04 & $6.036-01$ \\
20.59 & $7.074-01$ \\
25.30 & $7.277-01$ \\
29.99 & $7.467-01$ \\
31.75 & $7.567-01$ \\
34.60 & $7.099-01$ \\
39.88 & $7.945-01$ \\
45.18 & $8.205-01$ \\
\hline
\end{tabular}

$\log p=\log A+\alpha \log T$

$T=t+273.16$

\begin{tabular}{|c|c|c|c|c|}
\hline$t,{ }^{\circ} \mathrm{C}$ & $\rho, \Omega \cdot \mathrm{Cm}$ & \multicolumn{3}{|c|}{ range of $p$} \\
\hline .0 & $6.221-01$ & $6.195-01$ & TO & $6.247-01$ \\
\hline 10.0 & $6.634-01$ & $6 \cdot 015-01$ & TO & $6.654-01$ \\
\hline 20.0 & $7.059-01$ & $7.044-01$ & TO & $7.074-01$ \\
\hline 23.4 & $7 \cdot 189-01$ & $7.173-01$ & 10 & $7 \cdot 21,4-101$ \\
\hline 30.0 & $7.496-01$ & $7.478-01$ & TO & $7.514-01$ \\
\hline 40.0 & $7.944-01$ & $7.918-01$ & TO & $7.970-01$ \\
\hline 50.0 & B. $403-01$ & $8.366-01$ & TO & $8.441-01$ \\
\hline
\end{tabular}

$$
A=2.721-05
$$

ALPHA $=1.78915$

$W 4=\overline{3.4819-02}$

$\alpha=A L P H A \pm W 4$

ranges given are $95 \%$ confidence limits

SAMPLE NUMBER- 14

P-TYPE SI

DATA CORIPUIEU ON 283 NOV 67

DATA TAKEIS ON FEB 9, 1965

\begin{tabular}{|c|c|}
\hline$t,{ }^{\circ} \mathrm{C}$ & $\rho, \Omega \cdot \mathrm{cm}$ \\
\hline-.62 & $8.593-01$ \\
5.25 & $8.943-01$ \\
10.02 & $9.308-01$ \\
14.62 & $9.620-01$ \\
20.59 & $1.005+00$ \\
25.16 & $1.038+00$ \\
29.96 & $1.074+00$ \\
34.89 & $1.111+00$ \\
39.86 & $1.150+00$ \\
44.85 & $1.188+00$ \\
49.52 & $1.226+00$ \\
\hline
\end{tabular}

$\log \rho=\log A+\alpha \log T$

$T=t+273.16$

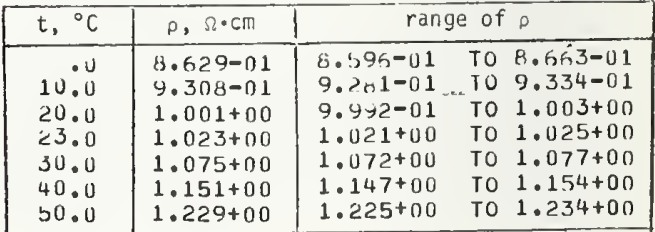

$\begin{aligned} A & =\frac{6.425-06}{2.10476} \\ \text { ALPHA } & =\frac{3.0142-02}{W 4}=\end{aligned}$

$\alpha=A L P H A \pm W 4$

ranges given are $95 \%$ confidence 1 imits 
SAMPLE NUMBER- $14 R$

DATA CUIPUTEU ON $2 \mathrm{~B}$ INOV 67

P-TYPE SI

UATA TAKEIV ON MAY 6, 1965

\begin{tabular}{|c|c|}
\hline$t,{ }^{\circ} \mathrm{C}$ & $0, \Omega \cdot \mathrm{cm}$ \\
\hline-.19 & $8.599-01$ \\
5.37 & $8.941-01$ \\
10.37 & $9.324-01$ \\
14.87 & $9.635-01$ \\
19.82 & $9.990-01$ \\
25.32 & $1.039+00$ \\
29.88 & $1.072+00$ \\
34.82 & $1.109+00$ \\
39.80 & $1.148+00$ \\
44.58 & $1.185+00$ \\
49.78 & $1.227+00$ \\
\hline
\end{tabular}

$\log \rho=\log A+\alpha \log T$

$T=t+273.16$

\begin{tabular}{|c|c|cc|}
\hline$t,{ }^{\circ} \mathrm{C}$ & $0, \Omega \cdot \mathrm{cm}$ & \multicolumn{2}{|c|}{ range of } \\
\hline .0 & $8.616-01$ & $8.607-01$ & T0 $8.025-01$ \\
10.0 & $9.295-01$ & $9.2138-01$ & T0 $9.302-01$ \\
20.0 & $1.000+00$ & $9.995-01$ & T0 $1.001+00$ \\
23.0 & $1.022+00$ & $1.021+00$ & T0 $1.022+00$ \\
30.0 & $1.073+00$ & $1.073+00$ & T0 $1.074+00$ \\
40.0 & $1.150+00$ & $1.149+00$ & T0 $1.150+00$ \\
50.0 & $1.228+00$ & $1.227+00$ & TO $1.230+00$ \\
\hline
\end{tabular}

$$
\begin{aligned}
A & =\frac{6.237-06}{2.10978} \\
\text { ALPHA } & =\frac{8.4114-03}{W 4}=
\end{aligned}
$$

$a=A L P H A \pm W 4$

ranges given are $95 \%$ confidence limits

SAMPLE NUMBER- $15-R$

DATA CUIPUTEU ON $\angle A$ I:OV 67

DATA TAKEI UN MAY 6, 1965

\begin{tabular}{|c|c|}
\hline$\tau,{ }^{\circ} \mathrm{C}$ & $0,20 \mathrm{~cm}$ \\
\hline-.38 & $1.317+00$ \\
5.28 & $1.380+00$ \\
10.30 & $1.436+00$ \\
14.84 & $1.447+00$ \\
19.80 & $1.545+00$ \\
25.33 & $1.610+00$ \\
29.91 & $1.665+00$ \\
34.87 & $1.725+00$ \\
39.68 & $1.788+00$ \\
44.65 & $1.848+00$ \\
49.38 & $1.917+00$ \\
\hline
\end{tabular}

$\log \rho=\log A+\alpha \log T$

$T=t+273.16$

\begin{tabular}{|c|c|c|c|}
\hline$t,{ }^{\circ} \mathrm{C}$ & $0,2 \cdot \mathrm{cm}$ & \multicolumn{2}{|c|}{ range of } \\
\hline .0 & $1.322+00$ & $1.318+00$ & TO $1.327+00$ \\
10.0 & $1.432+00$ & $1.424+00$ & TO $1.436+00$ \\
20.0 & $1.546+00$ & $1.543+00$ & TO $1.549+00$ \\
23.0 & $1.582+00$ & $1.579+00$ & T0 $1.594+00$ \\
30.0 & $1.666+00$ & $1.062+00$ & TO $1.659+00$ \\
40.0 & $1.790+00$ & $1.745+00$ & TO $1.794+00$ \\
50.0 & $1.919+00$ & $1.912+00$ & TO $1.925+00$ \\
\hline
\end{tabular}

$$
A=5.344-06
$$

ALPHA $=\frac{5.21371}{2.6318 .02}$

$$
W 4=\frac{2.6318-102}{2}
$$$$
a=A L P H A \pm W 4
$$

ranges given are $95 \%$ confidence limits
SAMPLE NUMBER- 15

UATA CUIMPUTED ON 28 MOV 67

\begin{tabular}{|c|c|c|c|c|}
\hline$t,{ }^{\circ} \mathrm{C}$ & $\rho, \Omega \cdot \mathrm{cm}$ & \multicolumn{3}{|c|}{ range of $\rho$} \\
\hline - Ú & $1 \cdot 326+00$ & $1.322+00$ & TO & $1.330+00$ \\
\hline 10.0 & $1.435+00$ & $1.432+00$ & TO & $1 \cdot 4.3 \mathrm{a}+00$ \\
\hline 20.0 & $1.550+00$ & $1.547+00$ & TO & $1.552+00$ \\
\hline 23.0 & $1.585+00$ & $1.583+00$ & TO & $1 \cdot 587+00$ \\
\hline 30.0 & $1.669+00$ & 1. $666+00$ & TO & $1.671+00$ \\
\hline 40.0 & $1.793+100$ & $1.789+00$ & TO & $1.796+00$ \\
\hline 50.0 & $1.922+00$ & 1. $916+00$ & TO & $1.927+00$ \\
\hline
\end{tabular}

DATA TAKEN OIN FEA 26,1965

\begin{tabular}{|r|c|}
\hline$t,{ }^{\circ} \mathrm{C}$ & $\rho, \Omega \cdot \mathrm{cm}$ \\
\hline .62 & $1.332+00$ \\
5.31 & $1.333+00$ \\
10.20 & $1.438+00$ \\
14.01 & $1.490+00$ \\
20.67 & $1.557+00$ \\
25.26 & $1.612+00$ \\
30.15 & $1.671+00$ \\
35.20 & $1.732+00$ \\
39.95 & $1.792+00$ \\
44.89 & $1.855+00$ \\
49.66 & $1.917+00$ \\
\hline
\end{tabular}

$\log \rho=\log A+\alpha \log T$

$T=t+273.16$

$A=5.537=06$

ALPHA $=2.20782$

$W 4=2 \cdot 1418-12$

$a=A L P H R \pm W 4$

ranges given are $95 \%$ confidence limits

5 AMPLE NUMBER- I6

$P=T Y P E S I$

DATA-CUMPUTED ON 28 HOV 67

\begin{tabular}{|c|c|c|c|c|}
\hline$t,{ }^{\circ} \mathrm{C}$ & $p, \Omega \cdot \mathrm{Cm}$ & \multicolumn{3}{|c|}{ range of $\rho$} \\
\hline - ij & $4.007+00$ & $4.004+00$ & TO & $4.010+00$ \\
\hline 10.0 & $4.362+00$ & $4.360+00$ & TO & $4.364+00$ \\
\hline 20.0 & $4.735+00$ & $4.733+00$ & 10 & $4.737+00$ \\
\hline 23.0 & $4.850+00$ & $4.348+00$ & TO & $4.852+00$ \\
\hline 30.0 & $5.126+00$ & $5.123+00$ & . TO & $5.128+00$ \\
\hline 40.0 & $5.534+00$ & $5.531+00$ & TO & $5.537+00$ \\
\hline 50.0 & $5.961+00$ & $5.957+00$ & TO & $5.966+00$ \\
\hline
\end{tabular}

DATA TAKEN OII FEH 9, 1965

\begin{tabular}{|c|c|}
\hline$t,{ }^{\circ} \mathrm{C}$ & $\rho, \Omega \cdot \mathrm{Cm}$ \\
\hline-.80 & $3.973+00$ \\
5.04 & $4.162+00$ \\
9.08 & $4.357+00$ \\
14.53 & $4.529+00$ \\
20.59 & $4.759+00$ \\
25.12 & $4.934+00$ \\
29.99 & $5.127+00$ \\
35.00 & $5.3 c^{2} 9+00$ \\
40.01 & $5.536+00$ \\
45.01 & $5.744+00$ \\
49.72 & $5.946+00$ \\
\hline
\end{tabular}

$\log p=\log A+\alpha \log T$

$T=t+273.16$

$A=6.981-06$

ALPHA $=\frac{2.36305}{5.8606013} \quad \alpha=$ ALPHA $\pm W 4$

$W 4=5 \cdot 8606-13$

ranges given are $95 \%$ confidence 1 imits 


\begin{tabular}{|c|c|}
\hline$t,{ }^{\circ} \mathrm{C}$ & $0,8 \cdot \mathrm{cm}$ \\
\hline .10 & $9.605+01$ \\
5.11 & $9.096+01$ \\
10.01 & $9.518+01$ \\
14.34 & $9.389+01$ \\
20.54 & $1.048+02$ \\
25.32 & $1.091+02$ \\
30.09 & $1.137+02$ \\
35.02 & $1.135+02$ \\
39.80 & $1.233+02$ \\
45.03 & $1.236+02$ \\
49.53 & $1.331+02$ \\
\hline
\end{tabular}

$\log \rho=\log A+\alpha \log T$

$T=t+273.16$

\begin{tabular}{|c|c|c|c|c|}
\hline$t,{ }^{\circ} \mathrm{C}$ & $0,32 \cdot \mathrm{cm}$ & \multicolumn{3}{|c|}{ range of $p$} \\
\hline & $8.668+01$ & $8.635+01$ & TO & $8.700+01$ \\
\hline 10.0 & $9.513+01$ & $9.4 B H+01$ & TO & $9.538+01$ \\
\hline 20.0 & $1.041+02$ & $1.03 y+02$ & To & 1. $043+02$ \\
\hline 23.0 & $1.069+02$ & $1.0,6+02$ & TO & $1.071+02$ \\
\hline 30.0 & $1.135+02$ & $1.133+02$ & 70 & $1.137+02$ \\
\hline 40.0 & $1 \cdot 235+02$ & $1.231+02$ & TO & $1.238+02$ \\
\hline 50.0 & $1.339+02$ & $1.335+02$ & TO & $1.344+02$ \\
\hline
\end{tabular}

$$
A=4.272-05
$$

ALPHA $=2.58875$

$W_{4}=\overline{2.8415-12}$

ranges given are 95: confidence limits

SAMPLE NUMBER- 19

DATA COAHUTED ON 28 NOV 67

P-TYPE SI

DATA TAKEI. OIS SEPT 28,1966

\begin{tabular}{|c|c|}
\hline$t,{ }^{\circ} \mathrm{C}$ & $p, \Omega \cdot \mathrm{cm}$ \\
\hline 1.84 & $8.953+02$ \\
6.35 & $9.459+02$ \\
10.06 & $9.733+02$ \\
14.92 & $1.017+03$ \\
19.64 & $1.050+03$ \\
24.80 & $1.096+03$ \\
29.73 & $1.143+03$ \\
34.82 & $1.193+03$ \\
38.94 & $1.234+03$ \\
44.06 & $1.285+03$ \\
49.37 & $1.340+03$ \\
\hline
\end{tabular}

$\log p=\log A+a \log T$

$T=t+273.16$

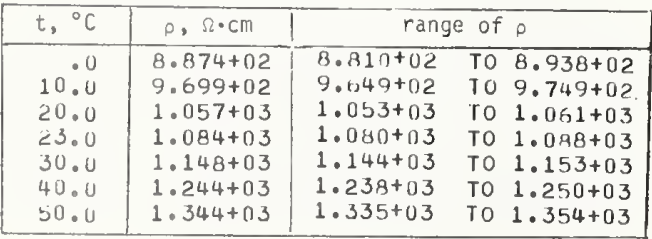

\footnotetext{
$A=8.437-04$

ALPHA $=2.47164$

$W_{4}=\overline{5.5790-n 2}$
}

$\alpha=A L P H A \pm W 4$

\begin{tabular}{|c|c|}
\hline$t,{ }^{\circ} \mathrm{C}$ & $\rho, \Omega \cdot \mathrm{cm}$ \\
\hline 6.36 & $9.1406+01$ \\
9.90 & $9.602+01$ \\
13.54 & $9.999+01$ \\
17.14 & $1.030+02$ \\
20.53 & $1.001+02$ \\
24.88 & $1.102+02$ \\
29.51 & $1.146+02$ \\
34.41 & $1.193+02$ \\
39.11. & $1.239+02$ \\
44.39 & $1.292+02$ \\
49.66 & $1.347+02$ \\
\hline
\end{tabular}

$\log \rho=\log A+\alpha \log T$

$T=t+273.16$

\begin{tabular}{|c|c|c|c|}
\hline$t,{ }^{\circ} \mathrm{C}$ & $\rho, \Omega \cdot \mathrm{cm}$ & \multicolumn{2}{|c|}{ range of $\rho$} \\
\hline .0 & $8.856+01$ & $8.609+01$ & T0 $8.903+01$ \\
10.0 & $9.692+01$ & $9.655+111$ & TO $9.728+01$ \\
20.0 & $1.057+02$ & $1.055+02$ & TO $1.060+02$ \\
23.0 & $1.085+02$ & $1.042+02$ & TO $1.087+02$ \\
30.0 & $1.150+02$ & $1.147+02$ & TO $1.153+02$ \\
40.0 & $1.248+02$ & $1.243+02$ & TO $1.252+02$ \\
50.0 & $1.350+02$ & $1.344+02$ & TO $1.356+02$ \\
\hline
\end{tabular}

$A=6.853-05$

ALPHA $=2.50834 \quad \alpha=$ ALPHA $\pm W 4$

$W_{4}=4.0844-02$

ranges given are $95 \%$ confidence limits

SAMPLE NUMBER- 20

P-TYPE 5

UAIA CUMPUTEU ON OH INOV O?

DATA TAKEIS ON SEPT $20,196,6$

\begin{tabular}{|c|c|}
\hline$t,{ }^{\circ} \mathrm{C}$ & $\rho, \Omega \cdot \mathrm{cm}$ \\
\hline 6.10 & $9.862+02$ \\
9.77 & $1.015+03$ \\
13.43 & $1.050+03$ \\
17.09 & $1.027+03$ \\
20.50 & $1.133+03$ \\
24.82 & $1.179+03$ \\
29.55 & $1.235+03$ \\
34.47 & $1.293+03$ \\
39.22 & $1.351+03$ \\
44.54 & $1.415+03$ \\
49.86 & $1.482+03$ \\
\hline
\end{tabular}

$\log \rho=\log A+\alpha \log T$

$T=t+273.16$

\begin{tabular}{|c|c|cc|}
\hline$t,{ }^{\circ} \mathrm{C}$ & $\rho, \Omega \cdot \mathrm{Cm}$ & \multicolumn{2}{|c|}{ range of $p$} \\
\hline .0 & $9.200+02$ & $9.126+02$ & T0 $9.275+02$ \\
10.0 & $1.019+03$ & $1.014+03$ & TO $1.025+03$ \\
20.0 & $1.125+03$ & $1.121+03$ & $101.130+03$ \\
23.0 & $1.159+03$ & $1.154+03$ & TO $1.163+03$ \\
30.0 & $1.238+03$ & $1.234+03$ & TO $1.243+03$ \\
40.0 & $1.358+03$ & $1.351+03$ & TO $1.365+03$ \\
50.0 & $1.486+03$ & $1.475+03$ & TO $1.497+03$ \\
\hline
\end{tabular}

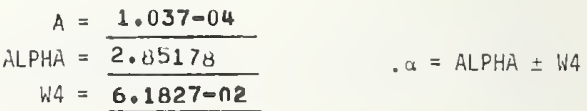

ranges given are $95 \%$ confidence limits 
DATA CONHUTED ON 2 A NOV 7

UATA TAKEIN UN FEIS 26, 1965

\begin{tabular}{|c|c|}
\hline$t,{ }^{\circ} \mathrm{C}$ & $\rho, s \cdot \mathrm{cm}$ \\
\hline .41 & $1.217+03$ \\
5.17 & $1.283+03$ \\
10.15 & $1.349+03$ \\
14.76 & $1.406+03$ \\
20.64 & $1.463+03$ \\
25.23 & $1.544+03$ \\
30.18 & $1.613+03$ \\
35.27 & $1.625+03$ \\
40.02. & $1.752+03$ \\
44.98 & $1.823+03$ \\
49.77 & $1.894+03$ \\
\hline
\end{tabular}

$\log \rho=\log A+\alpha \log T$

$T=t+273.16$

\begin{tabular}{|c|c|cc|}
\hline$t,{ }^{\circ} \mathrm{C}$ & $0, \Omega \cdot \mathrm{cm}$ & \multicolumn{2}{|c|}{ range of $\mathrm{p}$} \\
\hline 10.0 & $1.221+03$ & $1.215+03$ & TO $1.226+03$ \\
20.0 & $1.342+03$ & $1.338+03$ & TO $1.347+03$ \\
23.0 & $1.471+03$ & $1.468+03$ & TO $1.475+03$ \\
30.0 & $1.511+03$ & $1.508+03$ & TO $1.515+03$ \\
40.0 & $1.608+03$ & $1.604+03$ & TO $1.612+03$ \\
50.0 & $1.752+03$ & $1.746+03$ & TO $1.757+03$ \\
\hline
\end{tabular}

$\begin{aligned} A & =\frac{4.427-04}{2.64343} \\ \text { ALPHA } & =\frac{3.4265-02}{W 4}=\end{aligned} \quad a=$ ALPHA $\pm W 4$

ranges given are 95: confidence limits

SAMPLE NUMBER - 2

DATA CUVIPUTED OIN 29 WOV 67

N-TYPF ST

DATA TAKEII ON OCT 6,1966

\begin{tabular}{|c|c|}
\hline$t,{ }^{\circ} \mathrm{C}$ & $\rho, \Omega \cdot \mathrm{cm}$ \\
\hline .18 & $5.045-02$ \\
5.52 & $5.134-02$ \\
10.12 & $5.212-02$ \\
14.04 & $5.202-02$ \\
19.83 & $5.387-02$ \\
24.80 & $5.479-02$ \\
29.70 & $5.575-02$ \\
34.42 & $5.67 \mathrm{C}-02$ \\
39.34 & $5.771-02$ \\
44.28 & $5.876-02$ \\
49.42 & $5.988-02$ \\
\hline
\end{tabular}

$\log p=\log A+\alpha \log T$

$T=t+273.16$

\begin{tabular}{|c|c|cc|}
\hline$t,{ }^{\circ} \mathrm{C}$ & $2, \Omega \cdot \mathrm{cm}$ & \multicolumn{2}{|c|}{ range of $p$} \\
\hline 10.0 & $5.022-02$ & $4.936-02$ & T0 $5.048-02$ \\
20.0 & $5.212-02$ & $5.193-02$ & TO $5.232-02$ \\
23.0 & $5.403-02$ & $5.388-02$ & T0 $5.418-02$ \\
30.0 & $5.460-02$ & $5.445-02$ & T0 $5.475-02$ \\
40.0 & $5.593-02$ & $5.577-02$ & T0 $5.610-02$ \\
50.0 & $5.784-02$ & $5.762-02$ & TO $5.806-02$ \\
\hline
\end{tabular}

$A=1.517-04$

ALPHA $=1.03421$

$w_{4}=4.0205=02$

$. \alpha=A L P H A \pm W 4$

ranges given are $95:$ confidence limits
DAIA TAKEIJ UN UEC ?4, 1904

\begin{tabular}{|c|c|}
\hline$t,{ }^{\circ} \mathrm{C}$ & $\rho, 0 \cdot \mathrm{cm}$ \\
\hline-.05 & $1.028-03$ \\
4.88 & $1.037-03$ \\
10.03 & $1.047-03$ \\
14.814 & $1.055-03$ \\
20.77 & $1.067-03$ \\
25.31 & $1.075-03$ \\
30.04 & $1.083-03$ \\
35.37 & $1.093-03$ \\
40.10. & $1.101-03$ \\
45.11 & $1.111-03$ \\
50.01 & $1.120-03$ \\
\hline
\end{tabular}

$\log \rho=\log A+\alpha \log T$

$T=t+273.16$

\begin{tabular}{|c|c|c|c|c|}
\hline$t,{ }^{\circ} \mathrm{C}$ & $\rho, \Omega \cdot c m$ & \multicolumn{3}{|c|}{ range of $\rho$} \\
\hline .0 & $1.028-03$ & $1.024-03$ & TO & $1.031-03$ \\
\hline $10 \cdot 0$ & $1.047=03$ & $1.044-03$ & TO & $1.049-03$ \\
\hline 20.0 & $1.065-03$ & $1.063-03$ & TO & $1.0 \leqslant 7-03$ \\
\hline 23.0 & $1.071-03$ & 1. $069-03$ & TO & $1.073-03$ \\
\hline 30.0 & 1. $084-03$ & $1.0 \times 1-03$ & TO & 1. $0.16-03$ \\
\hline 40.0 & $1.102-03$ & $1.099-03$ & To & $1.104-03$ \\
\hline 50.0 & $1.119-03$ & $1.116-03$ & TO & $1.123-03$ \\
\hline
\end{tabular}

$$
\begin{aligned}
A & =\frac{5.912-05}{.50897} \\
\text { ALPHA } & =\frac{.59}{2.7103-02} \quad a=\text { ALPHA } \pm W 4 \\
W 4 & =W 4
\end{aligned}
$$

ranges given are $95 \%$ confidence 1 imits

SAMPLE NUMBER- 3

$N-T Y P E$ ST

WMIA LUIAUIEU ON 2 H HOV $\$ 7$

DATA IAKLi, OIJ ULC 29, 196',

\begin{tabular}{|c|c|}
\hline$t,{ }^{\circ} \mathrm{C}$ & $\rho, \Omega \cdot \mathrm{cm}$ \\
\hline .65 & $7.900-02$ \\
5.29 & $8.066-02$ \\
10.95 & $8.271-02$ \\
15.15 & $8.426-02$ \\
20.31 & $8.623-02$ \\
24.98 & $8.807-02$ \\
29.70 & $8.998-02$ \\
34.83 & $9.209-02$ \\
39.47 & $9.400-02$ \\
44.52 & $9.625-02$ \\
49.20 & $9.834-02$ \\
\hline
\end{tabular}

$\log p=\log A+\alpha \log T$

$T=t+273.16$

\begin{tabular}{|c|c|cc|}
\hline$t,{ }^{\circ} \mathrm{C}$ & $\rho, \Omega \cdot \mathrm{Cm}$ & \multicolumn{2}{|c|}{ range of $\rho$} \\
\hline .0 & $7.850-02$ & $7.812-02$ & TO $7.888-02$ \\
10.0 & $8.237-02$ & $8.209-02$ & TO $8.266-02$ \\
20.0 & $8.630-02$ & $8.608-02$ & TO $8.652-02$ \\
23.0 & $8.748-02$ & $8.727-02$ & T0 $8.770-02$ \\
30.0 & $9.026-02$ & $9.003-02$ & TO $9.050-02$ \\
40.0 & $9.428-02$ & $9.395-02$ & TO $9.460-02$ \\
50.0 & $9.833-02$ & $9.788-02$ & TO $9.879-02$ \\
\hline
\end{tabular}

$$
\begin{aligned}
A & =\frac{4.258-05}{1.34034} \\
\text { ALPHA } & =\frac{3.6930-02}{14}
\end{aligned}
$$

$\alpha=A L P H A \pm W 4$ 
SAMPLE NUMBER- 4

DATA CUIPUTED ON $2 A$ NOV 67

N-TYPE SI

DATA TAKEIN ON DEC 29, 1965

\begin{tabular}{|c|c|}
\hline$t,{ }^{\circ} \mathrm{C}$ & $p, \Omega \cdot \mathrm{cm}$ \\
\hline .53 & $7.934-02$ \\
5.22 & $8.103-02$ \\
10.88 & $8.309-02$ \\
15.12 & $8.468-02$ \\
20.29 & $8.667-02$ \\
24.98 & $8.852-02$ \\
29.72 & $9.048-02$ \\
34.87 & $9.201-02$ \\
39.52 & $9.461-02$ \\
44.59 & $9.681-02$ \\
49.27 & $9.693-02$ \\
\hline
\end{tabular}

$\log p=\log A+\alpha \log T$

$T=t+273.16$

\begin{tabular}{|c|c|c|c|c|}
\hline$t,{ }^{\circ} \mathrm{C}$ & P, $\Omega \cdot \mathrm{cm}$ & \multicolumn{3}{|c|}{ range of $p$} \\
\hline & $7.8 \cap 8-02$ & $7.857-02$ & & $7.919-02$ \\
\hline 10.0 & $8.279-02$ & $8 \cdot 255-02$ & TO & $8.302-02$ \\
\hline 20.0 & $8.675-02$ & $8.656-02$ & TO & $8.693-02$ \\
\hline c 3.0 & $8.704-02$ & $8.776-02$ & TO & $8.812-0 ?$ \\
\hline 30.0 & $9.075-02$ & $9.056-02$ & TO & $9.095-02$ \\
\hline 40.0 & $9.481-02$ & $9.454-02$ & TO & $9.507-0 ?$ \\
\hline 50.0 & $9.890-02$ & $9.6553-02$ & TO & $9.928-0 ?$ \\
\hline
\end{tabular}

$$
A=4.141005
$$

ALPHA $=\overline{1.34617}$

$W_{4}=3.0244-n 2$

$\alpha=A L P H A \pm W A$

ranges given are $95 \%$ confidence limits

SAMPLE NUMBER- 6

DATA CUMPUTEO ON 28 NOV 67

N-TYFE SI

UATA TAKEIN ON DEC 21, 1965

\begin{tabular}{|c|c|}
\hline$t,{ }^{\circ} \mathrm{C}$ & $\rho, \Omega \cdot \mathrm{Cm}$ \\
\hline .98 & $8.047-02$ \\
5.75 & $8.219-02$ \\
10.44 & $8.393-02$ \\
15.41 & $13.581-02$ \\
20.24 & $8.770-02$ \\
25.03 & $8.962-02$ \\
29.73 & $9.158-02$ \\
34.70 & $9.368-02$ \\
39.77 & $9.584-02$ \\
44.81 & $9.812-02$ \\
49.75 & $1.004-01$ \\
\hline
\end{tabular}

$\log p=\log A+\alpha \log T$

$T=t+273.16$

\begin{tabular}{|c|c|c|c|c|}
\hline$t,{ }^{\circ} \mathrm{C}$ & $\rho, \Omega \cdot \mathrm{cm}$ & \multicolumn{3}{|c|}{ range of $p$} \\
\hline .0 & $7.980-02$ & $7.936-02$ & To & $8.025-02$ \\
\hline 10.0 & $8.377-102$ & $8.344-02$ & TU & $8.411-0 ?$ \\
\hline 20.0 & $8.780-02$ & $8.753-02$ & TO & $8.806-02$ \\
\hline 23.1 & $8.901-02$ & $8.876-02$ & TO & $8.927-07$ \\
\hline $30 \cdot 0$ & $9.187-02$ & $9.159-02$ & To & $9.214-0 ?$ \\
\hline bo.0 & $9.598-02$ & $9.560-02$ & To & $9.636-02$ \\
\hline & $1.001-01$ & $9.961-02$ & To & $1.007-01$ \\
\hline
\end{tabular}

$$
A=4.080-05
$$

ALPHA $=1.35088$

$W_{4}=4.2721-n 2$

$\alpha=$ ALPHA $\pm W 4$

ranges given are $95 \%$ confidence limits
SAMPLE NUMBER- 5

DATA COIAPUTEU ON 28 NOV 67

UATA TAKEN ON DEC 21, 1965

\begin{tabular}{|c|c|}
\hline$t,{ }^{\circ} \mathrm{C}$ & $\rho, s \cdot \mathrm{cm}$ \\
\hline .90 & $8.010-02$ \\
5.63 & $8.183-02$ \\
10.33 & $8.356-02$ \\
15.34 & $8.547-02$ \\
20.22 & $8.736-02$ \\
24.50 & $8.926-02$ \\
29.75 & $9.122-02$ \\
34.71 & $9.331-02$ \\
39.84. & $9.552-02$ \\
44.90 & $9.777-02$ \\
49.88 & $1.000-01$ \\
\hline
\end{tabular}

$\log p=\log A+\alpha \log T$

$T=t+273.16$

\begin{tabular}{|c|c|cc|}
\hline$t,{ }^{\circ} \mathrm{C}$ & $\rho, \Omega \cdot \mathrm{Cm}$ & \multicolumn{2}{|c|}{ range of $\rho$} \\
\hline .0 & $7.951-02$ & $7.913-02$ & T0 $7.989-02$ \\
10.0 & $8.347-02$ & $8.318-02$ & $108.375-02$ \\
20.0 & $8.747-02$ & $8.725-02$ & TO $8.770-0 ?$ \\
23.0 & $8.868-02$ & $8.646-02$ & TO $8.890-02$ \\
30.0 & $9.152-02$ & $9.129-02$ & TO $9.176-0 ?$ \\
40.0 & $9.563-02$ & $9.530-02$ & T0 $9.595-0 ?$ \\
50.0 & $9.977-02$ & $9.932-02$ & TO $1.002-01$ \\
\hline
\end{tabular}

$A=4.075-05$

ALPHA $=1.35046$

$W 4=\overline{3.6609-n 2}$

$\alpha=\mathrm{ALPHA} \pm W 4$

ranges given are 95\% confidence limits

SAMPLE NUMBER- 7

DATA COMPUTED ON $2 B$ NOV 67

N-TYPE SI

UATA TAKEN ON FEH 26, 1965

\begin{tabular}{|r|c|}
\hline$t,{ }^{\circ} \mathrm{C}$ & $p, s \cdot \mathrm{cm}$ \\
\hline .91 & $18.405-02$ \\
5.50 & $8.582-02$ \\
10.39 & $8.776-02$ \\
14.90 & $8.959-02$ \\
20.70 & $9.202-02$ \\
25.30 & $9.400-02$ \\
30.07 & $9.611-02$ \\
35.07 & $9.837-02$ \\
39.82 & $1.006-01$ \\
44.76 & $1.029-01$ \\
49.47 & $1.052-01$ \\
\hline
\end{tabular}

$\log \rho=\log A+\alpha \log T$

\begin{tabular}{|c|c|c|c|c|}
\hline$t,{ }^{\circ} \mathrm{C}$ & $\rho, \Omega \cdot \mathrm{cm}$ & \multicolumn{3}{|c|}{ range of $p$} \\
\hline .0 & $3.340-02$ & $8.294-02$ & TO & $8.385-0 ?$ \\
\hline 10.0 & $63-02$ & $8.728-02$ & TO & 8.7 \\
\hline 20.0 & $9.191-02$ & $9.105-02$ & TO & $9.218-02$ \\
\hline 23.0 & 9.321 & $9.295-02$ & TO & $9.347-0 ?$ \\
\hline 30.0 & $9.626-02$ & $9.597-02$ & To & $9.654-02$ \\
\hline 40.0 & & $1.003-01$ & TO & $1.010-01$ \\
\hline 50.0 & $1.051-01$ & $1.046-01$ & TO & $1.057-01$ \\
\hline
\end{tabular}

$T=t+273.16$

\section{$A=3.694-05$}

ALPHA $=\frac{1.37645}{4.1722-02}$

$\alpha=A L P H A \pm W 4$ 
SAMPLE NUMBER- 8

DATA CUNPUTEL ON 28 NOV 67

N-TYPE SI

CATA TAKEIS OI DEC 24, 1964

\begin{tabular}{|c|c|}
\hline$t,{ }^{\circ} \mathrm{C}$ & $0,8 \cdot \mathrm{Cm}$ \\
\hline .15 & $1.607-01$ \\
4.99 & $1.716-01$ \\
10.17 & $1.709-01$ \\
14.91 & $1.818-01$ \\
20.79 & $1.802-01$ \\
25.31 & $1.932-01$ \\
30.01 & $1.985-01$ \\
35.29 & $2.047-01$ \\
40.29 & $2.103-01$ \\
44.99 & $2.164-01$ \\
49.34 & $2.225-01$ \\
\hline
\end{tabular}

$\log \rho=\log A+\alpha \log T$

$T=t+273.16$

\begin{tabular}{|c|c|c|}
\hline$t,{ }^{\circ} \mathrm{C}$ & $\rho, \Omega \cdot \mathrm{cm}$ & range of $\rho$ \\
\hline & $1.661-01$ & TO $1.6688-01$ \\
\hline 10.0 & $1.767-01$ & $1.762-01$ T0 $1.773-01$ \\
\hline 20.0 & $1.876-01$ & $1 . H 72-01$ TO $1.8 R 1-01$ \\
\hline 23.0 & $1.910-01$ & TO $1.914-01$ \\
\hline 30.0 & $1.988-01$ & TO $1.993-01$ \\
\hline 40.0 & $2.103-n 1$ & TO $2.109-01$ \\
\hline 50.0 & $2.220-01$ & TO $2.229-01$ \\
\hline
\end{tabular}

$A=1.044-05$

ALPHA $=\frac{1.72400}{3.1627002}$

$W 4=3.1627-02$

$. \alpha=$ ALPHA $\pm W 4$

ranges given are $95 \%$ confidence limits

SAMPLE NUMBER- 9

UATA CUMPUTEU ON 28 HOV 67

N-TYPE SI

DATA TAKEIN ON DEC 24, 1964

\begin{tabular}{|c|c|}
\hline $\mathrm{t},{ }^{\circ} \mathrm{C}$ & $0, \Omega \cdot \mathrm{Cm}$ \\
\hline .38 & $4.040-01$ \\
5.11 & $4.179-01$ \\
10.25 & $4.333-01$ \\
14.98 & $4.478-01$ \\
20.82 & $4.603-01$ \\
25.31 & $4.808-01$ \\
29.98 & $4.963-01$ \\
35.21 & $5.141-01$ \\
39.91 & $5.305-01$ \\
44.85 & $5.481-01$ \\
49.68 & $5.657-01$ \\
\hline
\end{tabular}

$\log p=\log A+a \log T$

$T=t+273.16$

\begin{tabular}{|c|c|c|c|}
\hline$t,{ }^{\circ} \mathrm{C}$ & $0,2 \cdot \mathrm{cm}$ & \multicolumn{2}{|c|}{ range of $\rho$} \\
\hline 10.0 & $4.021-01$ & $4.008-01$ & T0 $4.035-01$ \\
20.0 & $4.326-01$ & $4.316-01$ & To $4.337-01$ \\
23.0 & $4.642-01$ & $4.634-01$ & T0 $4.651-01$ \\
30.0 & $4.739-01$ & $4.731-01$ & To $4.747-01$ \\
40.0 & $5.969-01$ & $4.960-01$ & TO $4.979-01$ \\
30.0 & $5.658-01$ & $5.295-01$ & TO $5.321-01$ \\
\hline
\end{tabular}

$$
A=4.521-06
$$

ALPHA $=2.03132$

$W_{4}=\overline{2.5810-n 2}$

$a=A L P H \dot{A} \pm N 4$
SAMPLE NUMBER - $8-R$

DATA COMPUTEU ON 23 NOV 67

N-TYHE SI

\begin{tabular}{|c|c|}
\hline$t,{ }^{\circ} \mathrm{C}$ & $0,12 \cdot \mathrm{cm}$ \\
\hline .07 & $1.605-01$ \\
5.43 & $1.720-01$ \\
10.50 & $1.771-01$ \\
14.85 & $1.814-01$ \\
19.86 & $1.671-01$ \\
25.34 & $1.931-01$ \\
29.82 & $1.982-01$ \\
34.70 & $2.038-01$ \\
39.69 & $2.097-01$ \\
44.46 & $2.155-01$ \\
49.61 & $2.215-01$ \\
\hline
\end{tabular}

$\log \rho=\log A+\alpha \log T$

$T=t+273.16$

\begin{tabular}{|c|c|c|c|c|}
\hline$t,{ }^{\circ} \mathrm{C}$ & $0, \Omega \cdot \mathrm{cm}$ & \multicolumn{3}{|c|}{ range of $\rho$} \\
\hline .0 & $1.6 F_{2} 0-01$ & $1.652-01$ & TO & $1.66 A-01$ \\
\hline 10.0 & $1.766-01$ & $1.700-01$ & TO & $1.772-01$ \\
\hline 20.0 & $1.875-01$ & $1.870-01$ & TO & $1.879-01$ \\
\hline 23.0 & $1.908-01$ & $1.903-01$ & TO & $1.912-01$ \\
\hline 30.0 & $1.986-01$ & $1.981-01$ & TO & $1.991-01$ \\
\hline 40.0 & $2.100-01$ & $2.093-01$ & TO & $2.107-01$ \\
\hline 50.0 & $2.217-01$ & $2.207-01$ & TO & $2.227-01$ \\
\hline
\end{tabular}

$$
\begin{aligned}
A & =\frac{1.072-05}{1.71979} \\
\text { ALPHA } & =\frac{3.5886-02}{W 4}=
\end{aligned}
$$

ranges given are $95 \%$ confidence 1 imits

SAMPLE NUMBER- $9-R$

N-TYFE SI

DATA CUMPUTEU ON 2 ? INOV O7

DATA TAKEIN OIN MAY 6, 1965

\begin{tabular}{|c|c|c|c|c|}
\hline$t,{ }^{\circ} \mathrm{C}$ & $\rho, \Omega \cdot \mathrm{cm}$ & \multicolumn{3}{|c|}{ range of $\rho$} \\
\hline .0 & $4.013-01$ & $4.003-01$ & TO & $4.023-01$ \\
\hline 10.0 & $4.317-01$ & $4.309-01$ & TO & $4.325-01$ \\
\hline 20.0 & $4.632-01$ & $4.620-01$ & TO & $4.638-01$ \\
\hline 23.0 & $4.729-01$ & $4.723-01$ & TO & $4.735-01$ \\
\hline 30.0 & $4.959-01$ & $4.952-01$ & TO & $4.965-01$ \\
\hline 40.0 & $5.297-01$ & $5.287-01$ & To & $5.306-01$ \\
\hline 30.0 & $5.646-01$ & $5.632-01$ & TO & $5.659-01$ \\
\hline
\end{tabular}

\begin{tabular}{|r|c|}
\hline$t,{ }^{\circ} \mathrm{C}$ & $0, \Omega \cdot \mathrm{cm}$ \\
\hline-.05 & $4.017-01$ \\
5.46 & $4.162-01$ \\
10.45 & $4.331-01$ \\
14.91 & $4.467-01$ \\
19.84 & $4.023-01$ \\
25.32 & $4.7963-01$ \\
29.85 & $4.946-01$ \\
34.75 & $5.114-01$ \\
39.73 & $5.267-01$ \\
44.52 & $5.456-01$ \\
49.69 & $5.646-01$ \\
\hline
\end{tabular}

$\log \rho=\log A+\alpha \log T$

$T=t+273.16$

$$
\begin{aligned}
A & =\frac{4.528-06}{2.03067} \\
\text { ALPHA } & =\frac{1.9077-02}{W 4}=
\end{aligned}
$$

$. \alpha=A L P H A \pm W 4$

ranges given are $95 \%$ confidence 1 imits 
SAMPLE NUMBER- 10

UATA CUNPUTEU ON 28 NHOV 67

N-TYPE SI

UATA TAKEIV ON SEPT 28,1966

\begin{tabular}{|r|c|}
\hline$t,{ }^{\circ} \mathrm{C}$ & $\rho, \Omega \cdot \mathrm{cm}$ \\
\hline 1.63 & $9.927-01$ \\
6.14 & $1.028+00$ \\
9.85 & $1.058+00$ \\
14.79 & $1.098+00$ \\
19.39 & $1.138+00$ \\
24.81 & $1.132+00$ \\
29.80 & $1.225+00$ \\
34.89 & $1.270+00$ \\
39.14 & $1.308+00$ \\
44.30 & $1.355+00$ \\
49.64 & $1.405+00$ \\
\hline
\end{tabular}

$\log \rho=\log A+\alpha \log T$

$T=t+273.16$

\begin{tabular}{|c|c|c|c|c|}
\hline$t,{ }^{\circ} \mathrm{C}$ & $P, \Omega \cdot \mathrm{cm}$ & \multicolumn{3}{|c|}{ range of $p$} \\
\hline - 0 & $9.800-01$ & $9.766=01$ & TO & $9.836-01$ \\
\hline $1 i 0.0$ & 1. $059+00$ & $1.056+00$ & TO & 1. $0 \times 2+00$ \\
\hline 20.4 & 1. $141+00$ & $1.139+00$ & TO & $1 \cdot 143+00$ \\
\hline 23.0 & $1.167+00$ & $1.164+00$ & To & $1.169+00$ \\
\hline 30.0 & $1.227+00$ & $1.224+00$ & To & $1.229+00$ \\
\hline 40.0 & $1.316+00$ & $1.312+00$ & To & $1.319+00$ \\
\hline 50.0 & $1.408+00$ & 1. $403+00$ & To & $1.413+00$ \\
\hline
\end{tabular}

$A=5.491-06$

$1 L P H A=2.15545$

$W_{4}=2 \cdot 7607-02$

$a=A L P H A \pm W 4$

ranges given are $95 \%$ confidence limits

SAMPLE NUMBER- 12

WAIA CUMPUII.L ON 2.4 IJUV 67

$N=T Y P E \quad S I$

UAIA TAKLIJ ON DEC 24,1901

\begin{tabular}{|c|c|}
\hline$t,{ }^{\circ} \mathrm{C}$ & $\rho, \Omega \cdot \mathrm{cm}$ \\
\hline .71 & $7.412+00$ \\
5.22 & $7.719+00$ \\
10.33 & $B .063+00$ \\
15.03 & $8.367+00$ \\
20.84 & $8.801+00$ \\
25.31 & $9.127+00$ \\
29.96 & $9.472+00$ \\
35.15 & $9.871+00$ \\
39.81 & $1.024+01$ \\
44.71 & $1.003+01$ \\
49.50 & $1.103+01$ \\
\hline
\end{tabular}

$\log p=\log A+\alpha \log T$

$T=t+273.16$

\begin{tabular}{|c|c|cc|}
\hline$t,{ }^{\circ} \mathrm{C}$ & $\rho, \Omega \cdot \mathrm{cm}$ & \multicolumn{2}{|c|}{ range of $\rho$} \\
\hline 10.0 & $7.369+00$ & $7.353+00$ & To $7.345+00$ \\
20.0 & $8.038+00$ & $8.025+00$ & To $8.051+00$ \\
23.0 & $8.741+00$ & $8.731+00$ & To $8.752+00$ \\
30.0 & $8.959+00$ & $8.949+00$ & To $8.969+00$ \\
40.0 & $9.479+00$ & $9.468+00$ & TO $9.491+00$ \\
50.0 & $1.025+01$ & $1.024+01$ & To $1.027+01$ \\
& $1.106+01$ & $1.104+01$ & To $1.109+01$ \\
\hline
\end{tabular}

\footnotetext{
$A=9.514-06$

ALPHA $=2.41709$

$\alpha=\mathrm{ALPHA} \pm W 4$

$W 4=1.6730-02$
}

ranges given are $95 \%$ confidence limits
SAMPLE NUMBEH = /

UAIA CUIAPUILU ON $2 A$ NOV 67

\begin{tabular}{|r|r|}
\hline$t,{ }^{\circ} \mathrm{C}$ & $p, \Omega \cdot \mathrm{cm}$ \\
\hline .32 & $3.225+00$ \\
5.30 & $3.356+00$ \\
10.10 & $3.495+00$ \\
14.39 & $3.619+00$ \\
20.57 & $3.804+00$ \\
25.40 & $3.952+00$ \\
30.09 & $4.100+00$ \\
34.96 & $4.257+00$ \\
39.65 & $4.413+00$ \\
44.83 & $4.590+00$ \\
49.35 & $4.748+00$ \\
\hline
\end{tabular}

$\log p=\log A+\alpha \log T$

$T=t+273.16$

\begin{tabular}{|c|c|cc|}
\hline$t,{ }^{\circ} \mathrm{C}$ & $\rho, \Omega \cdot \mathrm{cm}$ & \multicolumn{2}{|c|}{ range of $p$} \\
\hline .0 & $3.208+00$ & $3.201+00$ & TO $3.215+00$ \\
10.0 & $3.491+00$ & $3.486+00$ & TO $3.497+00$ \\
20.0 & $3.789+00$ & $3.784+00$ & TO $3.793+00$ \\
23.0 & $3.880+00$ & $3.876+00$ & TO 3.8 3. $3+00$ \\
30.0 & $4.100+00$ & $4.095+00$ & TO $4.105+00$ \\
40.0 & $4.425+00$ & $4.418+00$ & TO $4.432+00$ \\
50.0 & $4.765+00$ & $4.755+00$ & TO $4.775+00$ \\
\hline
\end{tabular}

$$
\begin{aligned}
A & =\frac{5.912-06}{2.35366} \\
A L P H A & =\frac{1.7186-02}{W 4}=
\end{aligned}
$$

$\alpha=A L P H A \pm W 4$

ranges given are $95 \%$ confidence limits

SAMPLE NUMBER- $12-R-1$

DAIA CUMPUIIUS ON 24 INOV 67

II-TYPE $S I$

UATA TAKE! OIJ AU⿴ 16, 1967

\begin{tabular}{|c|c|}
\hline$t,{ }^{\circ} \mathrm{C}$ & $\rho, \Omega \cdot \mathrm{cm}$ \\
\hline .44 & $7.394+00$ \\
5.27 & $7.719+00$ \\
10.42 & $8.069+00$ \\
15.18 & $8.402+00$ \\
19.92 & $8.736+00$ \\
24.69 & $9.084+00$ \\
29.56 & $9.450+00$ \\
34.72 & $9.846+00$ \\
39.61 & $1.023+01$ \\
44.17 & $1.059+01$ \\
49.69 & $1.105+01$ \\
\hline
\end{tabular}

$\log p=\log A+\alpha \log T$

$T=t+273.16$

\begin{tabular}{|r|c|cc|}
\hline$t,{ }^{\circ} \mathrm{C}$ & $\rho, \Omega \cdot \mathrm{Cm}$ & \multicolumn{2}{|c|}{ range of $\rho$} \\
\hline 10.0 & $7.368+00$ & $7.346+00$ & TO $7.391+00$ \\
20.0 & $8.039+00$ & $8.021+00$ & To $8.056+00$ \\
23.0 & $8.744+00$ & $8.73 n+00$ & To $8.758+00$ \\
30.0 & $8.962+00$ & $8.948+00$ & TO $8.976+00$ \\
40.0 & $1.084+00$ & $9.408+00$ & To $9.500+00$ \\
50.0 & $1.107+01$ & $1.024+01$ & TO $1.028+01$ \\
\end{tabular}

$$
A=9.214-06
$$

ALPHA $=2.42279$

$a=A L P H A \pm W 4$

$W 4=2 \cdot 3417-n 2$

ranges given are $95 \%$ confidence 1 imits 
SAMPLE NUMBER- $12-R-2$

UAIA CUINUILU ON E': HUV 57

N-TYPE

UATA TAKE OII AUG 16,1967

\begin{tabular}{|r|c|}
\hline$t,{ }^{\circ} i$ & $\rho, \Omega \cdot c m$ \\
\hline .44 & $7.377+00$ \\
5.27 & $7.701+00$ \\
10.42 & $8.049+00$ \\
15.18 & $8.302+00$ \\
19.92 & $8.715+00$ \\
24.69 & $9.062+00$ \\
29.56 & $9.426+00$ \\
34.72 & $9.822+00$ \\
39.61 & $1.020+01$ \\
44.17 & $1.057+01$ \\
49.69 & $1.102+01$ \\
\hline
\end{tabular}

$\log \rho=\log A+a \log T$

$T=t+273.1 \overline{0}$

\begin{tabular}{|c|c|c|c|c|}
\hline$t,{ }^{\circ} \mathrm{C}$ & $0,2 . \mathrm{cm}$ & \multicolumn{3}{|c|}{ range ot $?$} \\
\hline . $u$ & $7.350+00$ & $-7 \cdot 325+00$ & TO & $7.376+00$ \\
\hline 10.0 & $8.019+00$ & $8.000+00$ & 10 & $8.039+00$ \\
\hline 20.0 & $8.723+00$ & $8.707+00$ & TO & $8.739+00$ \\
\hline 23.0 & B. $941+00$ & $8.925+00$ & 10 & $8.957+00$ \\
\hline 30.0 & $9.461+00$ & $9.444+00$ & TO & $9.479+00$ \\
\hline 40.0 & 1. $024+01$ & $1.021+01$ & TO & 1. $026+01$ \\
\hline 50.0 & $1.105+01$ & $1.101+01$ & TO & $1.108+01$ \\
\hline
\end{tabular}

$$
\begin{aligned}
& A=9.195-06 \\
& 14=2.6413-02 \\
& \alpha=A L P H \dot{4}=16
\end{aligned}
$$

ranges given are 95 , confidence limits

SAMPLE NUMAER- 14

UAIA COMUTED ON 28 WOV 67

N-TYPE SI

UATA TAKEIV OII SEPT ¿̈B. 1966

\begin{tabular}{|c|c|c|c|c|}
\hline$t,{ }^{\circ} \mathrm{C}$ & $p, \therefore \cdot \mathrm{Cm}$ & rang & of & $\rho$ \\
\hline . 11 & $7.752+01$ & $7.735+01$ & TO & 7. $768+\cup 1$ \\
\hline 10.0 & $8.464+01$ & $8.452+01$ & TO & $8.477+01$ \\
\hline 20.0 & $9.214+01$ & $9.204+01$ & TO & $9.224+01$ \\
\hline$<3.0$ & $9.447+01$ & $9.437+01$ & TO & $9.457+01$ \\
\hline $30 \cdot 0$ & $1.000+02$ & $9.491+01$ & TO & $1.001+02$ \\
\hline 40.0 & $1.083+02$ & $1.081+02$ & TO & $1.094+02$ \\
\hline 50.0 & $1.169+02$ & $1 \cdot 167+02$ & TO & $1.172+02$ \\
\hline
\end{tabular}

\begin{tabular}{|c|c|}
\hline$t,{ }^{\circ} \mathrm{C}$ & $0,2 \cdot \mathrm{cm}$ \\
\hline 1.73 & $7.871+01$ \\
6.23 & $8.193+01$ \\
9.95 & $8.461+01$ \\
14.85 & $8.627+01$ \\
19.00 & $9.164+01$ \\
24.80 & $9.565+01$ \\
29.77 & $9.900+01$ \\
34.86 & $1.039+02$ \\
39.04 & $1.075+02$ \\
44.18 & $1.118+02$ \\
49.51 & $1.166+02$ \\
\hline
\end{tabular}

$\log p=\log A+a \log T$

$T=t+273.16$

$$
\begin{aligned}
A & =\frac{A .508-05}{2.44603} \\
\therefore A & =\frac{1.6106-02}{11-P}
\end{aligned}
$$$$
i=i L P H A=64
$$

rarges given are 95 . conficarce linits
SAMPLE NUMBER- 13

UAIA CUMHIJLE ON $2 B$ INUV

N-TYPE SI

\begin{tabular}{|r|r|}
\hline$t,{ }^{\circ} \mathrm{C}$ & $0, \Omega \cdot \mathrm{cm}$ \\
\hline .33 & $3.926+00$ \\
5.21 & $9.307+00$ \\
10.06 & $9.699+00$ \\
14.37 & $1.00 t+01$ \\
20.56 & $1.046+01$ \\
25.37 & $1.100+01$ \\
30.09 & $1.143+01$ \\
34.98 & $1.188+01$ \\
39.72. & $1.233+01$ \\
44.92 & $1.204+01$ \\
49.43 & $1.328+01$ \\
\hline
\end{tabular}

$\log \rho=\log A+\alpha \log T$

$T=t+273.16$

\begin{tabular}{|c|c|c|c|}
\hline$t,{ }^{\circ} \mathrm{C}$ & $0, \Omega \cdot \mathrm{cm}$ & \multicolumn{3}{|c|}{ range of } \\
\hline .0 & $8.891+00$ & $3.665+00$ & T0 $8.917+00$ \\
10.0 & $9.695+00$ & $9.675+00$ & TO $9.716+00$ \\
20.0 & $1.054+01$ & $1.052+01$ & TO $1.056+01$ \\
23.0 & $1.080+01$ & $1.079+01$ & TO $1.042+01$ \\
30.0 & $1.143+01$ & $1.141+01$ & TO $1.145+01$ \\
40.0 & $1.236+01$ & $1.233+01$ & TO $1.238+01$ \\
50.0 & $1.333+01$ & $1.329+01$ & TO $1.337+01$ \\
\hline
\end{tabular}

$$
\begin{aligned}
A & =\frac{1.201-05}{2.40898} \\
\text { ALPHA } & =\frac{2.2603-02}{W 4}=
\end{aligned}
$$

\begin{tabular}{|c|c|c|c|c|}
\hline$t,{ }^{\circ} \mathrm{C}$ & $0, \Omega \cdot \mathrm{cm}$ & rang & ge of & $\rho$ \\
\hline .0 & $6.793+02$ & $6.75 .3+02$ & TO & $6.832+02$ \\
\hline 10.0 & $7 \cdot 419+02$ & $7.388+02$ & TO & $7.451+02$ \\
\hline 20.0 & $8.079+02$ & $8.053+02$ & TO & $8.105+02$ \\
\hline 23.0 & $8.284+02$ & $8.253+02$ & TO & $8.310+0 ?$ \\
\hline 30.0 & B. $773+02$ & $8.744+02$ & TO & $8.801+02$ \\
\hline 40.0 & $9.500+02$ & $9.46 n+02$ & TO & $9.541+02$ \\
\hline 50.0 & $1.026+03$ & $1.020+03$ & TO & $1.032+03$ \\
\hline
\end{tabular}

ranges given are 95: confidence limits

SAMPLE INUMBER - 15

DATA COMPUTEU ON $2 B$ INOV 67

DATA TAKE ON INOV 27. 1964

N-TYPE SI

\begin{tabular}{|c|c|}
\hline$t,{ }^{\circ} \mathrm{C}$ & $p, \Omega \cdot \mathrm{cm}$ \\
\hline .09 & $6.309+02$ \\
3.94 & $7.004+02$ \\
9.14 & $7.337+02$ \\
14.97 & $7.705+02$ \\
20.49 & $8.151+02$ \\
25.28 & $8.473+02$ \\
30.06 & $8.797+02$ \\
34.74 & $9.133+02$ \\
40.05 & $9.509+02$ \\
45.39 & $9.891+02$ \\
49.93 & $1.022+03$ \\
\hline
\end{tabular}

$\log \rho=\log A+\infty \log T$

$T=t+273.16$

\section{$A=7.098-04$}

ILPHA $=\frac{7.45480}{2.40}$

$\therefore 4=\frac{4.4718-02}{.42}$ 


\title{
TEMPERATURE COEFFICIENT OF RESISTIVITY OF SILICON AND GERMANIUM NEAR ROOM TEMPERATURE*
}

\author{
W. M. BULLIS, F. H. BREWER, C. D. KOLSTAD $\dagger$ and L. J. SWARTZENDRUBER
}

National Bureau of Standards, Washington, D.C. 20234, U.S.A.

(Received 22 January 1968; in revised form 19 February 1968)

\begin{abstract}
Temperature coefficients for the resistivity of $n$ - and $p$-type germanium and silicon in the neighborhood of room temperature have been determined over a wide range of resistivity. Linear temperature coefficients have been found for the extrinsic exhaustion region $(<5 \Omega$-cm for germanium and $<5000 \Omega-\mathrm{cm}$ for silicon). The results are presented as plots of temperature coefficient against resistivity at $23^{\circ} \mathrm{C}$. The plots may be used in connection with measurements of resistivity on extrinsic germanium and silicon doped with the usual shallow impurities such as boron, aluminum, gallium, phosphorus, arsenic, and antimony. Accurate linear coefficients cannot be found for specimens doped with deep-lying impurities in sufficient amounts to affect the carrier density nor for specimens with resistivity in the transition region between extrinsic and intrinsic conduction.
\end{abstract}

Résumé-Les coefficients de température de la résistivite du germanium et du silicium des types $n$ et $p$ dans les environs de la température ambiante ont été déterminés le long d'une gamme de résistivité étendue. Les coefficients de températures linéaires ont été trouvés dans la région extrinsèque d' exhaustion $(<5 \Omega-\mathrm{cm}$ pour le germanium et $<5000 \Omega-\mathrm{cm}$ pour le silicium). Les résultats sont présentés en forme de courbes de coefficients de température en fonction de la résistivité à $23^{\circ} \mathrm{C}$. Les courbes peuvent être employées en connexion aux mesures de la résistivité de germanium et silicium intrinsèque dopés d'impuretés peu profondes telles que le bore, l'aluminium, le gallium, le phosphore, l'arsenic et l'antimoine. Des coefficients linéaires exacts ne peuvent être trouvés, pour les specimens dopés d'impuretes profondes, en nombre suffisant pour affecter la densité de porteur ou pour des spécimens dont la résistivité se situe dans la régịon entre la conduction intrinsèque et extrinsèque.

Zusammenfassung-Die Temperaturkoeffizienten des spezifischen Widerstands von $n$ - und $p$ Silizium und Germanium nahe Raumtemperatur wurden über einen grossen Widerstandsbereich bestimmt. Lineare Temperaturkoeffizienten ergeben sich für den Bereich der Störstellenerschöpfung ( $<2 \Omega$-cm für Germanium und $<5000 \Omega-\mathrm{cm}$ für Silizium). Die Ergebnisse sind in Kurvenform dargestellt. Aufgetragen ist der Temperaturkoeffizient gegen den spezifischen Widerstand bei $23^{\circ} \mathrm{C}$. Die Kurven können in Verbindung mit Widerstandsmessungen an störstellenleitendem Silizium und Germanium verwendet werden, wobei die üblichen Dotierungsstoffe wie Bor, Aluminium, Gallium, Phosphor, Arsen und Antimon herangezogen sind, welche niedrige Störstellenniveaus ergeben. Genau lineare Koeffizienten finden sich weder für Proben, welche tiefliegende Störstellen in genügenden Anzahl enthalten um die Trägerdichten zu beeinflussen, noch für Proben mit Widerständen im Übergangsbereich zwischen Störstellenleitung und Eigenleitung.

* Supported in part by the NASA Electronics Research Center. Initial phases of the work were supported in part by. ARPA.

† Summer student, now at Bates College, Lewiston, Maine 04240. 
NBS.114A IREV

\begin{tabular}{|c|c|c|c|}
\hline $\begin{array}{l}\text { U.S. DEPT. OF COMM. } \\
\text { BIBLIOGRAPHIC DATA } \\
\text { SHEET }\end{array}$ & $\begin{array}{l}\text { 1. PUBIRATION (OR RIP()RT NO. } \\
\text { NBSIR 74-496 }\end{array}$ & $\begin{array}{l}\text { 2. (1ov't Acocosion } \\
\text { No. }\end{array}$ & 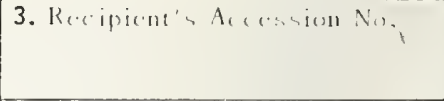 \\
\hline \multicolumn{3}{|l|}{ 4. TITLI: ANI) SIIHTHII: } & $\begin{array}{l}\text { 5. Publication } 1 \text { ats } \\
\text { August } 1974\end{array}$ \\
\hline \multicolumn{3}{|c|}{$\begin{array}{l}\text { Standard Measurements } \\
\text { Four-Probe Method }\end{array}$} & 6. Performing Organization (ode \\
\hline \multicolumn{3}{|l|}{$\begin{array}{l}\text { 7. Alling(s) } \\
\text { W. Murray Bullis }\end{array}$} & 8. Pcrforming Organ. Repore No. \\
\hline \multicolumn{3}{|c|}{$\begin{array}{l}\text { 9. PIERORMING, ORGANITATION NAMI: ANI) ADIRIESS } \\
\qquad \begin{array}{l}\text { NATIONAL BUREAU OF STANDARDS } \\
\text { DEPARTMENT OF COMAERCE } \\
\text { WASHINGTON, D.C. } 20234\end{array}\end{array}$} & $\begin{array}{l}\text { 10. Projuct/Task/Work linit No. } \\
\text { 11. Contract/Cirant No. } \\
\text { ER6576 }\end{array}$ \\
\hline \multicolumn{4}{|c|}{$\begin{array}{l}\text { 12. Sponsoring Organization Name and Complece Address (Street, City, State, ZIP) } \\
\text { NASA Electronics Research Center } \\
\text { (Now Defunct) }\end{array}$} \\
\hline
\end{tabular}

Supersedes NBS Report 9666 (NTIS Accession N68-18067). This report was the final report to the Electronics Research Center.

16. ABSTRACT (A 200-word or less tactual summary of most significant information. If document includes a significant bibliography or literature survey, mention it here.)

An improved standard procedure for measurement of circular silicon slices with four in-line point probes has been developed in cooperation with the Resistivity Task Force of ASTM Committee F-I. Detailed analysis of a series of round-robin experiments showed that the procedure can attain a precision of \pm 2 percent (three standard deviations) for interlaboratory comparisons of slices with room temperature resistivity between 0.005 and $120 \mathrm{ohm}-\mathrm{cm}$. Resistivity non-uniformity in the test slices was shown to be a significant factor in limiting the precision which could be achieved. The importance of including correction factors for temperature, finite thickness, finite diameter, and unequal probe separations was demonstrated. The results of the round-robin experiments also emphasized that the precision quoted can only be achieved if the measurements are carefully and correctly made on a well maintained, accurately calibrated test system which meets the requirements imposed by the test method. Determination of the precision to be expected from the method in non-referee applications such as routine production and quality control will require additional study of such factors as surface conditions, probe force, current levels, etc. Nevertheless, use of the various procedures of the method, in particular the sections on probe and measuring circuit evaluations and on thermal sinking of the wafer, would be expected to yield significantly improved precision in such applications. Use of these procedures on a regular and widespread basis should be encouraged.

17. KEY WORDS (six to twelve entries; alphabetical order; capitalize only the first letter of the first key word unless a proper name; separated by semicolons)

ASTM Committee F-I; electronics; four-probe method; resistivity; semiconductors; silicon.

18. AVAILABILITY X Unlimited

For Official Distribution. Do Not Release to NTIS

Order From Sup. of Doc., U.S. Government Printing Office Washington, D.C.20402, SDCat. No.C13

X Order From National Technical Information Service (NTIS) Springfield, Virginia 22151

\begin{tabular}{|l|c|}
\hline $\begin{array}{l}\text { 19. SECURITY CLASS } \\
\text { (THIS REPURT) } \\
\text { UNCLASSIFIEI) }\end{array}$ & 21. NO. OF PAGES \\
\hline $\begin{array}{l}\text { 20. SE(URITY ( LASS } \\
\text { (TIIISPAGE) }\end{array}$ & 22. PriCe \\
UNCLASSIIIED) & USCOMM-DC 29042-P74
\end{tabular}

